ORNL/TM-12250

Chemical Technology Division

\title{
METHODOLOGY TO REMEDIATE A MIXED WASTE SITE
}

J. B. Berry

Manuscript Completed: May 1992

Date of Publication: August 1994

Prepared for the

OAK RIDGE NATIONAL LABORATORY

Oak Ridge, Tennessee 37831-6285

managed by

MARTIN MARIETTA ENERGY SYSTEMS, INC.

for the

U.S. DEPARTMENT OF ENERGY

under contract

DE-AC05-84OR21400

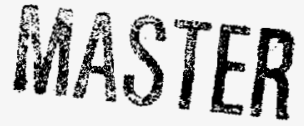




\section{DISCLAIMER}

This report was prepared as an account of work sponsored by an agency of the United States Government. Neither the United States Government nor any agency thereof, nor any of their employees, make any warranty, express or implied, or assumes any legal liability or responsibility for the accuracy, completeness, or usefulness of any information, apparatus, product, or process disclosed, or represents that its use would not infringe privately owned rights. Reference herein to any specific commercial product, process, or service by trade name, trademark, manufacturer, or otherwise does not necessarily constitute or imply its endorsement, recommendation, or favoring by the United States Government or any agency thereof. The views and opinions of authors expressed herein do not necessarily state or reflect those of the United States Government or any agency thereof. 


\section{DISCLAIMER}

Portions of this document may be illegible in electronic image products. Images are produced from the best available original document. 


\section{CONTENTS}

TABLES $\ldots \ldots \ldots \ldots \ldots \ldots \ldots \ldots \ldots \ldots \ldots \ldots \ldots \ldots \ldots \ldots \ldots$

FIGURES $\ldots \ldots \ldots \ldots \ldots \ldots \ldots \ldots \ldots \ldots \ldots \ldots \ldots \ldots \ldots \ldots \ldots \ldots$

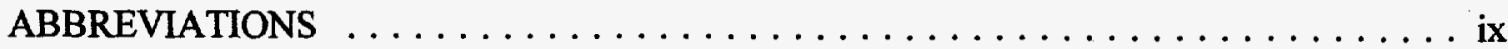

ABSTRACT $\ldots \ldots \ldots \ldots \ldots \ldots \ldots \ldots \ldots \ldots \ldots \ldots \ldots \ldots \ldots \ldots \ldots \ldots \ldots \ldots$

1. INTRODUCTION $\ldots \ldots \ldots \ldots \ldots \ldots \ldots \ldots \ldots \ldots \ldots \ldots \ldots \ldots \ldots$

2. BACKGROUND ON REMEDIATION METHODOLOGIES $\ldots \ldots \ldots \ldots \ldots \ldots \ldots$

2.1 PROCESS DESIGN METHODOLOGIES $\ldots \ldots \ldots \ldots \ldots \ldots \ldots \ldots$

2.2 REMEDIATION METHODOLOGIES $\ldots \ldots \ldots \ldots \ldots \ldots \ldots \ldots \ldots$

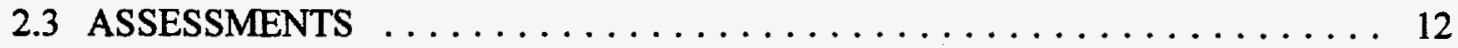

2.4 REMEDIATION PROJECTS . . . . . . . . . . . . . . . . . 14

3. DEVELOPMENT OF METHODOLOGY TO REMEDIATE A MIXED WASTE

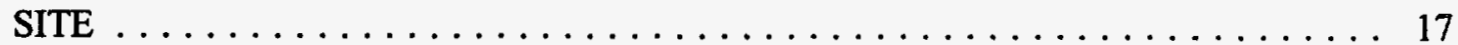

3.1 IDENTIFICATION OF PROBLEM $\ldots \ldots \ldots \ldots \ldots \ldots \ldots \ldots \ldots \ldots$

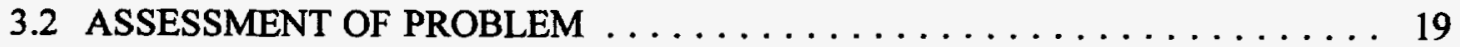

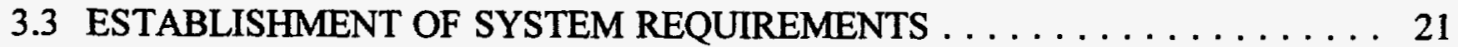

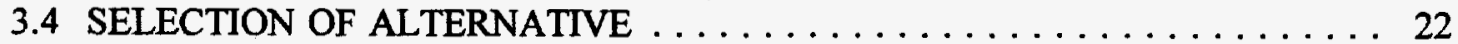

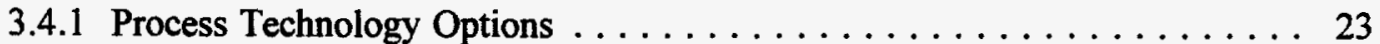

3.4.2 Criteria for Assessing Process Technology Options . . . . . . . . . . 23

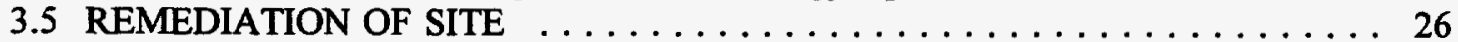

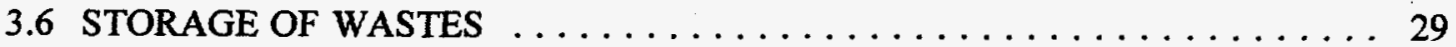

3.7 TREATMENT AND DISPOSAL OF WASTE . . . . . . . . . . . 29

4. APPLICATION OF METHODOLOGY TO THE REMEDIATION OF 32,000

DRUMS OF MIXED WASTE SLUDGE $\ldots \ldots \ldots \ldots \ldots \ldots \ldots \ldots \ldots \ldots \ldots$

4.1 IDENTIFICATION OF PROBLEM $\ldots \ldots \ldots \ldots \ldots \ldots \ldots \ldots \ldots \ldots \ldots \ldots$

4.2 ASSESSMENT OF PROBLEM $\ldots \ldots \ldots \ldots \ldots \ldots \ldots \ldots \ldots \ldots \ldots \ldots \ldots$

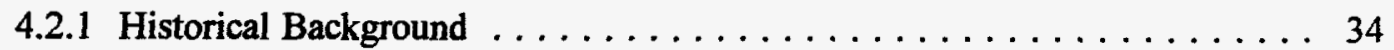

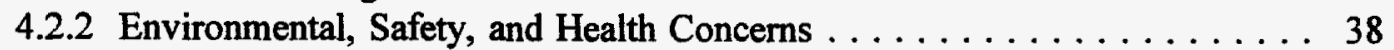

4.2 .3 Evaluation of Regulations . . . . . . . . . . . . . . . . . . 38

4.2 .4 Sampling and Characterization $\ldots \ldots \ldots \ldots \ldots \ldots \ldots \ldots . \ldots . \ldots 49$

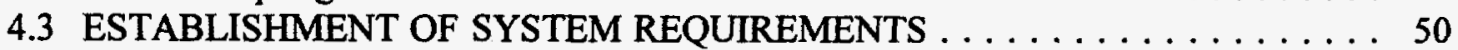

4.4 SELECTION OF ALTERNATIVE $\ldots \ldots \ldots \ldots \ldots \ldots \ldots \ldots \ldots \ldots \ldots$

4.4 .1 Process Options . . . . . . . . . . . . . . . . . . . . 52

4.4.2 Assessment of Alternatives That Met System Requirements . . . . . . . 56

4.4 .3 Bench-Scale Studies . . . . . . . . . . . . . . . . . . . 57

4.4 .4 Processing Assumptions . . . . . . . . . . . . . . . 59 


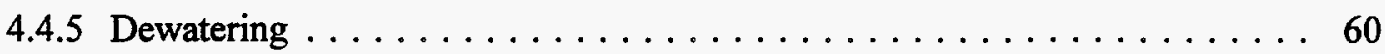

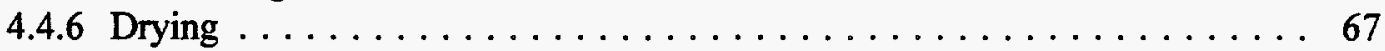

4.4.7 Solidification/stabilization . . . . . . . . . . . . . . . 69

4.4.8 Assessment of Process Technology Options $\ldots \ldots \ldots \ldots \ldots \ldots \ldots 75$

4.5 REMEDIATION OF SITE $\ldots \ldots \ldots \ldots \ldots \ldots \ldots \ldots \ldots \ldots \ldots \ldots \ldots$

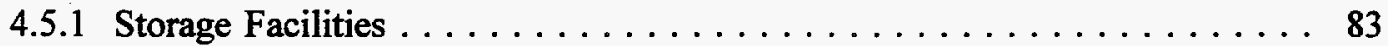

4.5.2 Drum Containment System . . . . . . . . . . . . . . 83

4.5.3 Treatment of Mixed waste Sludge ... . . . . . . . . . . 84

4.6 STORAGE OF WASTE $\ldots \ldots \ldots \ldots \ldots \ldots \ldots \ldots \ldots \ldots \ldots \ldots$

4.6 .1 Inspections . . . . . . . . . . . . . . . 87

4.6.2 Container Cleaning and Management $\ldots \ldots \ldots \ldots \ldots \ldots \ldots 9$

4.6.3 Spill Containment and Cleanup . . . . . . . . . . . . . . 93

4.6.4 Decontamination and Demobilization ................... 94

4.7 SUMMARY OF APPLICATION OF METHODOLOGY TO THE

REMEDIATION OF 32,000 DRUMS OF MIXED WASTE SLUDGE $\ldots \ldots \ldots 95$

5. EVALUATION AND CONCLUSIONS $\ldots \ldots \ldots \ldots \ldots \ldots \ldots \ldots \ldots$

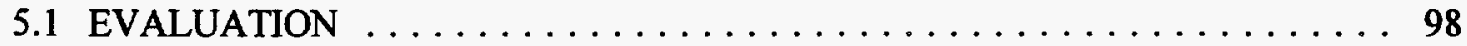

5.1 .1 Process Design Methodologies $\ldots \ldots \ldots \ldots \ldots \ldots \ldots \ldots \ldots$

5.1 .2 Remediation Methodologies . . . . . . . . . . . . . . . . 101

5.1 .3 Assessments . . . . . . . . . . . . . . . . . . . . . . . . 104

5.1 .4 Remediation Projects . . . . . . . . . . . . . . . . . . . 104

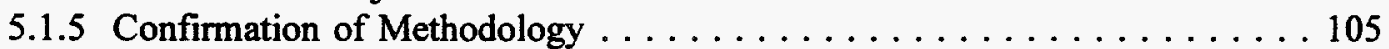

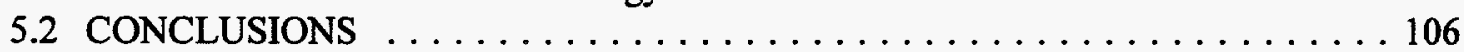

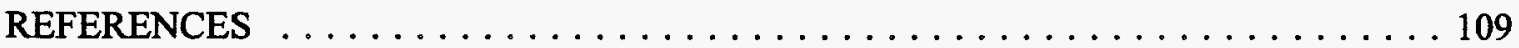

APPENDIX A. MANAGEMENT OF LOW-LEVEL WASTE ON THE OAK RIDGE

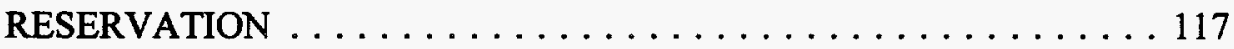

APPENDIX B. PRELIMINARY SLUDGE CONSTITUENT ANALYSIS $\ldots \ldots \ldots \ldots . .123$

APPENDIX C. SUMMARY OF DATA FOR SAMPLES OF SLUDGE CONTAINED IN DRUMS FROM PONDS B AND C . . . . . . . . . . . . 129

APPENDIX D. QUANTITATIVE ASSESSMENT OF ALTERNATIVES $\ldots \ldots \ldots 143$ 


\section{TABLES}

TABLE

PAGE

1. Formulas for assessing performance criteria for process effectiveness $\ldots \ldots \ldots \ldots 24$

2. Formulas for assessing performance criteria for process implementability $\ldots \ldots \ldots 25$

3. Formulas for assessing performance criteria for process cost-effectiveness $\ldots \ldots \ldots 26$

4. Definition of variables for assessing performance criteria $\ldots \ldots \ldots \ldots \ldots$

5. Summary of pond waste characterization data $\ldots \ldots \ldots \ldots \ldots \ldots \ldots$

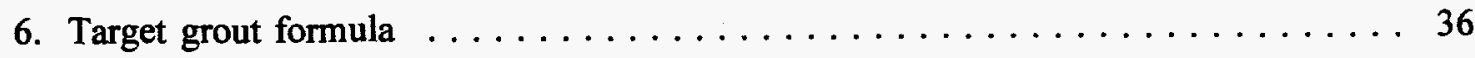

7. Summary of sample data that have regulatory implications $\ldots \ldots \ldots \ldots \ldots$

8. Rough order-of-magnitude cost estimates and implementation times for the Pond Waste Management Project . . . . . . . . . . . . . . . . 54

9. Limits for selected radionuclides in solids to be considered for disposal as

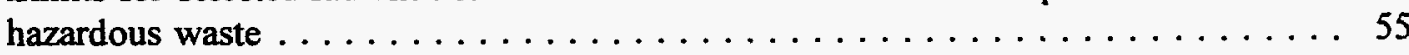

10. Summary of bench-scale testing data $\ldots \ldots \ldots \ldots \ldots \ldots \ldots$

11. Performance measures by process technology option $\ldots \ldots \ldots \ldots \ldots \ldots \ldots \ldots$

12. Training requirements for subcontracted personnel $\ldots \ldots \ldots \ldots \ldots \ldots \ldots$

13. Sequence of operations used in processing mixed waste sludge $\ldots \ldots \ldots \ldots$

A.1. Site-specific, dose-based concentration limits $\left(\mu \mathrm{Ci} / \mathrm{m}^{3}\right) \ldots \ldots \ldots \ldots \ldots \ldots$

B.1. Preliminary radionuclide analysis of a typical solidified drum $\ldots \ldots \ldots \ldots \ldots$

B.2 Summary data for B Pond sampling (September 1988) $\ldots \ldots \ldots \ldots \ldots \ldots$

B.3. Summary data for $C$ Pond sampling (September 1988) $\ldots \ldots \ldots \ldots \ldots \ldots$

C.1. Analyses required for raw pond waste $\ldots \ldots \ldots \ldots \ldots \ldots \ldots \ldots \ldots \ldots \ldots$

C.2. Summary of results from the K-1407-B holding pond and the K-1407-C retention basin 



\section{FIGURES}

FIGURE

PAGE

1. Hierarchy of mixed waste remediation activities $\ldots \ldots \ldots \ldots \ldots \ldots \ldots$

2. Logic for evaluating mixed waste disposal regulatory requirements $\ldots \ldots \ldots \ldots \ldots$

3. Block flow diagram-dewatering $\ldots \ldots \ldots \ldots \ldots \ldots \ldots \ldots \ldots \ldots \ldots \ldots \ldots$

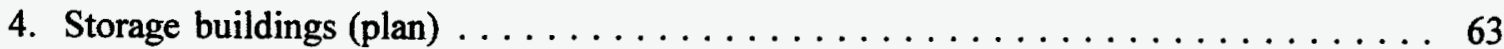

5. Block flow diagram - drying $\ldots \ldots \ldots \ldots \ldots \ldots \ldots \ldots \ldots \ldots \ldots$

6. Block flow diagram-solidification tank $\ldots \ldots \ldots \ldots \ldots \ldots \ldots \ldots \ldots$

7. Storage configuration for solidified waste $\ldots \ldots \ldots \ldots \ldots \ldots \ldots \ldots \ldots$

8. Common activities in current, CERCLA, and value engineering methodologies $\ldots \ldots 102$ 

Applicable or Relevant and Appropriate RequirementsARARs As Low as Reasonably Achievable ALARA

Atomic Energy Act AEA

Best Demonstrated Available Technology $\ldots \ldots \ldots \ldots \ldots \ldots \ldots \ldots \ldots \ldots$ BDAT

Central Neutralization Facility $\ldots \ldots \ldots \ldots \ldots \ldots \ldots \ldots \ldots \ldots \ldots \ldots \ldots$ CNF

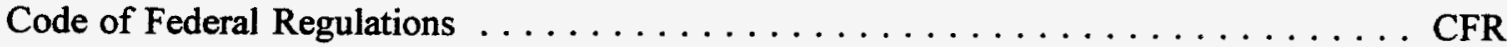

Comprehensive Environmental Response, Compensation, and Liability Act . . . . . CERCLA

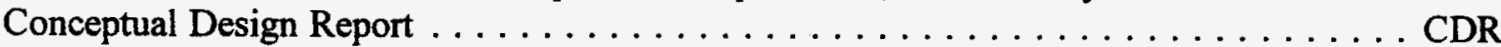

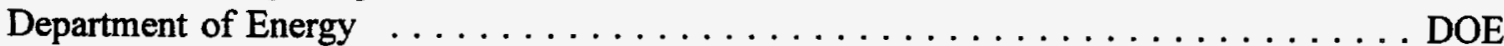

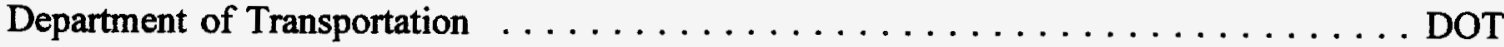

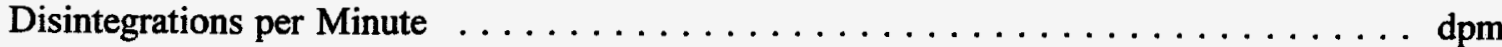

Environmental Protection Agency $\ldots \ldots \ldots \ldots \ldots \ldots \ldots \ldots \ldots \ldots \ldots \ldots$

Environmental, Safety, and Health $\ldots \ldots \ldots \ldots \ldots \ldots \ldots \ldots \ldots \ldots \ldots$

Expression of Interest $\ldots \ldots \ldots \ldots \ldots \ldots \ldots \ldots \ldots \ldots \ldots \ldots \ldots$ EOI

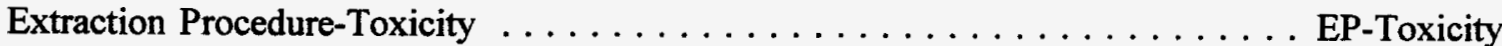

Federal Facilities Compliance Agreement $\ldots \ldots \ldots \ldots \ldots \ldots \ldots \ldots \ldots \ldots \ldots$

Health, Safety, and Environmental $\ldots \ldots \ldots \ldots \ldots \ldots \ldots \ldots \ldots \ldots \ldots \ldots$

High-Efficiency Particulate Air $\ldots \ldots \ldots \ldots \ldots \ldots \ldots \ldots \ldots \ldots \ldots \ldots \ldots \ldots \ldots$

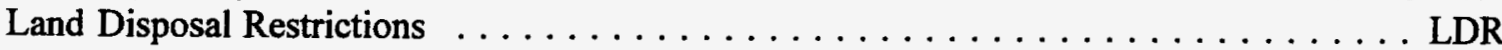

Liquid Release Test $\ldots \ldots \ldots \ldots \ldots \ldots \ldots \ldots \ldots \ldots \ldots \ldots \ldots \ldots$ LRT

Low-level Waste . . . . . . . . . . . . . . . . . . . . . . LLW

Low-Level Waste Disposal, Development, and Demonstration . . . . . . . . . LLWDDD

Multiple Extraction Procedure . . . . . . . . . . . . . . . . . . . MEP

National Environmental Policy Act $\ldots \ldots \ldots \ldots \ldots \ldots \ldots \ldots \ldots \ldots \ldots \ldots \ldots$

National Oil and Hazardous Substances Pollution Contingency Plan . . . . . . . . NCP

Nevada Test Site . . . . . . . . . . . . . . . . . . . . . NTS

Nuclear Regulatory Commission $\ldots \ldots \ldots \ldots \ldots \ldots \ldots \ldots \ldots \ldots \ldots \ldots \ldots$

National Pollutant Discharge Elimination System . . . . . . . . . . . NPDES

Oak Ridge National Laboratory $\ldots \ldots \ldots \ldots \ldots \ldots \ldots \ldots \ldots \ldots \ldots \ldots$ ORNL

Oak Ridge Reservation . . . . . . . . . . . . . . . . . . . . . . . .

Occupational Safety and Health Act $\ldots \ldots \ldots \ldots \ldots \ldots \ldots \ldots \ldots \ldots \ldots \ldots \ldots \ldots$

Polychlorinated Biphenyls $\ldots \ldots \ldots \ldots \ldots \ldots \ldots \ldots \ldots \ldots \ldots \ldots \ldots \ldots$ PCBs

Process Control Programs $\ldots \ldots \ldots \ldots \ldots \ldots \ldots \ldots \ldots \ldots \ldots \ldots \ldots \ldots$ PCPs

Quality Assurance/Quality Control $\ldots \ldots \ldots \ldots \ldots \ldots \ldots \ldots \ldots \ldots$ QA $\ldots \ldots C$

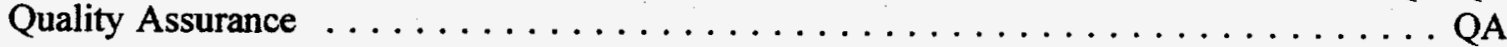

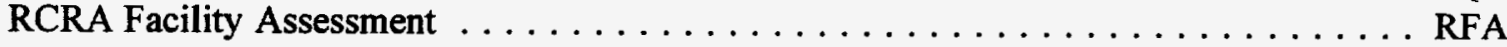

Remedial Investigation/Feasibility Study $\ldots \ldots \ldots \ldots \ldots \ldots \ldots \ldots \ldots \ldots \ldots$ RI/FS

Resource Conservation and Recovery Act $\ldots \ldots \ldots \ldots \ldots \ldots \ldots \ldots \ldots \ldots \ldots$

Sludge Treatment Facility $\ldots \ldots \ldots \ldots \ldots \ldots \ldots \ldots \ldots \ldots \ldots \ldots \ldots$ STF

Technical Position Paper . . . . . . . . . . . . . . . . . . . . . TPP

Tennessee Department of Environment and Conservation $\ldots \ldots \ldots \ldots \ldots \ldots$ TDEC

Toxicity Characteristic Leaching Procedure . . . . . . . . . . . . . . . TCLP 



\begin{abstract}
Both hazardous and radioactive species contaminate mixed waste. This creates circumstances where dual regulations, which were promulgated to govern the management of either hazardous or radioactive waste, apply. Throughout the Department of Energy (DOE) complex, the mixed waste problem is significant because definitive treatment standards have not been established and limited disposal facilities are available. In addition to these constraints, treatment capability and capacity are limited. Therefore, DOE sites must store mixed waste for future disposal, despite the fact that sites may present a risk to the public and regulations governing hazardous waste require remediation by specific deadlines.
\end{abstract}

In response to the need for a comprehensive and consistent approach to the complex issue of mixed waste management, a generalized methodology for remediation of a mixed waste site has been developed. The methodology is based on requirements set forth in the Comprehensive Environmental Response, Compensation, and Liability Act (CERCLA) and the Resource Conservation and Recovery Act (RCRA) and incorporates "lessons learned" from process design, remediation methodologies, and remediation projects. The methodology is applied to the treatment of 32,000 drums of mixed waste sludge at the Oak Ridge K-25 Site.

Process technology options are developed and evaluated, first with regard to meeting system requirements and then with regard to CERCLA performance criteria. The following process technology options are investigated: (1) no action, (2) separation of hazardous and radioactive species, (3) dewatering, (4) drying, and (5) solidification/stabilization. The first two options were eliminated from detailed consideration because they did not meet the system requirements. A quantitative evaluation clearly showed that, based on system constraints and project objectives, either dewatering or drying the mixed waste sludge was superior to the solidification/stabilization process option. The ultimate choice between the drying and the dewatering options will be made on the basis of a technical evaluation of the relative merits of proposals submitted by potential subcontractors. 
The methodology is generally applicable to mixed waste remediation projects and is comprehensive. An evaluation of regulations is presented that clarifies complex mixed waste requirements. The application of the methodology to the K-25 Site mixed waste remediation project is the first comprehensive case study, identified by the author, that is based on CERCLA evaluation criteria and uses a quantitative assessment of alternatives with data from rough order-of-magnitude material balance and cost estimates. This report serves as a guide to engineers and scientists who are evaluating options and implementing a mixed waste remediation project at a DOE site. 


\section{INTRODUCTION}

Mixed waste contains both hazardous and radioactive species, causing it to be managed under dual regulations ${ }^{1}$ that were promulgated to govern the handling of either hazardous or radioactive waste." These dual regulations provide driving forces for mixed waste environmental restoration activities at all stages. Definitive treatment standards have not been established. Treatment standards could be based on requirements set by specific disposal sites; however, disposal sites licensed to receive Department of Energy (DOE) mixed waste are limited. ${ }^{2,3}$ A Senate bill, sponsored by Majority Leader George Mitchell, has proposed legislation that would direct the Environmental Protection Agency (EPA) to "specify treatment standards or technologies for all the mixed waste streams . . . by Dec. $31,1992 . "{ }^{\prime 4}$ Because treatment standards have not been established, DOE sites must store mixed waste for future disposal in facilities for which criteria have not been established. Despite the lack of disposal criteria, numerous environmental restoration sites may present a risk to the public, and regulations governing hazardous waste require that remediation be done by specific deadlines. ${ }^{5}$ This regulatory quandary forms a challenging framework for environmental restoration and waste treatment activities associated with mixed waste.

Throughout the DOE complex, the mixed waste problem is significant. Approximately 80,000 $\mathrm{m}^{3}$ of mixed waste is stored at DOE sites; ${ }^{6}$ storage will not comply with Land Disposal Restrictions (LDR) as of the effective date, May 8, 1992. Mixed waste generation continues at the rate of $7700 \mathrm{~m}^{3} /$ year. DOE has identified 700 individual mixed waste streams. The problem can be further characterized by a lack of treatment capacity and "a lack of existing proven technology to treat and dispose of . . mixed waste to meet LDR treatment standards. The DOE lacks adequate funding for research, development, and implementation of treatment and disposal technologies."

In response to the need for a comprehensive and consistent approach to the complex issue of mixed waste management, a generalized methodology for remediation of a mixed waste site was developed, using requirements set forth in the Comprehensive Environmental Response,

\footnotetext{
'Regulations have not been promulgated for mixed waste management.
} 
Compensation, and Liability Act (CERCLA) and the Resource Conservation and Recovery Act (RCRA) as a basis. To validate the content and reliability of the model, the methodology has been applied to the treatment of 32,000 drums of mixed waste sludge at the Oak Ridge K-25 Site.

This unique methodology includes a hierarchy of activities to be undertaken to remediate a mixed waste problem. The hierarchy consists of the following steps: (1) identifying the problem; (2) assessing the problem; (3) establishing system requirements; (4) selecting an altemative; (5) remediating the site; and (6) storing or treating and disposing of the waste. ${ }^{78}$ This hierarchy of activities is shown in Fig. 1.

Problem identification and assessment include the programmatic requirements, historical background, existing chemical and physical conditions, and the regulatory situation. The system requirements are established, based on an analysis of program requirements, physical characterization, and regulatory environment. The CERCLA balancing criteria are used as a technical basis for quantifying system requirements. ${ }^{9,10}$ The result of the alternatives analysis is the selection of a process technology option based on a quantified score. ${ }^{11}$ The selected option is then documented in a Record of Decision if the site is being remediated under CERCLA.

Implementation of the option remediates the site. Technical specifications are developed to ensure that the remediation system meets functional and operating requirements. The remediated waste is either stored for future treatment or subjected to a prescribed treatment and disposal regimen.

The salient aspects of each activity, as applied to the remediation of 32,000 drums of mixed waste sludge, are described below.

Identify the problem: Immediate action was required to remediate drums of mixed waste sludge because of specific noncompliance issues regarding storage of the sludge. "Actual or threatened releases of hazardous substances from these drums, as well as physical conditions at the site, if not addressed by implementing the response action . . . may present a current or potential threat to human health or the environment." ${ }^{12}$ The methodology, as developed, requires a clear identification of the problem that must be solved. 


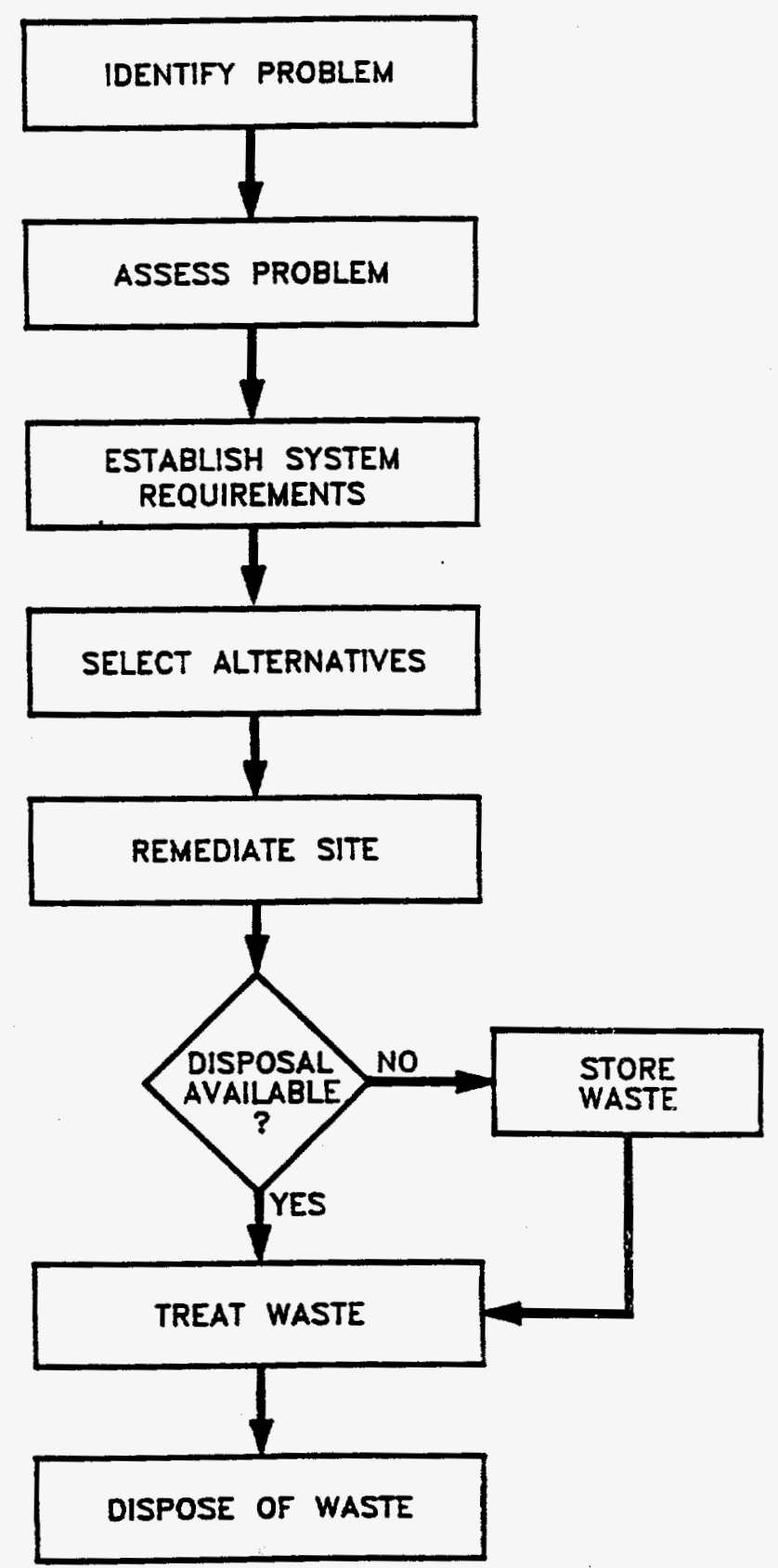

Fig. 1. Hierarchy of mixed waste remediation activities. 
Assess the problem: The current methodology requires characterization of the physical and chemical nature of the problem as well as assessment of the regulatory environment. Physical and chemical characterization of mixed waste is complicated by the application of requirements for sampling, developed for hazardous materials, to radioactive materials. For example, exposure of the worker to radioactivity must be considered. Further, the heterogeneous nature of the waste makes statistically representative sample collection difficult. Additionally, regulations governing the management of mixed waste are promulgated by the EPA, the applicable state, and DOE. The methodology considers requirements of each regulatory body.

Establish system requirements: Clearly defined system requirements facilitate analysis of alternatives and allow the elimination of inappropriate alternatives before significant resources are expended. However, in the mixed waste arena, the author has identified key issues that affect the ability of DOE sites to assign definitive system requirements to the treatment of mixed waste: ${ }^{13}$

- waste acceptance criteria for disposal-no criteria for on-site disposal have been established, and limited commercial disposal of radioactive materials has been approved.

- recycle of decontaminated material-no "de minimis" levels for radioactivity have been established.

- incineration of organic material and oxidation via thermal reaction-the public does not, generally, accept combustion technology.

- advanced technology-technology is not fully developed for mixed waste treatment.

In spite of these system constraints, deadlines for remediation actions have been established. The current method clearly identifies system constraints so that decisions are based on a comprehensive evaluation of the situation, and a logical, albeit constrained, course of action is established.

Select alternative: The method analyzes alternative process technology options, for the situation under study, by adapting a quantitative approach. ${ }^{11}$ This analysis is the first published application of this approach to a mixed waste remediation problem. Modifications to the definitions and formulas were required to more accurately reflect the performance criteria relevant to Oak Ridge Reservation (ORR) mixed waste. 
Remediate site and store the waste: Technical requirements apply to the implementation of the remediation project, the storage of waste, and the acquisition of viable storage facilities. The method incorporates comprehensive and detailed specifications for the implementation stage of the project. Because of the described constraints, "DOE will store wastes while treatment capacity is being developed." ${ }^{\text {Th }}$ The modology takes into consideration the requirements to achieve compliant storage. 


\section{BACKGROUND ON REMEDIATION METHODOLOGIES}

Approaches to waste remediation and environmental restoration projects could be strengthened by drawing on chemical engineering process design methods. ${ }^{14-16}$ The application of standardized process design techniques to mixed waste remediation efforts differs primarily in emphasis; chemical process design focuses on profitability, while remediation process design focuses on compliance with environmental regulations.

Based on the results of a literature survey and the author's personal experience, publications and technical exchanges regarding mixed waste treatment and methodologies for remediation are extensive." However, published approaches to the remediation of a mixed waste site that are both comprehensive and detailed are limited. Others have presented methodologies for waste remediation. ${ }^{17-30}$ Additional clarification regarding mixed waste problem resolution is needed because published methodologies do not provide guidance beyond the assessment stage of a project, do not include details regarding project implementation at a DOE site, do not cover issues specific to, or do not explicitly outline the methodology used for solution of the problem under consideration. In-depth waste minimization assessments have been made ${ }^{31-35}$ that incorporate systems analyses and contribute to understanding issues relative to the generation of mixed waste. Performance assessments that analyze the effect of disposal operations ${ }^{36-39}$ on the surrounding population have begun to clarify issues regarding disposal of mixed waste. Remediation projects have been implemented with varying degrees of success without explicitly identifying the methodology employed..$^{40-46}$

\subsection{PROCESS DESIGN METHODOLOGIES}

"Historically and traditionally, it has been the task of the science disciplines to teach about natural things: how they are and how they work. It has been the task of the engineering schools to teach about artificial things: how to make artifacts that have the desired properties and how to design .... Every one designs who devises courses of action aimed at changing existing situations into the preferred one." ${ }^{14}$ "Two broad kinds of mental activity, synthesis and analysis, occupy the

\footnotetext{
- A literature search was completed to support this report, resulting in the review of 70 citations.
} 
engineer during the development of a new and useful process. Synthesis is the combining of diverse conceptions into a coherent whole, and analysis is the examination of a complex situation, its elements, and their relations. In the words of Herbert A. Simon, " . . synthesis deals with how to make artifacts that have the desired properties and analysis deals with how things are and how they work."15 The development and application of a methodology that combines "diverse conceptions into a coherent whole" and that examines "a complex situation, its elements, and their relations," resulting in "courses of action aimed at changing existing situations into the preferred one," meets the "historical and traditional" definition of process design and engineering activities. A comprehensive methodology to remediate a mixed waste site, as developed in this report, uses both "synthesis and analysis, the engineering and the sciences, working hand in hand toward the solution of society's technical problems."

The similarity of industrial chemical engineering process design and process design and development in the environmental arena should be more widely recognized. The ability of chemical engineers to successfully design and implement an environmental project is not always apparent to those unfamiliar with the discipline, simply because the word "environmental" does not appear in the chemical engineer's title. Design and implementation of a waste remediation or environmental restoration process are identical to implementation of an industrial chemical engineering process.

A textbook definition of the procedure required to design a project includes ${ }^{16}$ identification of the type of design, feasibility survey, process development, preliminary system design, design, construction, and operations. Identification of the type of design includes formulating "the initial idea . . . as clearly and concisely as possible in order to define the scope of the project." ${ }^{16} \mathrm{~A}$ waste remediation method should also clearly identify the problem that requires resolution.

The textbook requirement to conduct a feasibility survey is similar to steps required in a waste remediation project. "Before any detailed work is done on the design, the technical and economic factors of the proposed process should be examined." ${ }^{16}$ Industrial process design and development are driven by profit motives in contrast to remediation projects, which are driven by regulatory compliance motives. If one substitutes the words "regulatory compliance" for "economic" in the above quote, the correlation of required activities is apparent. 
A feasibility survey includes the analysis of market, profits, sales and service, and competition. These issues are irrelevant to remediation projects, although consideration of other feasibility survey factors during assessment of a waste remediation problem is important [i.e., raw materials (availability, quantity, quality, cost), thermodynamics and kinetics of chemical reactions involved (equilibrium, yields, rates, optimum conditions), facilities and equipment available at present, facilities and equipment that must be purchased, estimation of production costs and total investment, materials of construction, safety considerations, properties of products (chemical and physical properties, specifications, effects of storage), shipping restrictions and containers, plant location, patent situation, and legal restrictions]. ${ }^{16}$

Selection of the process alternative is the next step outlined by Peters and Timmerhaus ${ }^{16}$ through process development and preliminary system design. Identifying the need for additional research is considered part of process development. Preliminary design includes ${ }^{16}$ refining the problem statement, conducting a literature survey, calculating material and energy balances, and designing and selecting equipment. "Quite often a number of alternative processes or methods may be available to manufacture the same product. Except for those processes obviously undesirable, each method should be given consideration."16 Several process options should be considered to implement a waste remediation project, and rough order-of-magnitude costs should be established for each. A remediation project methodology should consider cost factors during an analysis of remediation options; the most cost-effective method of complying with regulations should be selected. Each option should be compared with a set of system requirements, which include cost, so that alternatives that do not meet system requirements may be eliminated from further consideration. This procedure is recommended by Peters and Timmerhaus:

Evaluation of costs in the preliminary-design phases greatly assists the engineer in further eliminating many of the alternative cases. Preliminary design should be carried out as soon as sufficient data are available from the feasibility survey or the process-development step. In this way, the preliminary design can serve its main function of eliminating an undesirable project before large amounts of money and time are expended. ${ }^{16}$

Several principles of project implementation for industrial chemical processes and remediation projects are identical. The establishment of the basis for design, the preparation of a simplified flow diagram, the design of specific pieces of equipment, and the definition of utilities and labor 
are activities that must occur to implement both types of projects. For DOE remediation projects, however, a divergence occurs between the two project types in compliance with company policies vs compliance with DOE orders. Adherence to the policy of a company sponsoring chemical plant construction is beyond the scope of Peters and Timmerhaus, while compliance with DOE orders is required to successfully implement a project for DOE and is an important aspect of a methodology for remediation of a DOE mixed waste site.

Construction scheduling and coordination and successful operations are of concern in implementing any project, regardless of the purpose of the project. Urgency to build and operate a chemical plant is driven by profit incentives, while urgency to build and operate a remediation project is driven by environmental compliance milestones.

Whether a DOE remediation project is implemented through the use of a subcontractor or through construction of a capital facility, the principles of sound project management apply. Project scheduling requires significant planning; following a project through completion is imperative for successful implementation.

The similarity between industrial chemical plant and remediation project design and project implementation is apparent; remediation project implementation methodology could be strengthened by building on standard engineering practice. Significant uncertainty exists in regulatory requirements for mixed waste. This uncertainty is not reflected in standard industrial design practice because such uncertainty would typically be eliminated prior to project implementation.

\subsection{REMEDIATION METHODOLOGIES}

During a workshop on radioactive, hazardous, and/or mixed waste sludge management, ${ }^{17}$ issues regarding waste characterization, grouting, operations and certification, containment, and treatment of off-specification products were discussed. The workshop identified central issues that need resolution prior to treating off-specification products as (1) defining material to be treated, (2) determining the goal of treatment (i.e., shipment, storage, or disposal), and (3) assessing treatment alternatives. ${ }^{18}$ Assessment of treatment alternatives should include consideration of technical risk, 
institutional risk, health and safety issues, and future reprocessing or disposal liabilities. Cost and schedule were identified as significant factors to be considered during alternative evaluation. The working group pointed to the fact that the development of contingency plans is important because of the uncertainty of the regulatory environment and the criteria upon which a project is based. Guidance provided by the workshop did not address the CERCLA methodology ${ }^{10}$ for implementing activities. Additional guidance is needed that combines the identified steps sequentially into a comprehensive methodology and uses a quantitative analysis of alternative process technology options based on CERCLA guidance.

The CERCLA methodology ${ }^{19}$ presents detailed actions for the initial stages of a remediation project: scoping of the remedial investigation/feasibility study, site characterization, treatability investigations, development and screening of alternatives, and detailed analysis of alternatives. Implementation of the remediation project is beyond the scope of the CERCLA methodology because the method must be generally applicable and cannot include site-specific implementation requirements. The type of method needed is one that expands upon the CERCLA methodology by applying quantitative measures to selection of a process alternative and by describing, in detail, the implementation requirements for DOE sites.

The CERCLA process has been compared to a formal value engineering program as implemented by the Formerly Utilized Sites Remedial Action Program, "an environmental restoration program committed to the implementation of the EPA's remedial investigation and feasibility study process. ${ }^{120}$ Activities necessary to select a process alternative are identified as (1) information (i.e., fact gathering), (2) speculation (i.e., brainstorming), (3) analysis (i.e., evaluation), (4) development (i.e., selection), and (5) recommendation (i.e., reporting). The correlation between the value engineering process and the CERCLA process is described. ${ }^{20}$ The author is aware that value engineering is applied to plant design and construction; however, the referenced report ${ }^{20}$ limits the comparison between remediation project assessment and value engineering to the evaluation stage of the project. Expansion of the guidance to an in-depth assessment of factors affecting implementation is needed to support project success at DOE sites.

An overall process of site stabilization and closure has been presented by Trabalka, ${ }^{21}$ who outlines the following activities: determine exposure pathways of concern, determine performance 
objectives, select and apply stabilization action, assess site performance, maintain stabilized site, and achieve site closure. This comprehensive methodology addresses each stage of a remediation project. However, since these activities are directed toward in situ remediation projects, the activities differ in approach from those required to remediate a mixed waste site (e.g., assessment of site performance as compared with assessment of operational performance during waste treatment). Further, a quantitative approach to selection of the stabilization action is not employed.

Hanford Site cleanup is a complex task, and significant effort has been expended in developing comprehensive plans. $^{22}$ The plans and strategy are based on (1) assessments of regulatory requirements, ${ }^{23-25}$ risk, and waste characterization; (2) establishment of system requirements, including cost, schedule, and waste acceptance criteria; ${ }^{26,27}$ (3) evaluation of alternatives involving stakeholder groups; and (4) detailed assessment of disposal alternatives. ${ }^{28}$ Hanford remediation projects are being implemented in a three-phase strategy. The early stage is planned for completion in 2010; the intermediate stage is planned for completion about 2020; and the longterm stage is planned for operation through $2045 .^{22}$

Cleanup of the Hanford Site is being planned in a comprehensive manner with the expenditure of significant resources and addresses a complex, mixed waste problem. The author was unable to locate documentation of the Hanford strategy in terms of a comprehensive methodology, although, by piecing aspects of the Hanford plan together, the elements of a comprehensive methodology appear to be employed. No explicit reference to the use of CERCLA balancing criteria was noted in reviewing the Hanford literature, although the publication of a Record of Decision $^{24}$ implies that a CERCLA process is being followed. A method that explicitly follows the CERCLA methodology for evaluation of alternatives and documents the strategy for resolving a mixed waste problem is needed.

"A requirements-tree technique has been developed to help guide remedial actions through the complex network of regulatory and technical requirements. ${ }^{29}$ The approach refers to CERCLA criteria and applies the "logic-diagram technique to one complex remedial action, involving radioactive mixed waste at the Idaho National Engineering Laboratory." 29 The described remedial action program is a demonstration project and differs from a waste remediation action in that 
project controls, required for procurement of subcontracted services, are not included. The requirements-tree technique addresses (1) a statement of top-level goals of the remedial action; (2) a logical, step-by-step derivation of the technical and regulatory activities necessary to achieve the top-level goals; and (3) a list of performance requirements of individual tasks, studies, or tests. The technique is directed toward establishing system requirements and ensuring that proposed actions and the sequencing of these actions (e.g., demonstration of waste processing methods) are supported by system requirements. Operational requirements are also established as part of the technique. The use of the logic diagram technique appears to be quite powerful; however, specialized training is required to implement the approach. The requirements-tree technique addresses several aspects required to implement a waste remediation project except a quantitative assessment of alternative process options and a description of details regarding implementation of a project at a DOE site.

The need for "comprehensive planning . . . before remediating a hazardous waste site" ${ }^{130}$ has been recognized by Geffen. A call is made for "effective integration of scientific and engineering data with regulatory and institutional requirements. ${ }^{130}$ Steps are outlined for project implementation: "determine the nature and extent of site contamination, calculate the risk to the public, and assess the effectiveness of various remediation technologies. ${ }^{30}$ The approach refers to CERCLA criteria and screens and analyzes "appropriate remediation alternatives based on the characteristics of the site and the relevant regulations." ${ }^{130}$ The focus of the approach is directed toward meeting information needs and development of data bases rather than project implementation.

\subsection{ASSESSMENTS}

The assessment and implementation of waste minimization programs may be discussed in terms of conducting system analyses and defining courses of action related to mixed waste issues. Since the objective of a waste minimization program is to reduce volume, toxicity, and/or mass of waste as it is generated, issues such as availability of disposal sites and activities such as waste treatment and storage/disposal of waste do not apply. The result of waste minimization assessments has been to identify factors to consider in implementing a waste minimization program and to recommend methods for implementation. Examples of hierarchial approaches to waste minimization include systems developed at Oak Ridge National Laboratory (ORNL) and Hanford. 
ORNL employed a systems analysis approach to waste minimization to identify waste streams, characterize existing waste generation and treatment systems, establish criteria by which to measure progress and reporting of significant achievements, and recommend system modifications that would reduce waste generation. ${ }^{31-33}$ Systems analyses led to implementation of system modifications and of a system for charging waste generators for the volume of waste produced to encourage waste minimization. ${ }^{34}$

The Hanford facility established a hierarchy of environmental protection practices for waste minimization: "First, eliminate or minimize waste generation through source reduction." ${ }^{\text {"35 A }}$ thorough analysis and assessment of the source of waste are required to reduce waste generation. "Second, recycle potential waste materials that cannot be eliminated or minimized." ${ }^{135}$ Decisions to recycle waste materials must be based on an analysis and selection of process alternatives. "Third, treat all waste that is nevertheless generated to reduce volume, toxicity, or mobility before storage or disposal. ${ }^{135}$

Methodologies to assess the risk of disposing of mixed waste have been developed. Pathways analyses are used to establish concentration limits for radionuclides in various disposal scenarios as required by DOE Order $5820.2 \mathrm{~A}$.

Performance assessment calculations estimate the long-term radionuclide releases from the disposal system to the accessible environment. The estimation of the releases is probabilistic in nature, requiring system parameters to be described with probability distributions. Because direct experimental data in some areas are presently of insufficient quantity to form the basis for the required distributions, . . . formalized expert-judgment elicitation procedure is utilized..$^{36}$

The performance assessment methodology recognizes the importance of establishing system parameters and uses a quantitative evaluation of disposal options. ${ }^{36-39}$ The performance of the disposal system, as determined by the pathways analysis, is used to determine the waste acceptance criteria that a given waste form must meet. The approach to performance assessment is similar to the approach needed for mixed waste remediation to select a processing alternative, although probability distributions are not required to analyze rough order-of-magnitude material balance and cost data. A method to select a process alternative would evaluate engineering and 
design data, while the performance assessment evaluates scientific data (e.g., radionuclide concentrations in the brines of a repository room) to estimate long-term radionuclide releases.

\subsection{REMEDIATION PROJECTS}

DOE sites are engaged in remediation projects in response to the decision that DOE sites must comply with both EPA and DOE requirements. ${ }^{1}$ A review of remediation projects identified limited development of comprehensive methodologies for site-specific remediation (see Sect. 2.2); however, requirements for such a methodology can be identified by reviewing causes of project success or failure. Project success depends, in part, on the ability of the site to clearly define disposal requirements for treated waste. The Savannah River Site has negotiated disposal requirements with the state of South Carolina and EPA. ${ }^{40}$ Other sites are conducting performance assessments for proposed on-site disposal facilities or are awaiting the opening of national repositories. ${ }^{2}$ If disposal is not available, storage options must be evaluated. The following review of remediation projects illustrates the point that certain activities must occur to achieve project success.

The Savannah River Site has successfully implemented a "saltstone solidification" project. Disposal requirements have been clearly defined: a vault is filled with solidified waste and the saltstone releases "its contaminates (e.g., nitrate) in a controlled manner." ${ }^{40}$ Feed specifications to the process are based on extensive laboratory research. A rigorous process control strategy is employed in that "all the feeds are sampled, analyzed, and compared with the feed specifications before they are solidified."40 These technical standards provide the operating ranges in which an acceptable product will be produced. Compliance with disposal permit requirements is verified by conducting leach tests on specimens "every time we run." 40 The successful implementation of a waste remediation project at the Savannah River Site is clearly linked to the definition of system requirements and rigorous process control. A comprehensive methodology for waste remediation should incorporate both of these features to provide guidance on factors contributing to project success.

In contrast, the inability of Rocky Flats Plant to implement rigorous process control and clearly

define waste influent characteristics for the treatment of pond sludge and rejected 
pondcrete/saltcrete billets resulted in "equipment that was not adequate for the intended purpose and was not as efficient as other available technologies." 41 In an attempt to rectify the situation, "a subcontractor was solicited to provide continuous processing equipment that could provide realtime quality control measurements and could produce pondcrete at higher rates . . ." 41 "In March 1991, a contract was awarded . . . to stabilize the remaining solar evaporation pond sludge and remix and stabilize the pondcrete/saltcrete billets still stored on site at Rocky Flats. ${ }^{142}$ The contract included substantial requirements for sampling pond sludge "to support waste characterization and treatability studies ... . The overall Rocky Flats Project has been divided into three phases. Phase 1 includes all work up to the initiation of waste processing, including developing the Process Control Program, designing and installing process equipment, and installing the on-site laboratory. Phases 2 and 3 include the actual processing of the pond sludge and pondcrete/saltcrete waste." ${ }^{42}$ The approach adopted by Rocky Flats reflects aspects of a comprehensive waste remediation methodology. The point at which the process is subcontracted is of interest. The Rocky Flats Plant does not have adequate analytical chemistry services to support characterization of the pond waste. Delegation of the waste characterization activities to a subcontractor carries risk because the project scope and cost cannot be clearly defined until the extent of the problem has been determined. Assessment of this risk is part of the consideration of alternative methods of implementation.

The Portsmouth Gaseous Diffusion Plant was unable to clearly define physical constraints associated with implementation of a sludge dewatering project. ${ }^{43}$ An attempt to establish system requirements was made in that "the Environmental Control Department position at the time of storage was that the material would always be a solid once it successfully passed the paint filter test." ${ }^{\text {43 }}$ This requirement was imposed as one process control criterion. "The material stored inside a $B-25$ box, even though by definition a solid, was only $38 \%$ solids when packaged . . . The liquid separated from the solids . . and approximately $10 \%$ of the boxes are leaking ... . Our Environmental Control Department now takes the position that if liquids are present or suspected of being present, we must remove the liquids and repackage the materials at once to remain in compliance." ${ }^{143}$ This example illustrates the fact that a definition of regulatory requirements alone is not sufficient to establish system requirements. Engineering judgment and appropriate physical/chemical assessment of the problem must be integrated with requirements to meet regulatory standards to ensure project success. 
The management of low-level mixed waste at the Hanford Site provides an example of establishing system requirements with staged compliance objectives. Hanford's Low-Level Mixed Waste Disposal Facility is planned for completion "toward the end of 1992 . . . Waste that does not meet the disposal criteria . . . will be placed in permitted storage until treatment." ${ }^{144}$ The objective of the interim storage is to ensure compliance with storage requirements until treatment capacity is available. Waste containers that do not meet storage requirements are repackaged to meet "temporary storage regulations until the waste can be treated according to the disposal site waste acceptance criteria." ${ }^{44}$ This example points out the relative importance of compliance issues: compliance with interim storage objectives is preferred over the no-action alternative of leaving containers in noncompliant storage. A methodology for remediation of mixed waste sites should include a clear definition of the problem that must be resolved.

DOE sites are engaged in remediation projects that require a comprehensive and consistent approach. Regulatory requirements have been clarified by several authors, and the application of the regulations to specific DOE sites has been described. ${ }^{45,46}$ Each project employed a methodology to ensure project success: some methodologies are implicit, while others are explicit. A comprehensive methodology that ensures that all pertinent activities contributing to project success are considered would serve as a useful guide to engineers and scientists who implement mixed waste remediation projects. 


\section{DEVELOPMENT OF METHODOLOGY TO REMEDIATE A MIXED WASTE SITE}

In response to the confusing, complex, and sometimes contradictory issue of mixed waste management, which is DOE-complex wide, a methodology to remediate a mixed waste site was developed. The objectives of this work are to (1) establish a comprehensive, yet straightforward, approach to DOE mixed waste site remediation to serve as a guide for engineers and scientists who direct and implement remediation activities, and (2) ensure that the approach is based on regulatory guidance and requirements. The methodology presented in this report meets these objectives and, it is hoped, will assist others in tackling the mixed waste problem.

Mixed waste contains both hazardous and radioactive species, causing it to be regulated by dual regulations ${ }^{1}$ that were promulgated to govern the management of either hazardous or radioactive waste. These dual regulations provide driving forces for mixed waste environmental restoration activities at all stages. Definitive treatment standards have not been established. Treatment standards could be based on requirements set by specific disposal sites; however, disposal sites licensed to receive DOE mixed waste are limited. Because treatment standards have not been established, DOE sites must store mixed waste for future disposal in facilities for which criteria have not been established. Despite the lack of disposal criteria, numerous environmental restoration sites may present a risk to the public, and regulations governing hazardous waste require that remediation be done by specific deadlines. ${ }^{5}$ This regulatory quandary forms a challenging framework for environmental restoration and waste treatment activities associated with mixed waste.

In addition to regulatory constraints, significant institutional constraints exist for DOE projects. For example, implementation of DOE projects is constrained by the government procurement process (i.e., a period of 6 to 8 years is required to implement a capital project, and procurement of subcontractor services is governed by strict rules that ensure competition). Decision making relative to details of project implementation is reviewed by the management of the primary government contractor, DOE management, and regulatory agencies as appropriate. The current method identifies system constraints and provides an example of a project that met both short- and long-term institutional requirements. 
A unique methodology is therefore required for remediation of a mixed waste site. Such a methodology has been developed, based on the guidance set forth in CERCLA and RCRA. This methodology includes a hierarchy of activities to be undertaken to remediate a mixed waste environmental restoration problem. As shown in Fig. 1, the hierarchy consists of the following steps: (1) identifying the problem; (2) assessing the problem; (3) establishing system requirements; (4) selecting an alternative; (5) remediating the site; and (6) storing or treating and disposing of the waste. ${ }^{7,8}$

The comprehensive method is structured so that each activity builds on the previous one to result in successful project implementation. Problem identification and assessment include the programmatic requirements, historical background, existing chemical and physical conditions, and the regulatory situation. The system requirements are established, based on an analysis of program requirements, physical characterization, and regulatory environment. CERCLA balancing criteria are used as a technical basis for quantifying system requirements. ${ }^{9,10}$ The result of the alternatives analysis is the selection of a process technology option based on a quantified score. ${ }^{11}$ The selected option is then documented in a Record of Decision if the site is being remediated under CERCLA guidelines. Implementation of the option remediates the site. Technical specifications are developed to ensure that the remediation system meets functional and operating requirements. The remediated waste is either stored for future treatment or subjected to a prescribed treatment and disposal regimen.

\subsection{IENTIFICATION OF PROBLEM}

The current method requires a clear definition of the problem to be solved. Mixed waste issues are complex; separation of immediate concerns from longer-term concerns can clarify issues and focus resources on developing a successful strategy for resolution. A remediation problem can be identified through systems analysis, remedial investigation/feasibility study (RI/FS), RCRA facility assessment (RFA), regulatory noncompliance, or changes in regulations. Before 1984, DOE sites were not required to comply with RCRA guidelines because DOE contended that the environmental regulations were inconsistent with the Atomic Energy Act (AEA). Environmental issues were regulated by DOE under the authority of the AEA; however, self-regulation of environmental issues was reversed under a court decision that RCRA was not inconsistent with 
the AEA. ${ }^{1}$ As DOE began to assess the problems that would require remediation to bring facilities into compliance with RCRA, sites conducted system analyses to determine the extent of the problems. Comprehensive RI/FS and RFA have been conducted at several DOE sites. Cleanup goals have been established, and the required remediation efforts are generally understood.

Nevertheless, in the mixed waste arena, the lack of disposal sites makes the storage of wastes a standard practice. Stored waste must meet RCRA requirements established expressly to govern the storage of hazardous waste. The seriousness of the lack of disposal sites is compounded by the fact that LDR limit the time that such wastes can be stored. For example, by May 8, 1992, all wastes are to have been treated to meet LDR. ${ }^{47}$ Thus, numerous mixed waste streams within the DOE complex will soon be out of compliance. Federal Facility Compliance Agreements (FFCAs) are being negotiated in a case-by-case manner on a site-specific basis. Negotiations are supported by a national effort to obtain case-by-case extensions to the treatment deadline. ${ }^{5}$ The current methodology establishes structure and guidance for remediation of mixed waste that can be applied to these waste streams.

In addition to chemical/physical and regulatory problem identification, the current method requires the identification of the existing management structure of the "owner" of the problem. Problems (e.g., regulatory noncompliance) can result because of an inadequate management structure.

\subsection{ASSESSMENT OF PROBLEM}

Assessment of the problem should result in a clear definition of project objectives. The current methodology requires assessment of the physical and chemical situation as well as the regulatory environment. This approach strengthens the foundation for the ensuing project because regulatory drivers provide the incentive for project implementation. Assessment of regulations includes a determination as to whether disposal of the waste, after treatment, is an option that is available. If not, options for safe storage of waste are considered (see Sect. 4.2.3). Physical and chemical characterization is required to understand the problem and to assess alternative treatment processes. Understanding problems associated with equipment design and process failure requires a firm process engineering design. Incorporation of DOE requirements into the project baseline 
facilitates project implementation. The current method describes elements of successful problem assessment.

As the problem is identified, an interdisciplinary team must be formed to review the history, to determine the extent of the problem, and to establish and implement a plan to remediate the situation. The team should include the following disciplines: manager, technologist (e.g., chemical engineer), chemist, regulatory specialist, design engineer, plant operator, safety analysis engineer, quality assurance (QA) specialist, and support staff (including planners). As a minimum, a literature search should be conducted to determine if similar problems have been successfully resolved. Attendance of key team members at relevant conferences can strengthen the accurate identification of the problem. Projects implemented within the DOE system must comply with DOE Order 4700.1, which requires detailed planning and budgeting systems.

Regulators must be included early in the process. One should not underestimate the role of negotiations in identifying the problem and establishing strategies for remediation.

... negotiated settlement between industry and environmentalists would have been unheard of just a few years ago, when environmental politics meant a clearcut struggle between "them" and "us." Now, battle lines are becoming increasingly blurred, and a much-needed pragmatism stresses collaboration rather than confrontation. "Negotiation offers an alternative path," says Jay Beyea of the National Audubon Society, an environmental group. "It's good for the public, it's good for industry, it's good for environmentalist, and it's good for government regulators. ${ }^{348}$

Preliminary interaction with regulators and input from the interdisciplinary team will ensure that the groundwork is laid for the formation of a foundation of programmatic requirements.

Engineers understand the need for identifying and characterizing the chemical and physical nature of a problem; however, a rigorous analysis of both current and future regulations is equally important in establishing the criteria for assessing various process technology options. Compliance with regulations can be the primary driving force for conducting the project. This is particularly true in assessing a mixed waste problem because dual regulations may provide conflicting guidance. 
DOE on-site disposal of mixed waste has not been approved with the exception of the Nevada Test Site (NTS) and Hanford. NTS has developed criteria for receipt of defense wastes that meet LDR requirements; ${ }^{2}$ however, neither facility is actively receiving wastes. The DOE initiated an effort in the fall of 1991 to pursue use of off-site commercial mixed waste disposal sites for wastes that meet the requirements of the facility's license(s). ${ }^{3}$ Implementation of the commercial disposal option will facilitate the disposal of mixed waste streams that contain extremely low concentrations of man-made radionuclides or contain concentrations of radionuclides equivalent to naturally occurring radionuclides.

Characterization of the chemical and rheological properties of mixed waste streams is difficult. Specialized analytical procedures are being developed for analyzing highly radioactive mixed waste samples. Research and development is being conducted on nondestructive assay and examination techniques as well as on nonintrusive characterization methods. ${ }^{49}$

Detailed planning is required prior to sample collection. If possible, a protocol for collection of statistically significant samples should be designed. Because of health, safety, and cost issues surrounding the collection and analysis of samples, the minimum number of samples required to characterize the waste will be collected. In some cases, physical constraints may limit access to radioactive waste, making statistically significant sample collection impossible. Implementation of a sample plan is critical to accurately characterize the waste stream. In addition to the number and location of samples, the method of collecting the sample must be carefully planned. Thorough mixing of the waste and collection of "thief" samples are examples of methods that should be considered. System requirements and data quality objectives should be determined prior to the completion of sampling plans. ${ }^{50,51}$

\subsection{ESTABLISHMENT OF SYSTEM REQUIREMENTS}

A key feature of the current method is to establish system requirements by which process options can be eliminated. One will find that "external commenters" tend to suggest alternatives that cannot be achieved or that do not meet the project goal. By identifying the essential aspects of a given process (or system), attention can be focused on productive alternatives. 
The current method cites the definition of system requirements as a "set of top-level constraints that are used to select the course of action for the remediation project."11 Only those objectives which influence the selection of a course of action that will meet the cleanup goal and will ensure a viable selection are included in the system requirements. A matrix is established to cover input, output, and programmatic requirements. Requirements in each category are generated from a combination of technical and regulatory bases. ${ }^{11,52}$ The importance of establishing clear, discrete system requirements cannot be overestimated. Requirements can be revised as additional information is collected; however, activities will be predicated, based on the requirements. Once a course of action has been established, the momentum to proceed can stifle reevaluation of the basis for the action.

\subsection{SELECTION OF ALTERNATIVE}

The current method develops process technology options based on a review of the literature, determination of the best demonstrated technology for the RCRA waste category, the results of bench-scale studies, and an analysis of alternative process designs. Each option encompasses all aspects of project definition, efficiency, implementability, and cost-effectiveness. Typically, three to five options may be identified with the "no-action alternative" as the base case." Alternative action plans, including processing options, are compared with the system requirements. If an action plan does not meet system requirements, it is eliminated from further consideration, and the decision is documented. Usually the no-action alternative will be eliminated at this point, based on its inability to meet system requirements; however, costs and the environmental impact may be developed for the no-action alternative to provide a baseline for comparison of other alternatives.

Process technology options are developed for each action plan that meets the system requirements. Criteria for assessing the process technology options are applied to each. The result of implementing the formalized selection process is a prioritized ranking of alternative process technology options, including a rating for (1) effectiveness, (2) implementability, and (3) cost-

*The National Oil and Hazardous Substances Pollution Contingency Plan (NCP) requires analysis of the no-action alternative. 
effectiveness. Detailed performance criteria are defined for each category (see Tables 1 to 3 ). If key decision makers are not involved in developing the ratings, the rating for each performance criterion by process technology option should be provided to the decision maker(s). Caution must be exercised in the use of the ratings for the upper-level categories only; the trade-off between alternatives may be lost in the overall score. ${ }^{53}$ The use of a quantifiable score for each performance criterion is a tool to aid in decision making. The responsibility for sound decisions lies with project staff members and key decision makers.

\subsubsection{Process Technology Options}

Configuration options are established as top-level block flow diagrams and are assessed by comparison with the system requirements. Process technology options are developed to define specific technologies or requirements for each "block" within the "configuration option" flow diagram. Functional and operating requirements are established for each block or functional subelement. Alternatives are further screened against these performance requirements. The result is an engineered system that meets system as well as functional and operating requirements.

\subsubsection{Criteria for Assessing Process Technology Options}

The criteria for assessing process technology options have been grouped into three broad categories: effectiveness, implementability, and cost. ${ }^{10}$ Formulas were developed by $\mathrm{O}^{\prime} \mathrm{Brien}^{11}$ for each performance criterion to quantitatively evaluate process technology options." Criteria for the "development and screening of alternatives" are discussed in Title 40 of the Code of Federal Regulations (CFR), Part 300.430 .

The definition of each performance factor and the formula for calculating the score for each process option are shown in Tables 1 to 3 . Table 1 includes performance criteria for process effectiveness. The factors measure how well a process will meet project objectives. For example, the system requirements for a project may not include volume reduction, but it may be

"Titles and formulas for performance criteria have been modified by the author to more accurately reflect the performance criteria relevant to mixed wastes being stored on the ORR. 
Table 1. Formulas for assessing performance criteria for process effectiveness

\begin{tabular}{llc}
\hline \multicolumn{1}{c}{ Factor } & \multicolumn{1}{c}{ Performance measure } & Formula for scoring \\
\hline Volume reduction & $\begin{array}{l}\text { Volume reduction of primary } \\
\text { waste stream }\end{array}$ & $1-\mathrm{V}_{\mathrm{o}} / \mathrm{V}_{\mathrm{i}}$ \\
$\begin{array}{l}\text { Compliance with applicable or } \\
\text { relevant and appropriate } \\
\text { requirements (ARARs) }\end{array}$ & $\begin{array}{l}\text { Releases to the environment as } \\
\text { fraction of allowable release }\end{array}$ & $1-\mathrm{V}_{\mathrm{w}}\left(\mathrm{A}_{\mathrm{act}} / \mathrm{A}_{\mathrm{allow}}\right)$ \\
Secondary waste generation & $\begin{array}{l}\text { Amount of contaminated } \\
\text { material as compared with input } \\
\text { volume }\end{array}$ & $\mathrm{V}_{\mathrm{g}} / \mathrm{V}_{\mathrm{i}}$ \\
Throughput ${ }^{a}$ & $\begin{array}{l}\text { Time required to process per } \\
\text { unit of waste remediated }\end{array}$ & $1-\mathrm{T}_{\mathrm{r}} / \mathrm{V}_{\mathrm{i}}$ \\
Effective benefit ${ }^{a}$ & $\begin{array}{l}\text { Time required to process } 50 \% \\
\text { of waste }\end{array}$ & $1-\mathrm{Th}^{\mathrm{m}} / 30$ \\
Risk to employees & $\begin{array}{l}\text { Proportional risk to employees } \\
\text { with/without process }\end{array}$ & $0.2 \times \mathbf{R}_{\mathrm{pp}} / \mathrm{R}_{\mathrm{p}}$ \\
Environmental/public health & $\begin{array}{l}\text { Proportional risk to public } \\
\text { with/without process }\end{array}$ & $0.2 \times \mathbf{M}_{\mathrm{cp}} / \mathrm{M}_{\mathrm{c}}$ \\
\hline
\end{tabular}

${ }^{9}$ M. C. O'Brien, J. L. Morrison, M. J. Rudlin, and J. G. Richardson, Performance-Based Technology Selection Filter, Preliminary Description Report, EG\&G-WTD-9899, Rev. 0, Idaho National Engineering Laboratory, November 1991. 
Table 2. Formulas for assessing performance criteria for process implementability

\begin{tabular}{|c|c|c|}
\hline Factor & Performance measure & Formula for scoring \\
\hline Permits & Number of permits required & $1 / N_{p}$ \\
\hline Industrial availability & $\begin{array}{l}\text { Ability of subcontractor to supply } \\
\text { required equipment }\end{array}$ & $\mathrm{F}_{s} / \mathrm{F}_{\mathrm{t}}$ \\
\hline Simplicity of design & Number of functional subelements & $\mathrm{F}_{\mathrm{t}}$ \\
\hline Robustness & $\begin{array}{l}\text { Ability of system to process a } \\
\text { range of inputs without affecting } \\
\text { system operations or product } \\
\text { quality }\end{array}$ & $\mathrm{N}_{\mathrm{ok}} / \mathrm{N}_{\mathrm{o}}$ \\
\hline Implementation risk & $\begin{array}{l}\text { Scheduled time from approval of } \\
\text { contract to beginning of operation }\end{array}$ & $1-T_{c} / 30$ \\
\hline Technical risk & $\begin{array}{l}\text { Ratio of the number of } \\
\text { subelements demonstrated in both } \\
\text { actual and similar environments to } \\
\text { the total number of subelements }\end{array}$ & $\left(C_{d}+0.75 C_{s}\right) / F_{t}$ \\
\hline Demonstrability $^{a}$ & $\begin{array}{l}\text { Subelements not demonstrated } \\
\text { before full-scale implementation }\end{array}$ & $1-C_{n} / F_{t}$ \\
\hline Implementation time & $\begin{array}{l}\text { Time from identification of } \\
\text { problem to completion of } \\
\text { operations }\end{array}$ & $50 \times 1 / T_{i}$ \\
\hline Future disposal & $\begin{array}{l}\text { Fraction of waste that will be } \\
\text { difficult to reprocess }\end{array}$ & $1-\mathrm{V}_{\mathrm{no}} / \mathrm{V}_{\mathrm{o}}$ \\
\hline
\end{tabular}

'M. C. O’Brien, J. L. Morrison, M. J. Rudin, and J. G. Richardson, Performance-Based Technology Selection Filter, Preliminary Description Report, EG\&G-WTD-9899, Rev. 0, Idaho National Engineering Laboratory, November 1991. 
Table 3. Formulas for assessing performance criteria for process cost-effectiveness

\begin{tabular}{llc}
\hline \multicolumn{1}{c}{ Factor } & \multicolumn{1}{c}{ Performance measure } & Formula for scoring \\
\hline Implementation cost & $\begin{array}{l}\text { Cost per unit volume of waste } \\
\text { treated }\end{array}$ & $1-\mathrm{C}_{\mathrm{m}} / \mathrm{V}_{\mathrm{i}}$ \\
$\begin{array}{l}\text { Complexity of operations }- \\
\text { automation }\end{array}$ & $\begin{array}{l}\text { Operational labor hours per hour } \\
\text { of operation }\end{array}$ & $10 \times \mathrm{O} / \mathrm{L}$ \\
$\begin{array}{l}\text { Complexity of operations }- \\
\text { training }\end{array}$ & $\begin{array}{l}\text { Fraction of staff that requires } \\
\text { specialized training or experience } \\
\text { to operate system }\end{array}$ & $1-\mathrm{SE} / \mathrm{S}$ \\
\hline
\end{tabular}

extremely beneficial to reduce the volume of the primary waste stream. This method focuses attention on desirable attributes that contribute to project effectiveness. Similarly, Tables 2 and 3 show factors that contribute to project implementability and cost-effectiveness. Table 4 lists and defines variables used in calculating each performance factor.

The reader should note that data required to evaluate the performance factors are rough order-ofmagnitude values. The usefulness of such a method is dependent on the availability of data. Because alternatives are identified and evaluated early in the life of a project, the current method uses data that are typically available after a feasibility study to evaluate process options. The need for sound engineering judgment is not diminished but is enhanced through the use of this tool.

\subsection{REMEDIATION OF SITE}

The current methodology considers alternative procedures to implement the remediation activities. Project schedule, cost, and implementation are influenced by the procedure employed. Failure to analyze the implementability of a process technology option can result in project failure.

DOE facilities can implement a project using the following procedures: (1) design, build, and operate an on-site remediation facility or (2) initiate a subcontract with an industrial firm to mobilize privately owned equipment and remediate the site. 
Table 4. Definition of variables for assessing performance criteria

\begin{tabular}{|c|c|}
\hline Variable & Definition \\
\hline$A_{\text {act }}$ & Actual concentration of pollutant of concern \\
\hline A allow & Allowable concentration of pollutant of concern \\
\hline $\mathrm{C}_{\mathrm{d}}$ & Number of demonstrated subelements \\
\hline $\mathrm{C}_{\mathrm{m}}$ & $\begin{array}{l}\text { Implementation cost; cost of subcontract or capital and operational cost plus institutional } \\
\text { cost (e.g., project management, documentation) }\end{array}$ \\
\hline$C_{n}$ & Number of subelements that cannot be demonstrated \\
\hline $\mathrm{C}_{\mathrm{s}}$ & Number of similar demonstrated subelements \\
\hline$F_{s}$ & Commercially off-the-shelf functional subelements \\
\hline$F_{t}$ & Total functional subelements \\
\hline $\mathrm{L}$ & Operational labor hours \\
\hline $\mathbf{M}_{\mathrm{c}}$ & Potential toxic loss to environment \\
\hline $\mathrm{M}_{\mathrm{cp}}$ & Toxic content of processed waste input \\
\hline $\mathrm{N}_{\mathrm{o}}$ & Number of predefined influent characteristics the system will be required to process \\
\hline $\mathrm{N}_{\text {ok }}$ & $\begin{array}{l}\text { Number of predefined influent characteristics that do not have significant potential to } \\
\text { affect system performance }\end{array}$ \\
\hline$N_{p}$ & Number of permits required \\
\hline $\mathrm{O}$ & Operation hours \\
\hline$R_{\mathrm{np}}$ & Quantized risk without process \\
\hline $\mathbf{R}_{\mathbf{p}}$ & Quantized risk with process \\
\hline $\mathbf{S}$ & Total operational staff \\
\hline SE & Staff requiring specialized training or experience \\
\hline $\mathrm{T}_{\mathbf{c}}$ & Time to begin remediation after contract award \\
\hline $\mathrm{T}_{\mathrm{h}}$ & Time to treat $50 \%$ of waste \\
\hline $\mathrm{T}_{\mathrm{i}}$ & Time from identification of problem to completion of operations \\
\hline$T_{r}$ & Time to remediate \\
\hline $\mathbf{V}_{\mathrm{i}}$ & Volume of waste stream as defined in the input requirements \\
\hline$V_{\text {no }}$ & Volume of waste that will be difficult to reprocess \\
\hline$V_{0}$ & Volume of output material from the process that requires monitoring and storage \\
\hline $\mathrm{V}_{\mathrm{s}}$ & Volume of secondary waste produced by the system \\
\hline $\mathrm{V}_{\mathbf{w}}$ & Volume of waste stream that is discharged to environment \\
\hline
\end{tabular}


The first procedure is completed through a series of formal documents and budget requests. First, it is necessary to prepare a System Requirements Document and a Feasibility Study to outline the functional and operational requirements and to establish the basis for a Conceptual Design Report(CDR). The CDR includes a total estimated cost for the project as well as specifications for equipment and facility design. If the total estimated cost is greater than $\$ 1,300,000$, the CDR is used to submit a budget request to Congress for a "line-item project." If approved, an architect/engineer firm is awarded a contract for detailed design; the CDR forms the basis of the detailed design. Construction is completed by a subcontractor under the supervision of site engineers. Startup and operation of the facility are the responsibility of the contractor who operates the site for DOE. This process takes 6 to 8 years, making timely compliance with regulations difficult. DOE has modified this procedure somewhat in response to the need for timely remedial action. The modified approach is applied in environmental restoration projects only; it cannot be used in waste management projects. Under the revised scheme, the submission of line-item budget requests to Congress is not required, and the process can be shortened to 2 to 3 years.

The second procedure involves the selection of an industrial firm to accomplish the remediation project. The intent of DOE to subcontract the project is announced in the Commerce Business Daily. An Expression of Interest (EOI) is prepared by members of the interdisciplinary team to solicit technology options from industry. Based on preliminary information gained from the response to the EOI, detailed procurement documents are prepared by the team. Technical specifications can reflect the system requirements and the alternative selection. In some cases, the subcontractor is given more latitude and may be asked to develop alternative process technology options, (i.e., the subcontractor's duties may include conducting the alternatives assessment and selecting the alternative process). Performance-based specifications are typically issued, giving the subcontractor some latitude but limiting strategic decision making to DOE staff members, regulators, and prime contractor personnel. A competitive bid process and an evaluated procurement method are used to award the subcontract. The evaluated procurement utilizes weighting factors for significant performance criteria, thereby allowing the selection of a subcontract on technical merit as well as a cost basis. The selected subcontractor mobilizes privately owned equipment to remediate the environmental problem. A major issue in remediating mixed wastes is residual radioactivity that cannot be removed from equipment. Equipment 
decontamination must be considered during equipment design and must be thoroughly executed during demobilization. DOE prime contractor staff members oversee all phases of the subcontractor's work.

In either case, treatability studies must be conducted to support the design of the selected alternative. $^{54}$ In addition, performance criteria must be established. The actual waste should be used to determine the effectiveness of proposed equipment in meeting the performance criteria. Critical operational parameters are identified on the basis of the results of the treatability studies, and appropriate process control methods are developed. In the mixed waste arena, equipment modification is frequently required to meet health and safety requirements for operator exposure, secondary waste stream release limits, and unique process requirements.

\subsection{STORAGE OF WASTES}

The current method includes consideration of compliant storage facilities. Container, building, and implementation (e.g., labor and equipment) costs of waste storage are determined and incorporated into the overall project definition.

The guidelines stipulated by the EPA and DOE for hazardous and radioactive waste apply, respectively, to mixed waste. Even though no disposal sites have been approved for DOE mixed waste, LDR required treatment of hazardous waste by May 8, 1992, including all DOE mixed wastes for which alternative compliance dates have not been established. LDR further prevent storage of hazardous waste for more than 1 year, except for the purpose of accumulating sufficient quantities to treat the waste. Because of the lack of disposal facilities, perpetual storage of the treated waste is the logical, near-term "conclusion" to mixed waste remediation projects. Safe storage of mixed waste is preferred by regulators over the no-action alternative of leaving environmental restoration sites unremediated.

\subsection{TREATMENT AND DISPOSAL OF WASTE}

A strategic approach to the mixed waste quandary has been outlined:55,56 treat the waste to the most stringent criteria (e.g., glass waste form). A significant developmental effort is required to 
implement this strategy; therefore, near-term remediation projects would assume serious technical risk to adopt this strategy. Since treatment standards have been established for hazardous waste, waste can be treated to meet LDR. Repositories are planned for transuranic waste and for highlevel waste, but plans for these facilities have been delayed. REF WIPP Treatment standards for radioactive materials are, in many cases, lacking on a site-specific basis. Therefore, the treatment of mixed waste to meet LDR standards, without consideration for site-specific performance criteria, carries regulatory risk because disposal criteria are unspecified. The treatment of mixed waste to standards that apply to the retention of radionuclides (e.g., high waste loading, significant volume reduction, low leachability, and high durability) carries technical risk because processes and waste forms require development. ${ }^{12}$

Use of conventional technology (e.g., immobilization in grout) increases the volume of waste streams significantly ( 30 to $40 \mathrm{vol} \%$ ). In some cases, grouting alone may not meet future waste treatment requirements for on-site disposal. For example, waste streams that contain high concentrations of nitrate salts have historically been solidified in grout. Future, more stringent on-site disposal criteria may eliminate this option because nitrate is leachable from the grout matrix and is highly mobile in the environment. Without specific waste disposal criteria, no clearly superior near-term course of action for the "treat and dispose" activity can be identified.

The current method requires consideration of disposal options during assessment of the problem. Since disposal sites for DOE mixed waste are limited, this activity is not frequently pursued. 


\section{APPLICATION OF METHODOLOGY TO THE REMEDIATION OF 32,000 DRUMS OF MIXED WASTE SLUDGE}

The preceding methodology for remediation of a DOE mixed waste site has been applied to the solution of a specific problem: the management of 32,000 drums of mixed waste sludge at the Oak Ridge K-25 Site. The method is comprehensive, covering all aspects of project success, and detailed, covering all requirements for project implementation. Technical specifications include definitive performance criteria to ensure that the waste will meet regulatory requirements immediately after processing and, based on projected physical behavior, will continue to meet regulatory requirements during storage.

The methodology was applied to the resolution of this problem concurrently with project implementation, providing a unique opportunity to modify the model, as necessary, and test the content validity and reliability of the model. ${ }^{57}$ The assessment of the regulatory situation (see Sect. 4.2.3) was validated and strengthened by incorporation of comments from EPA, the state of Tennessee, ${ }^{58}$ and DOE managers." Highly qualified K-25 Site managers ${ }^{59}$ who are familiar with the project provided independent review and comment on the methodology and method application. This review also confirmed the content of the alternative analysis procedure. ${ }^{60}$

Because the remediation of 32,000 drums of mixed waste sludge proceeded in parallel with model development, the reliability of the model was independently confirmed. For example, the system requirements established in this method (see Sect. 4.3) provided the basis to eliminate process technology options from further consideration. Further, the level of detail developed in the technical specifications (see Sects. 4.5 and 4.6) provided clear guidance to potential subcontractors, especially with regard to preparation of the preliminary system design report and the process control plan. Revision and clarification of the specifications, required to proceed with procurement, are reflected in the current text.

"EPA, the state of Tennessee, and DOE managers did not review this report directly; however, a review of the logic and conclusions presented herein was conducted during a project review meeting held in July 1991. 
The most dramatic example of the reliability of the model is the ability of the quantitative alternative assessment methodology to predict the results of the more qualitative procurement assessment. Rough order-of-magnitude process design mass balances and costs were used to supply data for the alternatives assessment (see Sect. 4.4). These data were validated by data supplied by potential subcontractors. (Process data supplied by potential subcontractors are not published here because these data are "procurement sensitive.") The procurement team did not use the alternative assessment model presented herein. However, both evaluations of alternatives selected the same preferred option; thus, the alternative selection method was independently verified.

As described below, the closure of two surface impoundments generated 78,000 drums of mixed waste, which is classified into two populations: 46,000 drums of solidified waste and 32,000 drums of untreated sludge. This report describes the history of generation for both populations of waste. The analysis of regulations, system requirements, process options, and implementation is presented for the 32,000 drums of untreated sludge only. Action taken to remediate the 46,000 drums of solidified waste is beyond the scope of this report.

\subsection{IDENTIFICATION OF PROBLEM}

The first step in applying the current method is to identify both the physical and the regulatory situations that require resolution. A clear problem definition allows separation of issues so that resources can be focused.

The Oak Ridge K-25 Site (formerly known as the Oak Ridge Gaseous Diffusion Plant) closed two mixed waste surface impoundments by removing the sludge and contaminated pond-bottom clay and attempted to process these materials into durable, nonleachable, concrete monoliths. The strategy was to use interim, controlled, above ground storage of the drummed waste until the stabilized sludge could be delisted from hazardous to nonhazardous. The delisted monoliths could then be disposed of as Class I radioactive waste (see Appendix A).

Schedule constraints, along with process design and control deficiencies, made it necessary to store $\sim 46,000$ drums of material in various stages of solidification and $\sim 32,000$ barrels of 
unprocessed sludge. The abandoned treatment facility contained $\sim 16,000$ gal of raw sludge. An inspection during the summer of 1990 (ref. 61) resulted in a finding that such storage of mixed waste did not comply with RCRA guidelines. The current methodology requires a clear definition of the problem in terms of noncompliance issues.

In August 1990, the United States Environmental Protection Agency (EPA) and the Tennessee Department of Environment and Conservation (TDEC) transmitted a letter to the United States Department of Energy (DOE) requesting an action plan to correct the RCRA violations stemming from the . . . closure and to abate, prevent, or eliminate the threat to human health or the environment at the drum storage yards. ${ }^{62}$

The following is a list of the RCRA noncompliances associated with the storage of the wastes:

- Waste Stored in Nonpermitted Facility - Approximately 16,000 gal of raw pond sludge (listed as F006 waste) has been stored in holding tanks at the K-1419 STF since cessation of closure operations in 1989. The STF is permitted as a treatment facility but not as a storage facility. A revised Part A with a request to modify interim status has been submitted to the Tennessee Department of Environment and Conservation (TDEC) to correct this deficiency, but approval of that modification request has not been received.

- Noncompliant Storage Facilities - Because of the presence of free liquids in the ungrouted sludge and some populations of the solidified sludge, the stored wastes are being handled as liquid wastes. Unfortunately, the current secondary-waste-containment capability at the storage pad and in several of the K-25 building vaults will not meet the design requirements of TN Rule 1200-1-11-.06(9)(f) for the storage of liquid wastes. Some processed sludge drums may be dry and could qualify as wastes containing no free liquids; however, until an appropriate analysis program is performed, they will be managed in the same manner as liquid waste.

- Noncompliant Container Storage Configuration - The present drum storage configuration on the asphalt pad and in the K-25 building vaults does not provide sufficient aisle space for the unobstructed movement of personnel, emergency response, or drum retrieval equipment in accordance with TN Rule 1200-1-11-.06(3)(f). In addition, the stacking array does not allow for inspection of the drums in accordance with TN Rule 1200-1-11-06(9)(e).

- Incompatible Storage Containers - Requirements of TN Rule 1200-1-11-06(9)(c) state that waste storage containers must be compatible with the stored waste materials. Because of the presence of free liquids containing corrosive constituents, and/or a moist environment in both the raw and solidified sludge drums, the mild-steel drums (some with suspect liners) have not proved to be compatible with the stored waste. Internal corrosion of the drums has been evident, and holes have been observed in drums of both raw and solidified wastes. ${ }^{62}$ 


\subsection{ASSESSMENT OF PROBLEM}

\subsubsection{Historical Background}

Application of the current method to the remediation of drummed pond sludge required an expansion of previous efforts to assess the problem. A more in-depth analysis of sludge removal activities, hazardous classification of waste, applicable regulations, and chemical/physical characterization was required.

From 1955 to 1985 , the Oak Ridge K-25 Site utilized two ponds, B and C, as settling/holding basins for neutralized waste streams from the steam plant, metals cleaning facility, plating shop, and sludge generated by the system used for treating the gaseous effluent generated by the uranium enrichment process. The primary difference between the sludge in the two ponds is that off-gas scrubber blowdown sludge, ion-exchange resin, chlorides, and fluorides were added to Pond $\mathrm{C}$ only. Large quantities of sludge from treating runoff of a nearby coal pile, sludge for other steam plant activities, and fly ash were added to Pond B only.

In an attempt to meet a RCRA-directed closure of the ponds by November 1988, the pond sludge was excavated, and a portion was immobilized in a cement-based grout. All of the sludge was not grouted because of time constraints; raw sludge was drummed in order to close out the ponds prior to the deadline. As a result of this activity, $\sim 78,000$ drums containing either grouted sludge or raw sludge were stored at the Oak Ridge K-25 Site.

The waste involved generally falls into two categories: raw sludge, which is a mixture of liquids, clay, and sludge materials and processed solid. Approximately 32,000 drums contain raw sludge, while approximately 46,000 drums contain processed solid. The drums (55-, 89-, and 96-gal capacities) were stored on an asphalt storage pad and in K-25 building storage vaults in a manner that was not compliant with RCRA requirements, as discussed above. This situation resulted in a need to bring all 78,000 drums of grouted waste and raw sludge into compliance with these requirements. 
In addition to drummed raw sludge, $\sim 16,000$ gal of raw pond sludge was stored in holding tanks at the Sludge Treatment Facility (STF), and solidified waste was stored in two 6-ft culverts and four B- 25 boxes $(4 \times 4 \times 6 \mathrm{ft})$ on the asphalt storage pad.

The pond waste is classified as a mixed waste because waste generated from electroplating operations was discharged to the ponds, causing the waste to be listed as F006 by RCRA regulations. The sludge also contains low levels of radionuclides, primarily technetium and uranium (see Table 5).

A cement-based grout formula was developed for use with sludge from both ponds. The target formulation used the proportions determined to be optimal, as shown in Table $6 .^{63}$

In this formulation, the optimum solids content of the influent slurry was $25 \mathrm{wt} \%$ during all batching operations, which normally produced between 12 and 20 drums per batch. Following the stabilization of sludge from each pond, some drums contained solid concrete monoliths "that collected water inside through diurnal cycles of exposure to the heat of the day and the night coolness. Some of these concrete monoliths have interstitial and/or trapped water that can leach through the concrete during hot weather, followed by condensation on the inside walls of the drums during cool conditions." ${ }^{61}$

During solidification operations, grab samples of grout slurry were removed from various batches to cast into cubes for the unconfined compressive strength and for Extraction Procedure-Toxicity (EP-Toxicity) testing, Multiple Extraction Procedure (MEP), total-constituent analyses, organic chemicals, and oil and grease. Radionuclide data are reported for 18 samples in Appendix B. The unconfined compressive strengths were found to range between 1000 and 1500 psi (American Society for Testing and Materials Procedure C-109), and the leachates from 40 cubes of grout easily passed the EP-Toxicity test as the primary and secondary drinking water standards when applied directly. Because a statistical sampling methodology was not used, these data are not considered to be representative of the entire process-only of the 40 batches sampled. ${ }^{64}$ 
Table 5. Summary of pond waste characterization data ${ }^{a}$

\begin{tabular}{lccl}
\hline & \multicolumn{2}{c}{ Mean concentration } & \\
\cline { 2 - 3 } & Pond B & Pond C & Units ${ }^{b, c}$ \\
\hline Density & 1.1 & 1.4 & \\
$\mathrm{pH}$ & 7.0 & 10 & \\
Technetium & 3640 & 1570 & $\mathrm{pCi} / \mathrm{g}$ \\
Plutonium & 3.2 & 27.9 & $\mathrm{pCi} / \mathrm{g}$ \\
Cesium & 53.6 & 6.8 & $\mathrm{pCi} / \mathrm{g}$ \\
Neptunium & 3.2 & 20.3 & $\mathrm{pCi} / \mathrm{g}$ \\
Uranium & 444 & 550 & $\mathrm{pCi} / \mathrm{g}$ \\
${ }^{235}$ U enrichment & 1.2 & 1.6 & $\mathrm{wt} \%$ \\
\hline
\end{tabular}

"Because of electroplating solutions, waste is RCRA-listed as F006.

${ }^{b}$ The Department of Transportation defines radiological material as material that has an activity greater than $2000 \mathrm{pCi} / \mathrm{g}$.

'Nuclear Regulatory Commission (NRC) criteria stipulate that lowest-classification material (Class A) is material that has an activity greater than $3 \times 10^{6} \mathrm{pCi} / \mathrm{g}$.

Table 6. Target grout formula

\begin{tabular}{lc}
\hline \multicolumn{1}{c}{ Component } & Weight percent \\
\hline Portland cement (Type I) & 25 \\
Fly ash (Class F) & 25 \\
Sludge (15-30 wt \% solids) & 50 \\
Admixture (MB-AE 10) & 0.125 \\
\hline
\end{tabular}


The raw waste was heterogeneous; that is, the drummed sludge was removed from Ponds B and $\mathrm{C}$ by five different removal and drum-filling methods, ${ }^{64}$ which are described as follows:

1. Sludge, rocks, and debris were removed directly from the ponds by backhoe or dragline and placed directly into drums.

2. Sludge, rocks, and debris were removed directly from the ponds by backhoe or dragline, put into a concrete truck, mixed and transported, and then placed in drums from the concrete truck.

3. Sludge in the ponds was mixed into pockets or pools by use of graders and/or dragline. Pond waste and bottom clay were also mixed into the pools on occasion. These blended pools were placed into drums by direct pumping, direct backhoe or dragline filling, or pumping to concrete trucks prior to drum filling.

4. Sludge was removed by floating dredge pump, transferred to a 15,000 -gal blend tank (located at the STF), blended, and pumped into drums after rocks and debris had been screened.

5. Sludge was removed by dragline; put into concrete trucks; transferred to a 2700 -gal, twinscrew, mix tank; blended; and pumped into drums after the rocks and trash had been screened out. ${ }^{64}$

The resulting composition of the drummed raw waste is therefore heterogeneous with regard to chemical and physical properties. For example, the volume of liquid contained in individual drums is quite variable, ranging from 0 to $75 \mathrm{vol} \%$ free liquid. Furthermore, the fraction of solids in the sludge ranges between 20 and $60 \mathrm{wt} \% .^{65}$ The liquid associated with this sludge has been shown to have an extremely low dissolved solids content because of solubles leaching from the material contained in the holding ponds over a number of years. Despite this fact, enough chloride and fluoride are present in the liquid to promote corrosion and cause holes to form in the mild-steel drums. Prior to September 1991, analytical data on the sludge from the ponds were limited to pond sampling that occurred in May 1985. These data were obtained from core 
samples of the ponds and the underlying clay bed. ${ }^{64}$ Twelve samples of sludge were removed from Pond B, while 15 samples were removed from Pond C. The data, which are summarized in Appendix B, are based on the statistical sampling process employed at that time. As can be seen from Table 5, the radionuclides of concern are $\mathrm{U}\left({ }^{235,238} \mathrm{U}\right), \mathrm{Cs}, \mathrm{Np}, \mathrm{Pu}$, and Tc.

\subsubsection{Environmental, Safety, and Health Concerns}

The presence of radioactive mixed waste in uncontrolled storage conditions represented a manageable environmental, safety, and health (ES\&H) concern. ${ }^{62}$ The radioactivity levels in the stored waste do not result in an external radiation hazard to inspection or waste handling personnel. The hazardous constituents in the waste are principally heavy-metal and radioactive substances in extremely low concentrations and some free liquid in excess of pH 12.5. None of these factors would pose a significant ES\&H threat in a controlled, monitored storage environment. Therefore, short of a catastrophic failure or destructive natural event affecting a large number of drums simultaneously, the risk to public health and safety was low in the initial storage configuration. Also, past analysis of samples collected from surface water runoff, soil, and sediment in the areas adjacent to the drum storage pad and Mitchell Branch (outfall for runoff from the pad) indicated that contaminant levels were well below the National Pollutant Discharge Elimination System (NPDES) limits. The ES\&H consideration of greatest concern, then, was the stability of the existing drum storage array. This situation was both an Occupational Safety and Health Act (OSHA) issue and a potential RCRA release concern. ${ }^{62}$

\subsubsection{Evaluation of Regulations}

\section{Storage Requirements}

Process options that address the identified RCRA storage violations by bringing the pond waste into compliance with storage requirements would meet with regulatory approval. Compliance issues of concern to regulators fall into the following areas and are discussed below:

- Waste Stored in Nonpermitted Facility

- Noncompliant Storage Facilities

- Noncompliant Container Storage Configuration 


\section{- Incompatible Storage Containers}

Regulatory requirements for storage must address the storage of $\sim 16,000$ gal of raw pond sludge in holding tanks at the STF. The STF is permitted as a treatment facility but not as a storage facility. A permitting strategy to submit a revised Part $A$ with a request to modify interim status to the TDEC would correct the regulatory deficiency but does not address the long-term management of the waste. The combined process of removing the sludge from the holding tanks and processing with the 32,000 drums of raw sludge combines the waste with other raw sludge and simplifies the regulatory requirements.

Secondary waste containment is required by TN Rule 1200-1-11-.06(9)(f) for the storage of liquid wastes. This requirement dictates that the raw sludge must be processed so that it may be classified in one of the following categories: (1) liquid waste stored in facilities with double containment or (2) dry waste. The definition of "dry" for the purpose of determining whether double containment is necessary was the topic of several conversations with regulators. ${ }^{58}$ The result of these conferences was that waste is considered to have free liquid present if it does not pass the paint filter test, in accordance with Title 40, Parts 264 and 265, of the CFR. A waste that passes the paint filter test may be stored without double containment; however, if freestanding liquid is observed at some future date, double containment would be required.

The storage configuration for RCRA waste must provide sufficient aisle space for the unobstructed movement of personnel, emergency response, or drum retrieval equipment in accordance with TN Rule 1200-1-11-.06(3)(f). In addition, the stacking array must allow for inspection of the drums in accordance with TN Rule 1200-1-11-06(9)(e).

Requirements of TN Rule 1200-1-11-06(9)(c) state that waste storage containers must be compatible with the stored waste materials. Therefore, the raw sludge must be treated so that it is not corrosive, and/or it must be placed in containers that will not corrode because of contact with the processed raw waste. 
Additional insight regarding the relative importance placed on environmentally responsible management of waste vs meeting the requirements of LDR was provided by the EPA in a policy statement, ${ }^{66}$ as follows:

EPA is announcing its policy on the civil enforcement of the storage prohibition in section 3004(j) of the RCRA at facilities which generate "mixed wastes" regulated under both the RCRA subtitle $C$ hazardous waste program and the Atomic Energy Act (AEA). The policy affects certain mixed wastes that are prohibited from land disposal under the RCRA LDR and for which there are no available options for treatment or disposal.

Generators and storers of these wastes may find it impossible to comply with the section 3004(j) storage prohibition if there are no available options for treatment or disposal of the wastes. Nevertheless, generators of these mixed waste may, if they pursue prudent waste management practices, be capable of storing their mixed wastes for the limited duration of this policy in a manner that poses minimal risk to public health or the environment. ${ }^{66}$

The policy does not apply directly to the $\mathrm{K}-25$ pond waste because it is applicable only to generators that produce less than $1000 \mathrm{ft}^{3}$ of land-disposal-prohibited mixed waste per year. Further, the policy is in effect until December 31, 1993, at which time EPA may decide to renew it. Schedules for process technology options result in providing "prudent waste management practices" for the raw pond sludge by February 1993 at the earliest. However, the rulemaking does suggest that EPA consider environmentally responsible storage of land-disposal-prohibited waste to be a prudent waste management practice although such storage may be subject to civil penalties.

More specific guidance was provided by DOE, the state of Tennessee, and EPA Region IV in the Interim Action Record of Decision for the K-1417-A and K-1417-B Drum Storage Yards Oak Ridge $K-25$ Site after the results of the alternatives assessment were completed:

The purpose of this interim action is to prevent or mitigate the imminent threat of release of contaminants to the surrounding environment and to minimize the threat to human health. An additional goal of this interim action is to assure that the sludges are managed in compliance with the requirements of the RCRA .... Subsequent actions are planned to address the final disposition of the sludges as well as any remaining problems posed by the conditions ... ${ }^{12}$ 


\section{Disposal Regulations}

Regulations for mixed waste disposal can be grouped into requirements for hazardous waste (as governed by RCRA) and radioactive waste (as governed by DOE). Each set of requirements is evaluated to select system requirements. A logic diagram for evaluating mixed waste regulatory requirements for disposal is shown in Fig. 2 (Ref 67). The first two steps, as shown in the diagram, are to compare the waste stream characteristics to treatment standards and to evaluate various treatment scenarios with regard to their effectiveness in meeting treatment standards. Guidance on waste form performance and methods for process control is provided by the NRC. The NRC also provides functional and operating requirements for solidified waste forms. In the case of the K-25 untreated pond sludge, requirements for radioactive waste disposal have not been established. The last step in evaluating regulatory requirements is an analysis of disposal or storage options. The evaluation of both treatment standards and disposal options should be completed before system requirements are established for selecting processing options.

Untreated K-25 pond waste must be treated to meet both RCRA and radioactive waste requirements prior to disposal. No disposal site has been identified for mixed waste generated on the ORR. Potential off-site mixed waste disposal sites are (1) Envirocare of Utah-a commercial mixed waste disposal facility, and (2) Nevada Test Site-a DOE-operated disposal facility for defense waste. A change in DOE policy would be required before either of these facilities could be used for K-25 mixed waste. On-site disposal of mixed waste is not being considered in the long term for the waste management strategy for Oak Ridge.

The lack of disposal options provides an incentive to separate untreated waste into hazardous and radioactive fractions and dispose of the former; however, no limit for de minimis concentrations of radioactive material has been established. A method for reclassifying the material as "nonradioactive," once it has been classified as "radioactive," has not been established. Perpetual, compliant storage of the treated material as mixed waste would bring the waste stream into compliance with RCRA storage requirements and LDR time limits for storage. Perpetual storage as radioactive waste is another likely end point because there are currently no approved disposal sites. Disposal of radioactive waste off-site at a commercial location would require a change in DOE policy. 


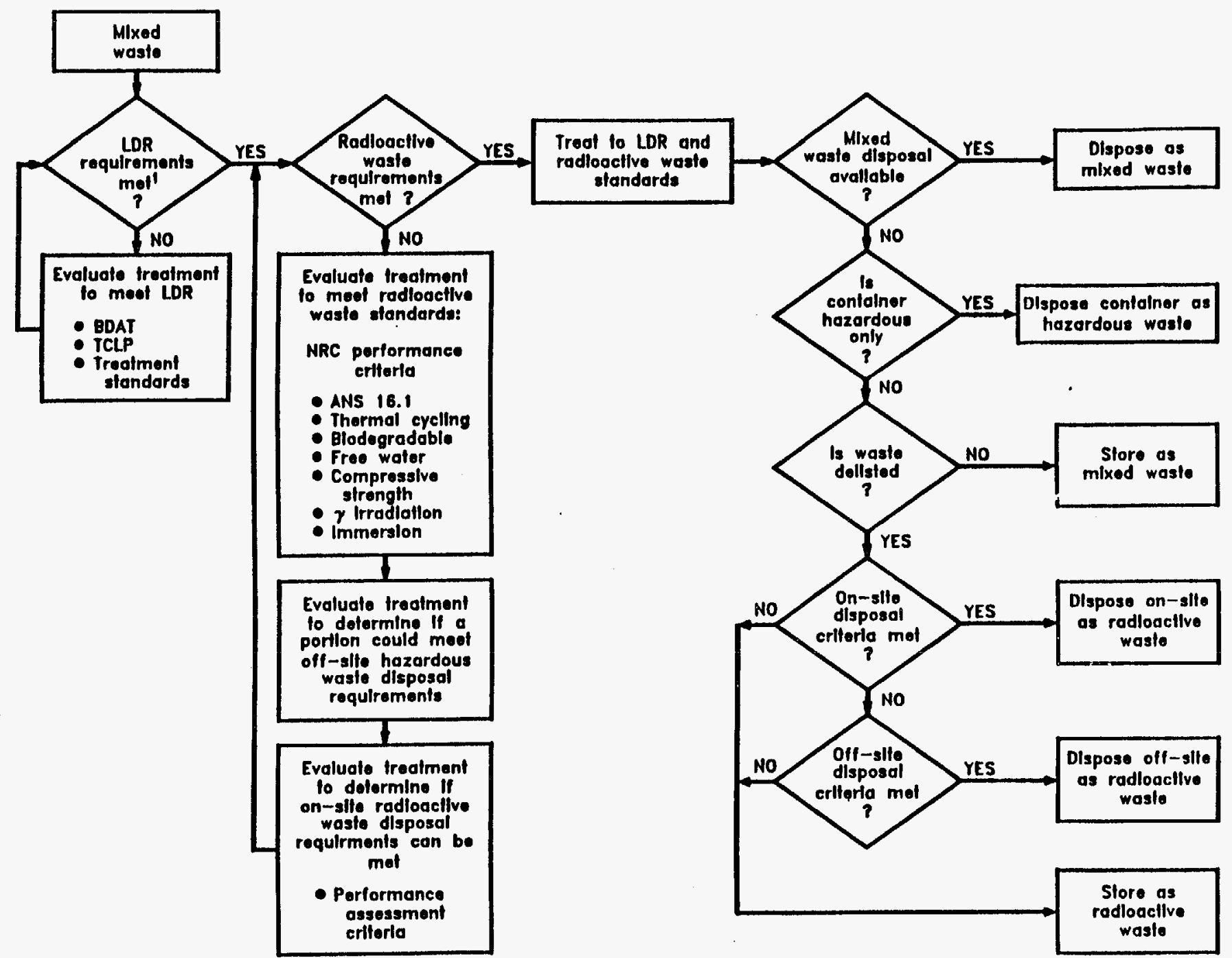

'Moy 8. 1992, Is deadlline for disposing of land ban wasto without May o 1992 . Is deadline tor disposing of land ban
Irealment to Land Dlsposal Restriletions (LDR) stondards.

Fig 2. Logic for evaluating mixed waste disposal regulatory requirements. 
Fortunately, plans for disposal of radioactive waste on the ORR are progressing. Preliminary concentration limits have been established for on-site low-level radioactive waste disposal (see Appendix A).

\section{Summary of Land Disposal Restrictions}

The disposal of hazardous waste on land and deadlines for the storage of untreated waste are governed by LDR. Treatment standards and limitations on the length of storage of untreated waste are established. Regulators (i.e., the state of Tennessee and EPA Region IV) can negotiate a waste-stream-specific action plan for bringing the waste stream into compliance with RCRA regulations, which may include a deadline for the treatment of untreated waste. ${ }^{68}$ An additional vehicle for negotiations is the FFCA for noncompliant LDR radioactive mixed waste. ${ }^{5,69}$ The untreated waste could be classified as "California list" (i.e., terminology that refers to a group of hazardous wastes that were banned from land disposal by the state of California), in which case a more stringent deadline for storage of untreated waste may be applied.

An analysis of the regulatory background establishes the framework for evaluating regulations applicable to the problem. A brief history of pertinent regulations can be summarized as follows: $:^{47,67}$

1. In 1976, Congress passed the original hazardous waste legislation known as RCRA. Regulatory requirements were imposed on facilities that practiced land-disposed-of hazardous wastes (see 40 CFR, Parts 264 and 265).

2. In 1984, Congress required EPA to address the land management of waste by issuing four major sets of regulations. Disposal of hazardous waste on the land without treatment could no longer be permitted (1984 Hazardous and Solid Waste Amendments to RCRA). The two sets of regulations that apply to the K-25 pond waste are described below.

(a) Regulations deal with "California list" wastes. The species on this list that are of primary concern to the management of $\mathrm{K}-25$ pond waste are cyanides, heavy metals, and highly toxic compounds known as polychlorinated biphenyls (PCBs). On July 8, 1987, EPA promulgated regulations for certain California list wastes. Radioactive 
waste mixed with California list waste is prohibited from land disposal pursuant to these regulations. All extensions pertaining to the effective dates for implementation of California list treatment standards have expired; therefore, waste subject to California list standards must be treated to meet these standards prior to land disposal.

(b) Regulations deal with all wastes listed in 40 CFR 261, including F006 listed wastes. "Because this involved hundreds of wastes, EPA was allowed to divide the wastes into ... categories. Restrictions applicable to radioactive mixed waste were to be issued by ... May $8,1990 .{ }^{n 47}$

3. On August 11, 1987, the state of Tennessee received authorization from EPA to regulate radioactive mixed waste.

4. On May 8, 1990, EPA promulgated regulations as required; however, radioactive mixed waste was granted a 2-year capacity extension. Therefore, effective May 8, 1992, hazardous wastes that are radioactive mixed wastes are prohibited from land disposal.

5. EPA and TDEC determined ${ }^{12,58}$ that the storage of wastes prohibited from land disposal constitutes a violation of applicable hazardous waste laws and regulations, including RCRA regulations found in 40 CFR Part 268.50 and Tennessee Rule 1200-1-11-.10(4). The ORR is currently storing prohibited waste (e.g., 32,000 drums of mixed waste sludge), and such storage could be construed to be for purposes other than accumulating quantities necessary to facilitate proper recovery, treatment, or disposal of such wastes. On August 9, 1989, DOE-Headquarters proposed instituting compliance agreements with EPA to address the mixed waste issue. These agreements are entitled Federal Facility Compliance Agreements (FFCA).

6. Under LDR, a 1-year limit for storage prior to treatment is imposed unless the waste is being stored for the purpose of accumulating quantities necessary to facilitate proper recovery, treatment, or disposal of such wastes. Variances to this 1-year limit can be negotiated under an FFCA, a National Capacity Variance, or a waste-stream-specific action plan. 
7. EPA may grant case-by-case extensions to application of LDR regulations of up to 2 years. ${ }^{5}$ These extensions allow continued generation and storage of LDR waste- not unrestricted disposal.

8. RCRA closure of the Oak Ridge K-25 Site's B and C settling ponds resulted in the generation of sludge that met the LDR definition of an F006 listed waste and potentially met the LDR definition of a California list waste because of the presence of free liquid contaminated with nickel.

\section{Evaluation of LDR Deadline for Storage of Untreated Waste}

The ponds were excavated during 1987-1988, resulting in the storage of K-25 pond waste after the effective date for regulations governing California list waste (July 8, 1987). Additionally, remediation schedules for all process options include "actively handling" the waste after May 8 , 1992. If "waste generated prior to the effective date of the land disposal restrictions is removed from a storage or disposal unit, it becomes subject to the land disposal restrictions at that time." ${ }^{47}$ Extensive discussions with regulators and staff regulatory specialists resulted in verification that the conditions cited above apply to the K-25 raw sludge. Under LDR, a 1-year limit for storage prior to treatment is imposed unless the waste is being stored for the purpose of accumulating quantities necessary to facilitate proper recovery, treatment, or disposal of such wastes. Variances to this 1-year limit can be negotiated under the FFCA, the National Capacity Variance, or a wastestream-specific action plan.

1. If the raw waste solids pass the Toxicity Characteristic Leaching Procedure (TCLP) criteria, the products will meet LDR treatability standards. LDR requirements would be met, and the logic of Fig. 2 could be pursued without further consideration of LDR requirements.

2. If the raw waste solids fail the criteria, they must be treated prior to disposal to meet LDR standards. The treated waste would then be subject to TCLP, and the product would be stored as mixed waste, pending action on the delisting petition.

3. The deadline for storage of untreated waste is negotiated. The waste classification plays a role in establishing effective dates of applicable regulations as described above. 
4. Both the state of Tennessee and EPA provided guidance regarding the actions to be taken on the 32,000 drums of mixed waste; the deadline for final treatment could be negotiated separately from deadlines and issues with regard to bringing the waste into compliance with the storage issues. ${ }^{12,68}$ A project plan is negotiated with the state of Tennessee and EPA Region IV to establish compliance issues that are the primary concern of the regulators for the pond waste. ${ }^{62}$

5. Effective dates for both California list waste and third-third waste (e.g., radioactive mixed waste) will pass before the selected process option can be implemented. If analytical data show that the raw waste does not pass the TCLP, the waste stream will be out of compliance with LDR unless LDR treatment standards are met by the selected treatment option.

6. The FFCA can be used as the vehicle for negotiating the deadline for final treatment.

\section{Determination of Applicability of "California List" to Pond Waste}

The determination of the applicability of the California list to the pond waste can influence negotiations with regard to the deadline for storage and processing options because differing regulations are applied. However, because the schedule for remediation using any option results in "actively handling the waste" after May 8, 1992, the waste stream will be out of compliance with LDR unless LDR treatment standards are met by the selected option. This situation means that the California list determination will not affect the regulatory status of the waste stream. The steps for determining the applicability of the California list to the ponds' waste and regulatory implications follow:

1. If free liquid is present in the waste, only the liquid should be analyzed for the presence of California list constituents.

2. If sampling indicates that free liquid contains $>134 \mathrm{mg} / \mathrm{L}$, the waste would be classified as a California-list mixed waste. Management of such a waste would then be negotiated under the FFCA. 
3. If sampling indicates that the free liquid contains nickel at a concentration $<134 \mathrm{mg} / \mathrm{L}$, the California list does not apply.

4. If free liquid contains nickel at $<134 \mathrm{mg} / \mathrm{L}$, the waste would be classified as F006 listed nonwaste water. The deadline for storage of raw waste would then be negotiated under the National Capacity Variance or the FFCA.

\section{Radioactive Waste Disposal Requirements}

Regulatory aspects of radioactive waste management are governed by DOE orders. Guidance on waste form performance and methods for process control is provided by NRC. NRC also provides functional and operating requirements for solidified waste forms. No deadlines for the storage of untreated waste are imposed by radioactive waste requirements.

Pathways analyses are used to establish concentration limits for radionuclides in various disposal scenarios as required by DOE Order 5820.2A. These analyses have not been completed for ORR wastes or disposal configurations. Preliminary limits for on-site disposal of radioactive materials are described in Appendix A. Concentration limits for radionuclides, referred to as "de minimis" quantities of radionuclides, are also being established for hazardous waste disposal. Off-site disposal of hazardous waste cannot be implemented until de minimis standards are established.

\section{Regulations Regarding Used Containers}

Regulations governing the treatment and disposal of used containers were evaluated. Waste acceptance criteria for decontaminated used drums fall into four categories: (1) RCRA, (2) radioactively contaminated material, (3) clean material, and (4) Department of Transportation (DOT). These categories can be described as follows:

1. RCRA (mandatory). The used container must meet criteria for "residues of hazardous waste in empty containers," as defined by RCRA Subsection 261.7 (b)(1) (i.e., $<2.54 \mathrm{~cm}$ of residue), and must be considered best management practices. 
2. Low-level radioactive waste. If used containers cannot be decontaminated, options may be limited, in the best case, to reuse in the collection of low-level radioactive waste for disposal or, in the worst case, to disposal per se as radioactive waste.

3. Clean scrap metal. Methods may be employed to clean used containers to meet the plant standard for clean material. ${ }^{70}$ This standard defines clean equipment or material as follows: "Equipment or material which has a surface contamination level of less than $5,000 \mathrm{~d} / \mathrm{min} / 100$ $\mathrm{cm}^{2}$ surface alpha; $1,000 \mathrm{~d} / \mathrm{min} / 100 \mathrm{~cm}^{2}$ transferable alpha and a beta-gamma surface reading less than $0.1 \mathrm{mr} / \mathrm{hr} . "$

4. Department of Transportation(DOT). Used containers may be shipped off-site for treatment. Appropriate DOT shipping requirements, including the use of strong-tight containers for shipment, will be met if this option is chosen.

\section{Permit Requirements}

Requirements for permitting must be evaluated to establish system requirements. The state of Tennessee is responsible for review of permits for secondary waste stream emissions (i.e., water and air). Secondary waste water generated during processing can be discharged to the K-25 Site Central Neutralization Facility (CNF) if the waste characterization complies with the waste acceptance criteria for the facility. All process options are classified as "waste water treatment units" and qualify for operating authority under the RCRA permit-by-rule application for the K-25 Site. ${ }^{71}$ Each process option must be evaluated for potential air emissions, and appropriate air permits must be obtained.

In addition to state permits, DOE orders require that NEPA documentation be obtained for new projects. DOE further published rulemaking stating that mobile processes qualify for a "categorical exclusion" from the National Environmental Policy Act (NEPA) documentation. ${ }^{72}$ Documentation regarding the safety of the operation must be submitted to DOE for review and determination of the applicability of the categorical exclusion criterion. ${ }^{73}$

Vendors who conduct off-site treatability studies must possess appropriate licenses. Data on the concentration of radionuclides and the hazardous nature of the waste must be collected, analyzed, 
and reported in order to determine whether the licenses of the proposed vendors are adequate. Further, these data are used to establish shipping requirements for the treatability study samples. ${ }^{74}$

\subsubsection{Sampling and Characterization}

The above analysis of regulations established data requirements for the sampling plan. Data were required to support regulatory decisions, permit applications, treatability studies (including shipment and facility license analysis), and the selection of a process option.

In July 1991, statistically based random samples were collected from drums ${ }^{75}$ containing raw sludge to support selection of a treatment option and meet data needs. The samples were chemically analyzed to characterize raw sludge from the $B$ and $C$ Ponds.

Raw sludge drum sampling consisted of 5 gal of waste being withdrawn from 22 of the $C$ Pond drums and 5 gal from 16 of the B Pond drums. The liquid and solid phases of the sampled sludge were withdrawn in the same proportions as found in the drum. Random sampling was conducted, based on a selection plan that called for randomly selecting drums from a list of every 100th top outside drum. Most of the drums are stored in rows, stacked two high and four across. The starting drum was randomly selected from the first 100 top outside drums, in the first randomly selected row of drums. Since the storage configuration of the drums is believed to be related in some degree to the order of pond excavation, it was important to randomly select from drums that geographically covered the storage yard.

The selection plan (1) picked only drums of raw sludge stored on the asphalt pad (none of the drums that are stored in vaults were selected), (2) selected only from drums that were stacked on the top outside of the rows of drums (no sludge was sampled from the inaccessible drums), (3) did not require a current listing of the drum identification numbers, (4) allowed for the possibility that a few of the drum aisles could not be safely entered, and (5) was resilient to errors in counting to 100 (one reason for flagging the "hundredth" drum). The sampling plan (1) did not permit the use of drums solely from the perimeter of the storage yard; (2) did not allow extensive nonrandom drum skipping or drum substitution for reasons such as type of container lid, size of 
drum, difficulty in sludge sampling; and (3) could not be used if too many of the aisles were impassable. $^{76}$

There is $\sim 90 \%$ confidence that no more than $10 \%$ of the $\mathrm{C}$ Pond drums in the K-1417 storage yard would contain concentrations of chemicals that would exceed the largest of the $22 \mathrm{C}$ Pond analytical results. ${ }^{76}$ With 16 drums sampled, there is $~ 90 \%$ confidence that no more than $13.5 \%$ of the B Pond drums in the storage yard would contain concentrations of chemicals that would exceed the largest of the $16 \mathrm{~B}$ Pond analytical results. In terms of population means, with 22 drums sampled, the $95 \%$ confidence interval on the true population mean is given by average \pm 0.418. . With 16 samples, a $95 \%$ confidence interval on the true population mean is given by average $\pm 0.490 \cdot \sigma$. This is a $17 \%$ increase in width of the confidence interval. ${ }^{76}$ Data are presented in Appendix C. ${ }^{77}$ Summary parameters relevant to establishing regulatory compliance and system requirements are shown in Table 7.

\subsection{ESTABLISHMENT OF SYSTEM REQUIREMENTS}

The current method requires establishment of clear system requirements based on sound engineering judgment. Desirable outcomes are distinguished from necessary attributes. The method incorporated the attributes necessary for project success into a set of system requirements.

System requirements were established as a set of top-level constraints that are used to select the course of action for the remediation project. System requirements are limited to objectives influencing the selection of a course of action that will meet the cleanup goal and ensure a viable selection. Requirements are generated from a combination of technical and regulatory bases. Programmatic criteria establish the system requirements as follows:

1. Regulatory requirements were established, based on an analysis of the regulations and negotiations with regulatory authorities. The key system requirement is to bring the waste into compliance with RCRA storage requirements.

2. Based on an analysis of NEPA documentation requirements, the process must be constructed for temporary use and must be mobile. 
Table 7. Summary of sample data that have regulatory implications

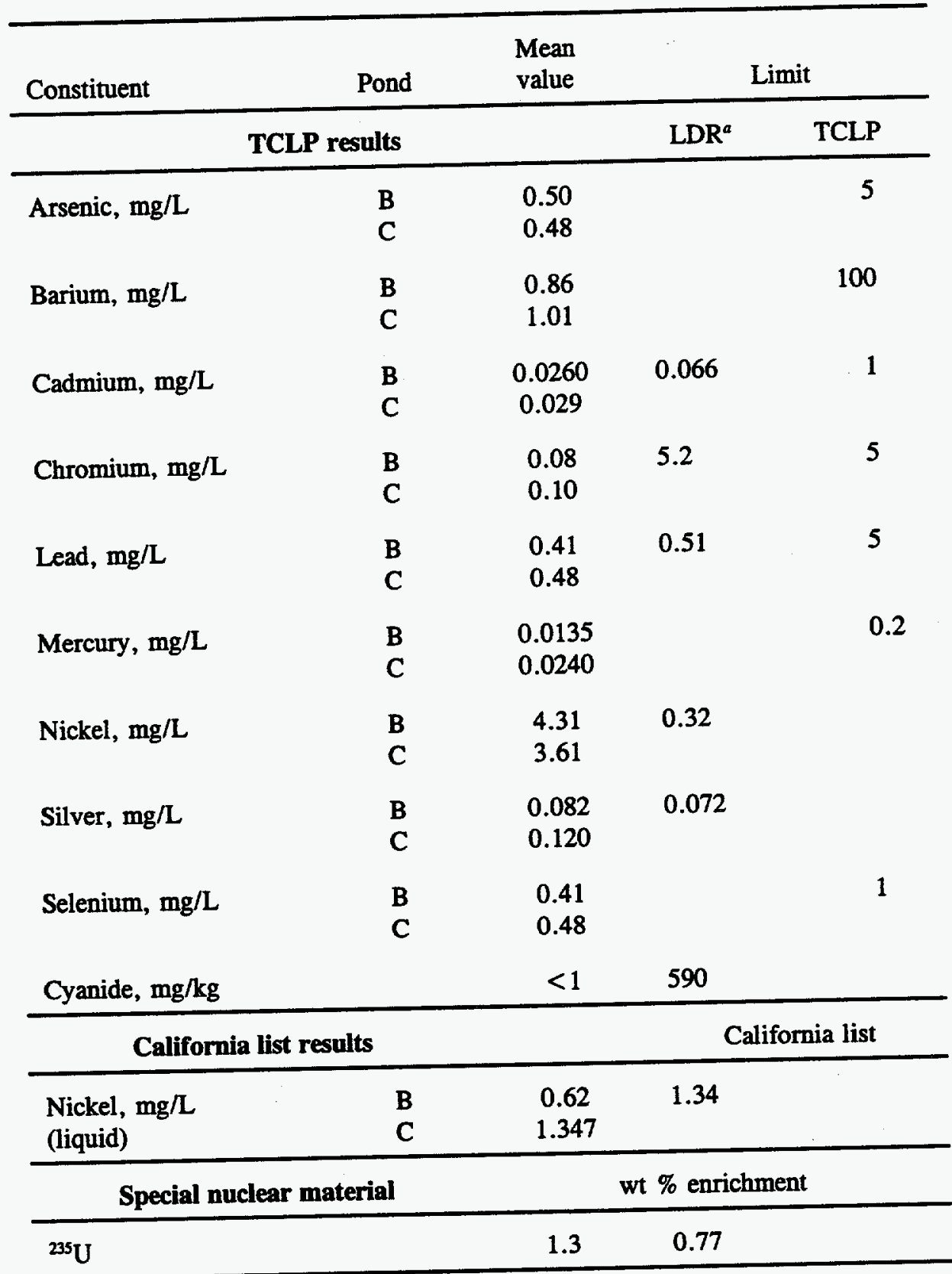

Treatability standard for F006 nonwaste waters. 
3. Based on an analysis of implementation strategies available to DOE sites, the process must be subcontracted. Near-term compliance milestones (February 1993) preclude design and implementation of a capital project, governed by DOE procurement schedules and orders. Therefore, the selected alternative must be available industrially. Subcontractors must be willing to implement the process at the K-25 Site and to meet the functional and operating requirements of the selected process option.

4. During the treatment process, the insult to human health and the environment must be minimized in accordance with the as low as reasonably achievable (ALARA) principle in all phases of processing.

5. General system requirements are formalized in the project System Requirements Document. ${ }^{78}$ This document references the documents that must be prepared to support process implementation.

\subsection{SELECTION OF ALTERNATIVE}

\subsubsection{Process Options}

The current method employs a rigorous assessment of process options, which were identified through a literature search, definition of the RCRA best demonstrated technology, analysis of regulations, and discussions with potential vendors ${ }^{79}$ and knowledgeable staff. In addition, DOE organized a conference with participants throughout the DOE complex and industry with regard to sludge processing. This conference was arranged, based on the recognized need to reprocess the pond sludge. ${ }^{17}$ Ordinarily, such a conference would not be held to establish the background and process alternatives for a specific remediation problem. The technical knowledge exchange that occurred during the workshop strengthens the basis for subsequent action taken by this project. 
The following process options were identified:

1. no action,

2. separation of radioactive and hazardous constituents,

3. dewatering,

4. drying, and

5. solidification/stabilization.

Each option was screened against the system requirements (see Sect. 4.3). The first two options were eliminated from further consideration because system requirements would not be met, as described below. Options that met system requirements were developed by preparing simplified flowsheets, rough order-of-magnitude mass balances, and cost estimates. Functional and operating requirements were specified for those process options that met system requirements.

Prior to the assessment of the two waste treatment alternatives (i.e., separation of radioactive and hazardous constituents and solidification/stabilization), vendors were contacted through a formal procurement procedure - an Expression of Interest. Proposed treatment processes that would meet treatment and waste form criteria were solicited. By this method, a wide range of processes was evaluated. ${ }^{80}$

\section{No Action}

The no-action alternative would involve "leaving the drummed sludges on the site as they were situated in 1991. Continued surveillance of the site would be required to inspect for leaking, leaning, or fallen drums. Containers in seriously deteriorated condition would be repackaged into new containers. The continued storage of raw sludges in the drum storage yards, in the noncompliant configuration, would constitute a continuing RCRA violation. Eventually the drums would deteriorate to the point that they all would have to be replaced. At a future date, all the sludges would have to be treated and permanently disposed." 12

The no-action alternative does not meet the key system requirement to bring the waste into compliance with RCRA storage requirements; however, costs were estimated to serve as a baseline for comparison of other alternatives (see Table 8). ${ }^{81}$ 
Table 8. Rough order-of-magnitude cost estimates and implementation times for the Pond Waste Management Project

\begin{tabular}{llccc}
\hline \multicolumn{1}{c}{ Element } & No action & Stabilization & Dewatering & Drying \\
\hline $\begin{array}{l}\text { Total project } \\
\text { capital cost, } \\
\$ 10^{6}\end{array}$ & 0.1 & 80 & 69 & 63 \\
$\begin{array}{l}\text { Operating cost, } \\
\$ 10^{3} / \text { year }\end{array}$ & 500 & 400 & 400 & 400 \\
$\begin{array}{l}\text { Implementation } \\
\text { time, months }\end{array}$ & Ongoing & 26 & & \\
\hline
\end{tabular}

\section{Separation of Hazardous and Radioactive Species}

The use of processes to separate hazardous and radioactive species was considered as an option. The waste form resulting from the proposed treatment would be required to meet the waste form requirements for a stabilized waste (see the functional and operating requirements for solidification/stabilization). Potential treatment scenarios were considered by assuming concentration limits for radionuclides acceptable for on-site disposal and acceptable for classification as "below regulatory concern." The tabulated concentrations are based on proposed limits and were used only for the purpose of evaluating alternative processes.

Scenario 1: Treatment of waste to allow a portion of the waste to be handled as nonradioactive, hazardous waste. Treated wastes may be considered to be hazardous only (nonradioactive) if the concentrations of the radionuclides meet the limits shown in Table 9.

Scenario 2: Treatment of the radioactive fraction of the waste so that the bulk of the material will meet proposed on-site disposal concentrations as specified in Appendix A. The pond waste cannot qualify as Class II waste because it contains radionuclides (e.g., uranium) with half-lives greater than 30 years. Therefore, the goal of treatment is to qualify a fraction of the waste for designation as Class I. 
Table 9. Limits for selected radionuclides in solids to be considered for disposal as hazardous waste ${ }^{a}$

\begin{tabular}{ll}
\hline Radionuclide & Limit \\
\hline Gross alpha & $\leq 2.0 \mathrm{pCi} / \mathrm{g}$ \\
Gross beta & $\leq 4.0 \mathrm{pCi} / \mathrm{g}$ \\
${ }^{99} \mathrm{Tc}$ & $\leq 8.0 \mathrm{pCi} / \mathrm{g}$ \\
${ }^{237} \mathrm{~Np}$ & $\leq 0.5 \mathrm{pCi} / \mathrm{g}$ \\
${ }^{238} \mathrm{Pu}$ & $\leq 0.5 \mathrm{pCi} / \mathrm{g}$ \\
${ }^{239.240} \mathrm{Pu}$ & $\leq 0.5 \mathrm{pCi} / \mathrm{g}$ \\
${ }^{228} \mathrm{Th}$ & $\leq 0.5 \mathrm{pCi} / \mathrm{g}$ \\
${ }^{230} \mathrm{Th}$ & $\leq 0.5 \mathrm{pCi} / \mathrm{g}$ \\
${ }^{234} \mathrm{Th}$ & $\leq 7.0 \mathrm{pCi} / \mathrm{g}$ \\
${ }^{137} \mathrm{Cs}$ & $\leq 16.0$ \\
${ }^{234 m} \mathrm{~Pa}$ & $\mathrm{pCi} / \mathrm{g}$ \\
$\mathrm{U}$ & $\leq 55.0$ \\
\hline
\end{tabular}

Detection limits are quoted on the basis of analyses of soil samples by the K-25 Quality and Technical Services Division.

Implementation of the waste separation process options would result in a fraction of the material being classified for disposal off-site as hazardous waste. The remainder would be stored as mixed waste.

Prime contractor personnel prepared an EOI in which industrial firms interested in providing a treatment service contract were asked to evaluate the technical feasibility of the waste segregation process option. It should be recalled that one system requirement is that the selected process must be industrially available; therefore, this method for determining technical feasibility is entirely appropriate. If an industrial firm had identified a waste separation process option, the feasibility of the proposed waste segregation process would have been evaluated and confirmed independently; however, no firm identified a process for separating the hazardous and radioactive 
species. Industrial firms were apparently unwilling to accept the technical risk inherent in the waste separation process. Thus, this process option was eliminated from further consideration because it did not meet one of the system requirements.

\subsubsection{Assessment of Alternatives That Met System Requirements}

Process flowsheets were developed and performance factors were determined for those processes that met system requirements as determined by employing the current method: (1) dewatering, (2) drying, and (3) solidification/stabilization. The treatment of raw waste could be conducted to achieve two different objectives: (1) to reduce the volume of waste requiring storage and (2) to ensure that LDR treatability standards are met. Treatment alternatives were analyzed with regard to these criteria, as well as other criteria such as the cost and risk of each (see Sect. 4.4.8 for a quantitative assessment of each process technology option with regard to performance criteria).

As described below, the mass of waste to be treated and the material handling aspects of each process are similar. Primary differential cost drivers are the equipment, solidification agents, operation, and volume of treated waste requiring storage. Major assumptions include the operating schedule, the mass of the raw waste to be treated, the bulk density and solids content of the treated waste, and the assumed solids content of the packaged material. Capital costs to install each treatment system and to construct the required storage facilities were estimated, along with container and storage facility costs, to establish the basis for an assessment of process technology options. Energy Systems will subcontract an industrial firm to treat the waste; however, the actual subcontract price has not been negotiated. Charges incurred because of processing will be determined through the negotiation of technically detailed contracts. The rough order-ofmagnitude cost for the entire project, including the cost of supporting organizations (e.g., project management, treatability studies, environmental compliance, health and safety, and industrial hygiene), was estimated for each treatment option (see Table 8). ${ }^{1262,81,82}$ 


\subsubsection{Bench-Scale Studies}

Implementation of the methodology requires an assessment of the waste with respect to proposed treatment processes. Bench-scale studies were conducted ${ }^{83}$ using composite samples, and the results of these studies provided data necessary to improve assumptions regarding waste processing performance, to support the specification of procurement requirements for the process, and to evaluate potential treatment subcontractors. Experimental assessment of the drying and dewatering alternative treatment processes is discussed in the paragraphs that follow.

Individual samples from each of the drums were combined to form a composite sample for both $\mathrm{B}$ and $\mathrm{C}$ Ponds ( $\sim 5 \mathrm{gal}$ of each composite). The composite was obtained in the following manner: (1) individual samples were placed in a plastic bucket and (2) the resulting material was blended with a mixing paddle connected to an electric drill motor. The material, which is thixotropic in nature, was blended as shear was applied. The composite contained small quantities of gravel.

The C Pond composite was described as having a brownish color and the consistency of mud. The B Pond composite was black in color and had the consistency of soupy water. After the composites were allowed to sit overnight, the $C$ Pond composite had about 1 in. of water on top; the B Pond composite had not changed in appearance.

The data reported below were collected using subsamples of the composite after mixing. The bulk density of the composite sample was determined. One $100-\mathrm{mL}$ sample of each composite was placed in a graduated cylinder and weighed. The resulting bulk densities were determined to be 1.51 and $1.24 \mathrm{~g} / \mathrm{mL}$ for the $\mathrm{C}$ and $\mathrm{B}$ Ponds, respectively. The free water content of the composite sample was important to estimate the volume of secondary waste water that could be generated during processing. Four replicate samples of each composite were dried overnight in an oven at $\sim 100^{\circ} \mathrm{C}$. Liquid content values were: B Pond, 58.7, 70.6, 70.3, and $69.7 \mathrm{wt} \%$; C Pond, 48.4, 48.6 48.5, and 48.8 wt \%. The resulting average values of water content were $70.2 \mathrm{wt} \%$ for the B Pond and $48.6 \mathrm{wt} \%$ for the C Pond. Note that the average for B Pond does not include the first data point $(58.7 \%)$ as the sample was observed to contain gravel..$^{65,82}$ 
The sludge dewatering potential was estimated by using laboratory-scale equipment and the following three methodologies: (1) oven drying, (2) vacuum filtration, and (3) centrifugation. In each case, water content and density data were obtained from analyses of the resulting dewatered material. The collected data were then used to estimate the waste volume reduction potential resulting from these three methods, a critical parameter in assessing performance of each process alternative.

The data established that the dewatered or dried waste will not meet LDR treatability standards for F006 nonwaste waters (see Table 7). p 54 A comparison of liquid characterization data was made with CNF waste acceptance criteria. This comparison provides the data necessary to determine whether pretreatment is required (and, if so, what type) prior to acceptance of this material at the CNF.

The water release potential of dewatered sludge was also determined. It is recognized that complete drying of the sludge samples will eliminate the potential for long-term water release during storage and that dewatering by use of either a filter or a centrifuge will leave residual water in the final products. An evaluation of the water release potential of these materials was performed. Specifically, sludge samples were dewatered to varying degrees (ranging from the raw sludge, as received, to zero water content), and the resulting dewatered material was subjected to the following three tests: (1) EPA paint filter liquids test (SW-846 Method 9095); (2) EPA liquid release test (LRT) (SW-846 Method 9096); and (3) a modified ASTM B553 thermal cycle test. The paint filter test is an EPA-approved method used to determine that no free liquids are present in waste destined for a RCRA landfill. The LRT, presently under development, is expected to eventually be used in conjunction with, or as a replacement for, the paint filter test. The LRT, which evaluates liquid release potential under an overburden pressure of $50 \mathrm{psi}$, coupled with a modified ASTM B553 test (which evaluates liquid release potential under potential temperature variations during storage), appears to reasonably approximate the potential environmentally induced liquid release mechanisms during actual storage of the waste. This evaluation provides the data necessary to evaluate the potential for liquid release during storage. ${ }^{83}$ Results of these tests are presented in Table 10. 
Table 10. Summary of bench-scale ${ }^{a}$ testing data

\begin{tabular}{lcc}
\hline Type of test & B Pond & C Pond \\
\hline & Physical Data & \\
Density, g/mL & 1.24 & 1.51 \\
Solids, wt \% & 29.8 & 51.4 \\
& Process Data & \\
Centrifuge, wt \% & 51 & 64 \\
Vacuum filtration, wt \% & 57.8 & - \\
Filter press, wt \% & No data & $65-70$ \\
Paint filter test, wt \% & $>43$ & 51.4 \\
\hline
\end{tabular}

"Bench-scale tests were conducted with composite sample.

In addition to the bench-scale testing conducted by Energy Systems staff, potential subcontractors conducted experiments using a representative sample of the mixed waste sludge. Data were collected to support the detailed design of the proposed treatment process.

Prior to bench-scale tests being conducted at a vendor's facility, that vendor was required to provide written documentation of NRC and state licenses to handle the specific types and quantities of radionuclides likely to be present in the mixed waste sludge, namely, enriched uranium. In addition, all expenses related to bench-scale testing would be incurred by the vendor.

\subsubsection{Processing Assumptions}

Average densities and solids contents for both K-1407-B Pond and K-1407-C Pond sludge were estimated, based on process knowledge (and confirmed by experimental results ${ }^{65}$ ), and were assumed to be as follows: ${ }^{64}$

B Pond

\begin{tabular}{lcc}
\hline Density, $\mathrm{g} / \mathrm{cm}^{3}$ & 1.30 & 1.40 \\
Solids content, wt \% & 30 & 45 \\
\hline
\end{tabular}


The distribution of the 32,000 drums of raw waste was assumed to be $50 \% 89$-gal drums and $50 \%$ 96-gal drums, and each was assumed to be $90 \%$ full, resulting in a total of $2,600,000$ gal of waste. The operating schedule was assumed to be 7 days per week and $16 \mathrm{~h}$ per day, with each operating day including $1 \mathrm{~h}$ for startup and $1 \mathrm{~h}$ for shutdown (i.e., 14 actual operating hours per day). All subsequent calculations were based on these assumptions.

The handling of used drums and pallets is an important aspect of the process that is consistent between all process technology options. The empty drums were assumed to be cleaned to RCRA standards but not decontaminated to radiological standards because it is doubtful that decontamination could be accomplished and verified with old, rusty drums. They were then assumed to be compacted to a height of 3 in. and packaged in strong, tight containers (ST-5 boxes) at 64 crushed drums per box, resulting in the production of 500 ST-5 boxes of secondary waste."

It was assumed that the pallets would be low-level waste, not mixed waste, and that they could be incinerated. The amount of ash was calculated by assuming that the pallets were about $5 \mathrm{ft}$ $\times 5 \mathrm{ft} \times 6$ in. high and that incineration would result in a 100:1 volume reduction factor. It was assumed that this ash would be placed in ST-5 boxes and returned to the K-25 Site, resulting in the generation of 12 boxes of secondary waste.

\subsubsection{Dewatering}

\section{Process Description}

The basis for investigating the dewatering system was that 32,000 drums would be processed in 30 weeks. The availability factor was assumed to be $80 \%$, and the average processing rate was calculated to be 14 drums per hour, or $\sim 22 \mathrm{gal} / \mathrm{min}$. A flow diagram is shown in Fig. 3.

A filter press was considered to be the most likely dewatering device, based on literature ${ }^{84,85}$ that indicates it is capable of achieving the highest level of dryness of the various types of dewatering

"Subsequent analyses indicated that this estimate may be conservative. However, the number of ST-5 boxes is valid for the purpose of comparing alternatives. 


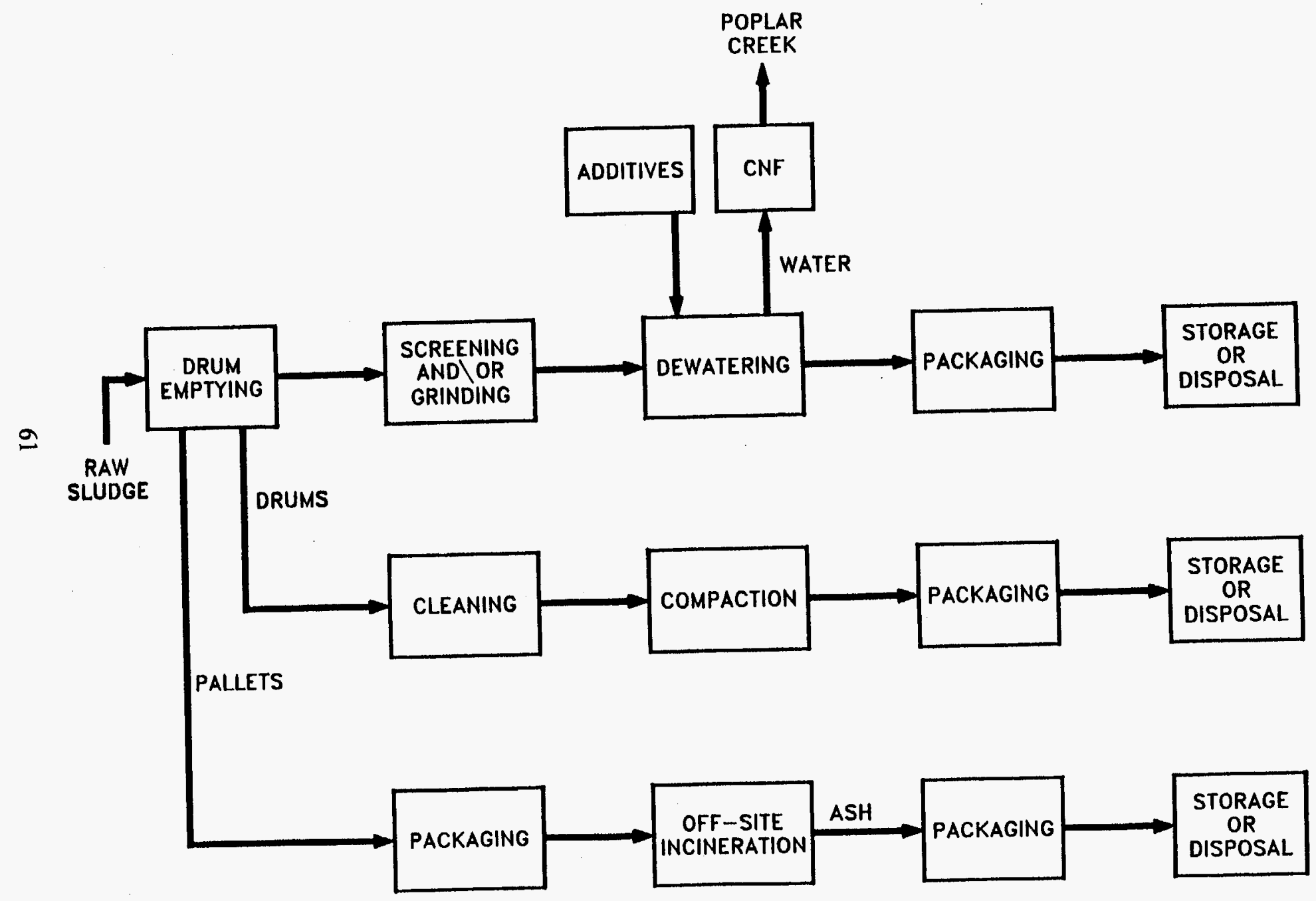

Fig. 3. Block flow diagram-dewatering. 
devices employed in the municipal waste water industry. The filter press was assumed to have a 2-h cycle time (from the start of filtration to discharge of the dewatered cake) to be able to dewater the raw waste to $50 \%$ solids.

In calculating the final volume of filter cake that would require packaging for storage, the bulk volume of the broken-up cake was assumed to be $25 \%$ less than the cake density calculated, based on the sludge solids content. It was assumed that the dewatered filter cake would be packaged in 120 -gal containers that would be filled to $90 \%$ capacity. ${ }^{86}$

The dewatered product is expected to have $\sim 30$ to $50 \mathrm{wt} \%$ liquid content; therefore, the storage containers must be corrosion resistant. Structural integrity must be sufficient to stack the containers in a three-high array to meet requirements for inspectability and for the designed storage configuration. Figure 4 shows the storage configuration in a three-bay storage building. Eight storage bays would be required to implement the dewatering process option.

The process will produce a more homogeneous waste form, place the waste in containers constructed of material that is compatible with the waste, reduce the amount of liquid requiring storage, and prepare used mild-steel drums and pallets for disposal. The dewatered waste will not meet LDR requirements (see Table 7).

\section{Functional and Operating Requirements}

The current method requires each process technology alternative to be assessed with regard to its ability to meet functional and operating requirements. The requirements are technical and specific.

The level of detail developed to evaluate alternatives was more comprehensive than other specifications, resulting in minimal changes during the procurement process. Operating requirements do not vary between the process alternatives and are described below for all options. Functional requirements have some variation between process options. ${ }^{80,82,87,88}$ The changes in functional requirements for the drying and solidification/stabilization process technology options are described in Sects. 4.4.6 and 4.4.7, respectively. 


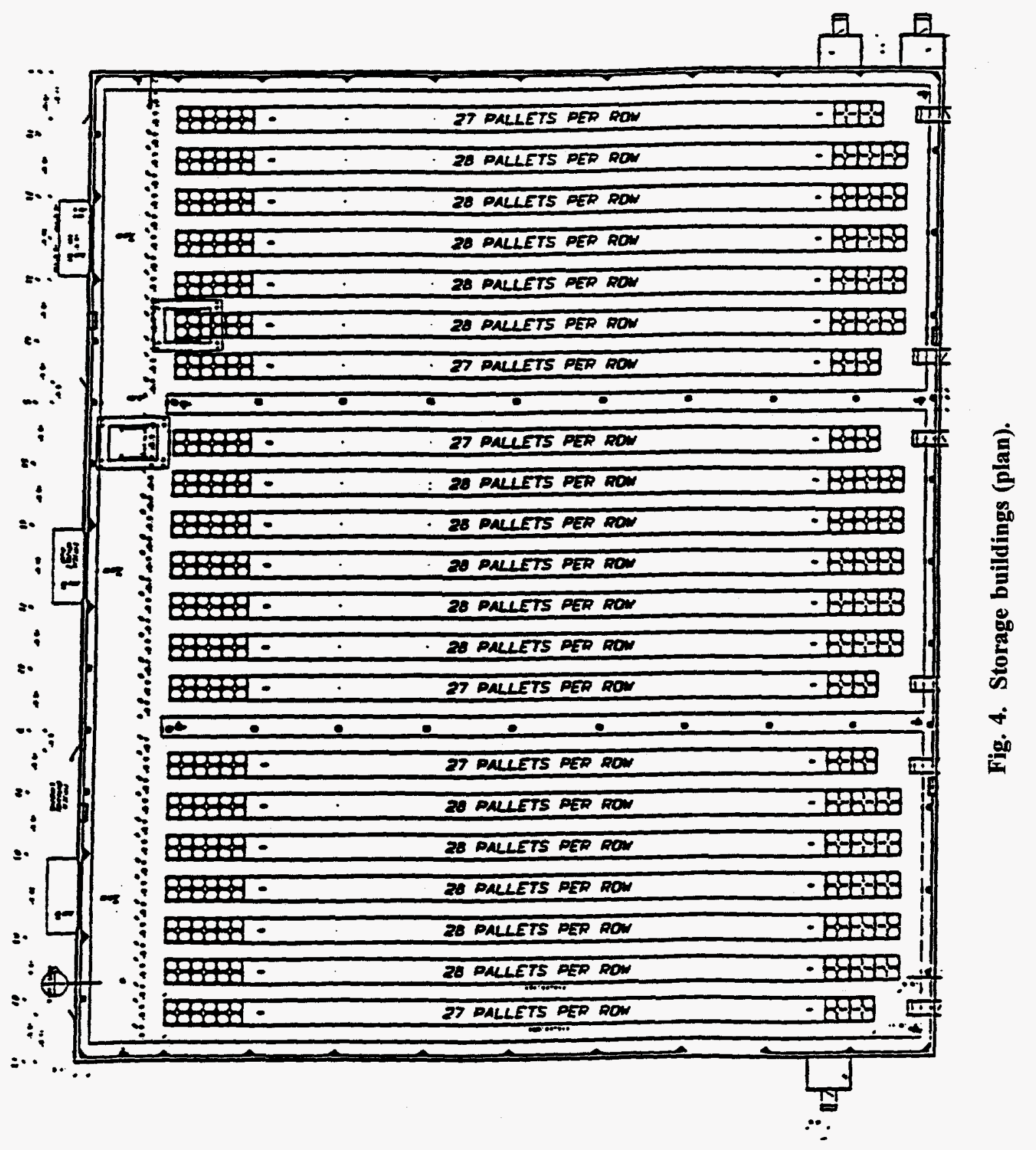


Treatment Performance Criteria. The sludge shall be processed so as to meet the following criteria, as stipulated in the LRT (SW-846 Method 9096): (1) rocks, debris, and drum liners shall be removed prior to treatment; (2) the B and C Pond sludges shall not be mixed. The selected process must be capable of meeting these criteria, and compliance must be warranted by the subcontractor. The treated sludge shall be characterized as described below.

The volume of water used in the proposed process shall be limited to that required to remove waste from the drums. Chemical additives will not be used if such chemicals might hamper subsequent removal of the processed waste from containers or interfere with future stabilization/solidification operations.

Each of the final waste storage containers shall be filled to within 6 in. of the top. The process may include compaction of sludge in the containers so as to achieve maximum volume reduction without damaging the containers. It shall also be an objective of any treatment scheme to minimize the generation of new secondary or tertiary products that may be classified as new waste.

\section{Secondary Waste Disposal}

All secondary waste generation shall be minimized. Secondary wastes are new waste streams that are comprised of components of the original, primary waste stream (i.e., the drums of raw sludge). Inventory management of all secondary wastes is required.

Liquid secondary waste shall be collected in a polyethylene tank mounted on a trailer, which Energy Systems staff members will use to transport the waste to the K-25 Site CNF. This waste shall be sampled by the subcontractor, and data must indicate that it meets the CNF waste acceptance criteria ${ }^{89}$ before being transferred to the CNF. The tank shall have a valved 2-in. bottom end outlet for gravity discharge into a sump. Two tank/trailer units shall be provided for collection while one is enroute to the CNF, for a total of three tank/trailer units.

Solid secondary wastes include the drums, pallets, rocks and debris, and plastic drum liners. These shall be volume-reduced whenever possible. The reduced volume shall be prepared and delivered to storage in accordance with waste acceptance criteria for storage. ${ }^{90}$ Off-site 
subcontractors who have been licensed by the NRC may be used for this volume reduction as long as shipment is in accordance with approved regulations, the subcontractor has all applicable permits, and prior approval is obtained from Energy Systems staff members. A Readiness Review, CWMD-RR-2 (issued on August 30, 1991), shall be used as guidance for obtaining Energy Systems approval for such off-site shipments. ${ }^{91}$ Rocks and debris shall be placed in containers in a manner that excludes drainable free water.

The method of handling used drums in which the raw waste was stored before processing must result in used drums and plastic drum liners meeting waste acceptance criteria for solid metal waste. ${ }^{70}$ These waste acceptance criteria are discussed in Sect. 4.2.3.

Any gaseous secondary waste that has the potential for carrying radionuclides or particulates shall be filtered through high-efficiency particulate air (HEPA) filters prior to discharge to the atmosphere.

\section{Tertiary Waste Disposal}

Tertiary waste is material generated incidental to construction, processing, handling, transport, spill cleanup, processing, and other operations (e.g., rags, wipes, gloves, Tyvek suits). Launderable items shall be delivered to the on-site laundry and decontamination service; all such waste generation shall be minimized. Tertiary waste destined for disposal shall be volume-reduced. The reduced volume shall be prepared and delivered to on-site storage in accordance with waste acceptance criteria. Off-site subcontractors may be used for volume reduction as long as shipment is in accordance with approved regulations, the subcontractor has all applicable permits, and prior approval is obtained from the Energy Systems staff members as outlined for secondary waste..$^{74,91}$ Inventory management of tertiary waste containers is required.

\section{Process Control}

Production of a consistent and acceptable product that meets the treatment performance requirements shall be ensured through the implementation of process control. A statistically valid sampling plan shall be designed by the subcontractor and shall control the sludge treatment process with $95 \%$ confidence that $95 \%$ of the processed sludge will pass the LRT. Effects of failure to meet the performance criterion and the potential need for reprocessing of waste shall 
be accommodated by the process design. If a particular sample fails the LRT, the subcontractor may request a retest. If the sample passes on a second or third trial, it shall be considered to have passed the test. Further, the subcontractor shall ensure that $100 \%$ of the processed sludge passes the paint filter test. Any waste that does not pass the paint filter test must be reprocessed. Data gathered as a result of this plan shall be entered into and tracked through a computerized data base.

\section{Waste Characterization}

The product of the process shall be characterized in accordance with a statistically valid sampling plan. The objectives of this sampling plan are to

1. demonstrate that the processed waste passed the LRT;

2. ensure that the waste acceptance criteria ${ }^{90}$ for storage of processed waste are met;

3. obtain physical, chemical, and radiological characterization data for future treatment; and 4. ensure that filtrate meets CNF waste acceptance criteria. ${ }^{89}$

Sampling, analysis, and quality assurance/quality control (QA/QC) procedures shall be in accordance with the EPA document, Test Methods for the Evaluation of Solid Waste, Physical/Chemical Methods, SW-846, third edition, as amended in the Federal Register (January 23, 1989). When performing sample analyses, the subcontractor shall use only EPAapproved analytical methods performed in a laboratory that has been approved by Energy Systems staff members. The subcontractor shall also ensure that all documentation and analytical procedures employed are closely guided by applicable NQA-1 procedures and shall obtain approval from Energy Systems staff for the proposed quality control program.

Portions of each sample shall be archived. Two computerized systems will be used to track sample data: one system will contain the sample data, while the other system will contain inventory information. Analytical data shall be entered into a computerized analytical data management system, with a discrete identification number assigned to each sample in order to reference to the sample batch. This sample identification number shall be entered into the computerized inventory management system. 


\subsubsection{Drying}

\section{Process Description}

The basis for investigation of the drying system was that 32,000 drums of raw sludge would be processed in 30 weeks at an average processing rate of 14 drums per hour, or about $22 \mathrm{gal} / \mathrm{min}$. A flow diagram is shown in Fig. 5.

A process consisting of mechanical dewatering followed by thermal drying was analyzed, ${ }^{86}$ based on the premise that it would be less expensive to remove as much water as possible by mechanical means prior to achieving final dryness with the application of heat.

A filter press was considered to be the most likely dewatering device, based on literature that indicated it is capable of achieving the highest level of dryness of the various types of dewatering devices employed in the municipal waste water industry. The filter press was assumed to use a 2-h cycle time (from the start of filtration to discharge of the dewatered cake) and to be capable of dewatering the sludge to $50 \%$ solids.

An indirect, steam-heated rotary disk dryer was considered as the thermal drying device, based on descriptions of such equipment in various textbooks and periodicals. ${ }^{92,93}$ The dryer was assumed to be capable of drying the dewatered cake to $95 \%$ solids. Textbook values for the evaporation rate and the steam requirement of $1.8 \mathrm{lb}$ per square foot per hour and $1.3 \mathrm{lb}$ steam/lb water evaporated, respectively, were assumed. The air flow rate through the dryer was based on the vessel volume and the normal working level of the material in the dryer, which is 60 to $90 \%$ (according to the manufacturer's literature). It was assumed that one air change per minute would be required to remove water vapor at the necessary rate. Based on data that indicate the radionuclides will not volatilize at the estimated drying temperature, water vapor and particulate matter (from entrainment) were assumed to be the only contaminants in the off-gas. Therefore, the off-gas treatment system was comprised of a mist eliminator, a reheat coil, a roughing filter, and a HEPA filter.

In calculating the final volume of filter cake that would require packaging for storage, the bulk volume of the broken-up cake was assumed to be $50 \%$ less than that calculated from the cake 
ORNL DWG 92A-382

ஓ

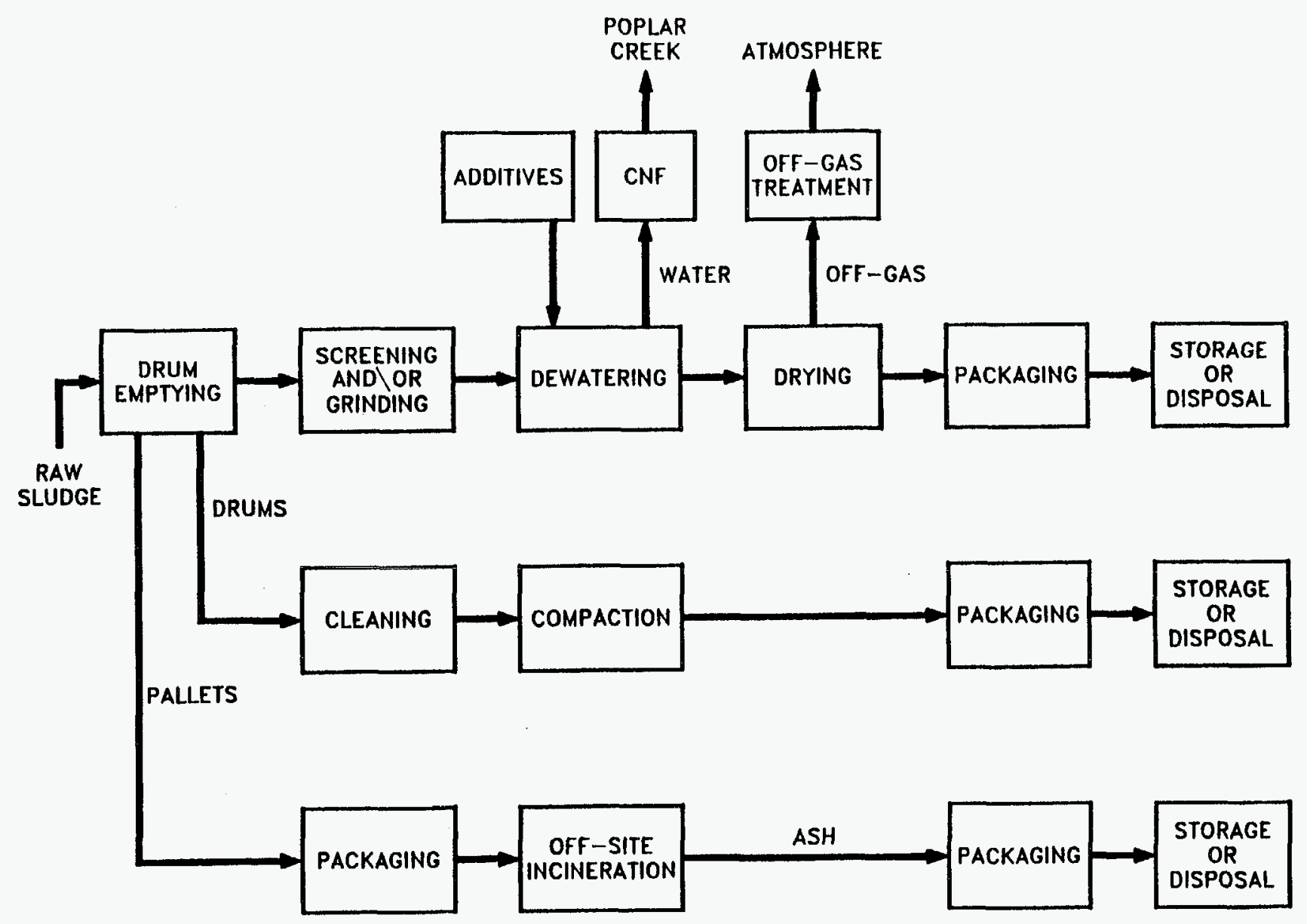

Fig. 5. Block flow diagram-drying. 
density, based on the sludge solids content. It was assumed that the dewatered filter cake would be packaged in 120 -gal containers that would be filled to $90 \%$ capacity. ${ }^{86}$

The uncertainty regarding the corrosive nature of the dried sludge mandates the corrosion-resistant storage containers. The proposed storage configuration and the requirement for inspectability dictate that the containers would have a structural integrity sufficient to stack in a three-high array. Figure 4 shows the storage configuration in a three-bay storage building. Four storage bays would be required to implement the drying process option. The treatment process would result in a more homogeneous, dried material with unknown characteristics (e.g., particle size, packing density) that would not meet LDR requirements.

\section{Functional and Operating Requirements}

In addition to the functional and operating requirements specified in Sect. 4.4.5, the drying process technology option must implement strict control over gaseous emissions. An air permit would be required to implement this technology because of the increased potential for volatilization of waste chemicals and release of radionuclides to the environment through the mechanism of entrainment.

\subsubsection{Solidification/stabilization}

\section{Process Description}

The basis for the investigation of the solidification system was that 32,000 drums of raw sludge would be processed in 49 weeks at an average processing rate of 9 drums per hour, or $\sim 14 \mathrm{gal} / \mathrm{min}$. Because the QA procedures for solidification operations would be more rigorous than those for dewatering or drying options, the process throughput was assumed to be slower. A flow diagram is shown in Fig. 6.

It was assumed ${ }^{94}$ that the sludge would be formulated into grout using the proportions determined to be optimal prior to the previous solidification campaign, as shown in Table 10. The drums would be processed in batches that are adjusted to $25 \mathrm{wt} \%$ solids before being mixed with cement and fly ash. It is assumed that the batch size (on the order of 27 drums) would be large enough to require decantation of supernate to adjust the solids concentration to $25 \mathrm{wt} \%$, although the 


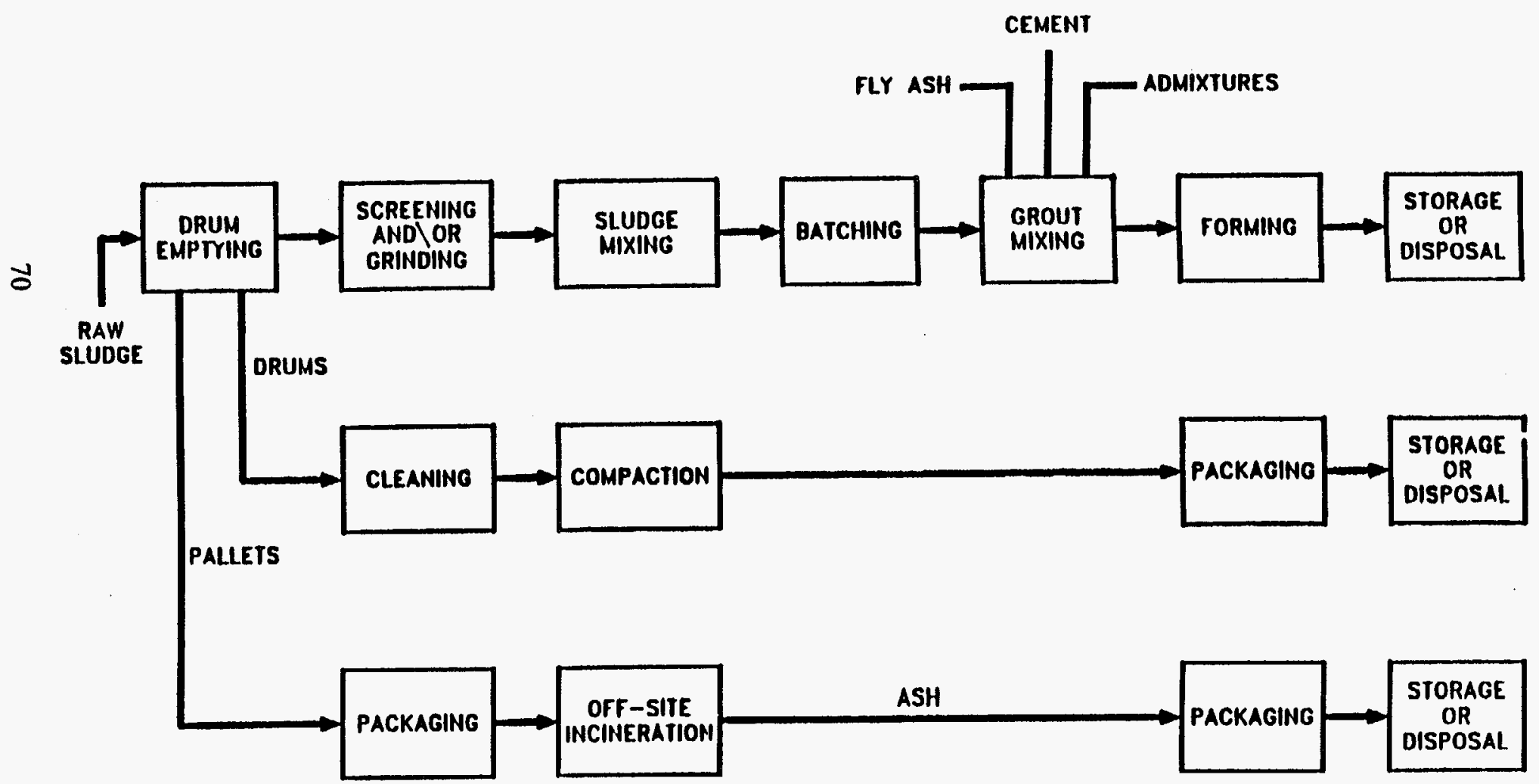

Fig. 6. Block flow diagram-solidification tank. 
addition of water to some batches would be necessary for concentration adjustment. Since the sludge consistency in the drums would range from a slurry to solids similar to clay, it would be necessary to use heavy-duty blending equipment to homogenize the batches of sludge. The 2600-gal, conical, twin-screw auger tank used in the previous operation with pond sludge operated very satisfactorily in pulverizing, delumping, and blending the sludge. Based on this information, the same type of blend tanks was selected for the sludge solidification flowsheet.

Two 2600-gal conical auger tanks would be operated in parallel. Sludge from the dumping station would be transported into one tank while the other is being processed. The tanks would operate on a 3-h-fill, 3-h-discharge cycle. The sludge would be blended, sampled, and water added (if required) to adjust the concentration. It would be necessary to transfer the sludge rapidly from the blend tank to meet the production schedule. A slurry pump operating at the rate of $50 \mathrm{gal} / \mathrm{min}$ would be installed at the discharge of each blend tank. A batch-mixing operation was selected over a continuous process since it would provide more effective process control. A weigh tank (for weighing each batch of sludge that goes into the grout mixer) would be located downstream of each blend tank.

The equipment items most likely to be used for grout mixing are high-energy mixers, pug mills, and in-line mixers. The high-energy mixer appears to be more suitable for the batch operation flowsheet. The Littleford mixer gave good performance in the previous sludge processing operation. Two $5-\mathrm{yd}^{3}$, high-energy mixers operated in parallel were selected for grout mixing. At the processing rate of 9 drums per hour and $14 \mathrm{~h}$ of operation per day, each mixer would process about 11 batches of sludge per day. This is a conservative design since each mixer should be capable of processing 2 or more batches per hour.

A standard cement plant with $100-\mathrm{yd}^{3}$ silos (each of which provides approximately a 3-d supply of materials) would be used for storage of the cement and fly ash. The cement plant would include the conveyor and separate weigh tanks for the cement and fly ash. A 2000-gal additive storage tank and metering system would be provided. The system would also require a tank or basin for the holdup of water used to wash the grouting equipment at the end of each operating period. Grout from the mixers would be pumped directly into the grout containers. ${ }^{94}$ 
The waste loading of solids, based on the grout formulation shown in Table 10, was calculated to be $12.5 \%$ solidified material. A trough-like configuration was assumed for receipt of the solidification process effluent. One trough would support 24 boxes $(4 \times 4 \times 6 \mathrm{ft})$ that would be filled sequentially. The grout would be maintained in the trough/box configuration to cure for 4 d so that it would develop enough strength to be self-supporting. Bleed water would be managed before the boxes were moved into storage buildings.

It was assumed that the treated waste would be classified as a "waste pile" as defined in 40 CFR Part 264.250(c). The exterior of the storage building would be inspected periodically and after storm events; however, no inspection of individual containers would be required. This assumption allows a stacking array that is more dense than the array required for dewatered or dried waste. A cubical configuration was also assumed, further increasing the stacking density of the solidified material (see Fig. 7). Because of the bearing strength of the storage building floor, cubes of solidified material could be stacked in an array no more than two high.

The process would yield a solid monolith that would meet LDR requirements because solidification is considered the best demonstrated available technology (BDAT) for F006 wastes. A significant volume increase of 2.2 times would result from solidification of the mixed waste sludge.

\section{Functional and Operating Requirements}

Both the functional and the operating requirements of Sect. 4.4 .5 apply to the solidification/stabilization process technology option except with regard to the performance criteria of the product passing the LRT. The following performance criteria would be applied to a solidification/stabilization process.

A solidification/stabilization subcontractor would be required to warrant that the waste will meet LDR treatability standards after treatment. Compliance with performance criteria originates from the governing regulatory agencies (i.e., the DOE, TDEC, and the EPA) for the chosen process and any final resulting waste form. 


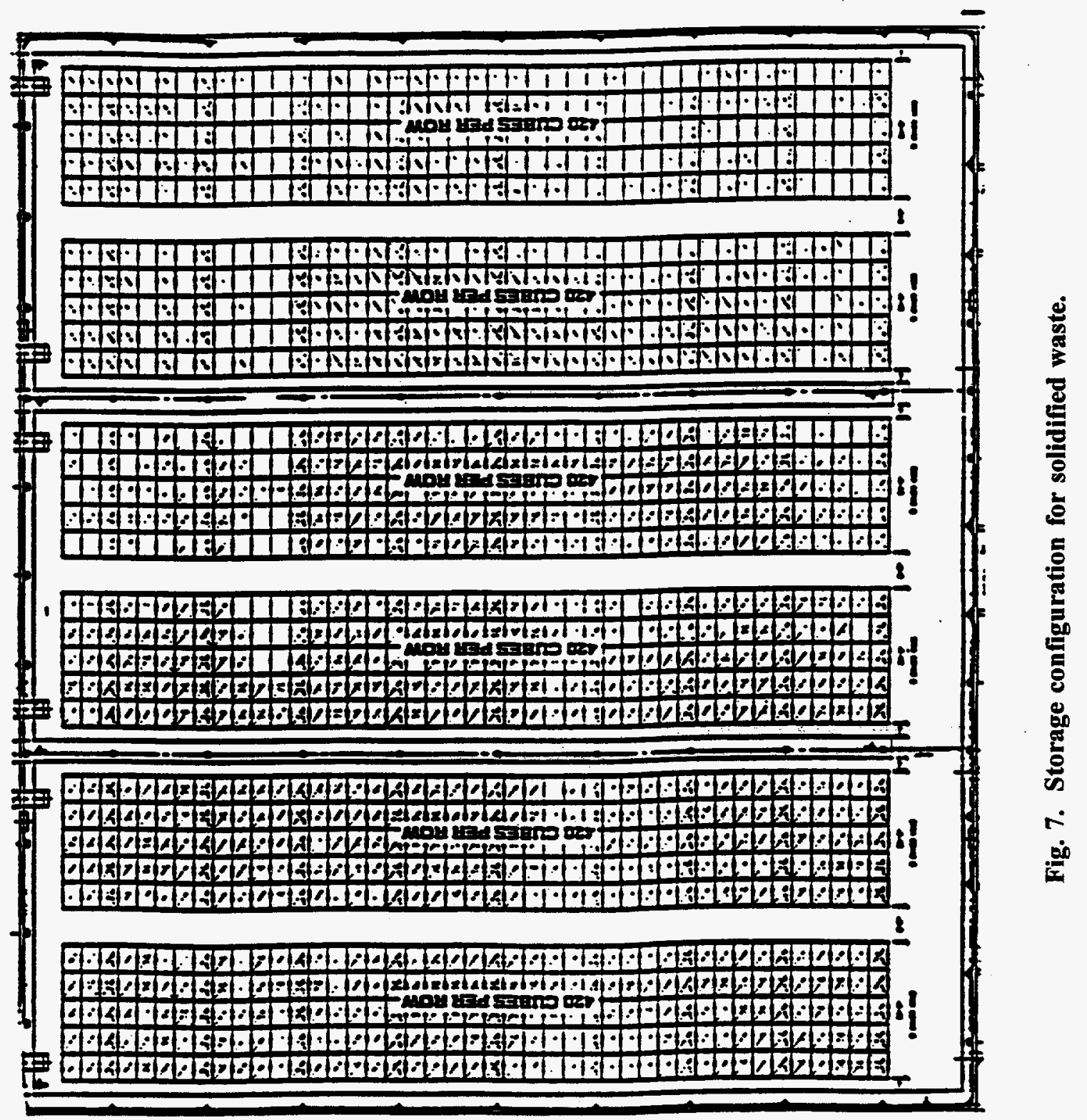


Performance criteria for final waste forms, as well as requirements for the treatment of wastes, are outlined in DOE Order 5820.2A, dated September 1988. Included in this order is the requirement for each site to conduct a performance assessment to determine radionuclide concentration limits for on-site disposal. Appendix A includes a discussion of draft on-site disposal requirements for the ORR.

The NRC has established criteria for the treatment of radioactive waste; however, these criteria are not directly applicable to DOE waste. In lieu of DOE guidance, NRC criteria have been used as guidelines by some DOE facilities. The regulation, "Licensing Requirements for Land Disposal of Radioactive Waste" (also known as 10 CFR Part 61), has contained the most comprehensive guidance on waste forms under NRC since its issuance in 1983. This document, entitled "Technical Position on Waste Form, Revision 1," was revised and issued as draft guidance in January 1991. Under guidance from this document, the stabilization process implementation and the final product performance would be required to meet all the requirements put forth in this new NRC Technical Position Paper (TPP).

Test methods proposed in the TPP would be used to show that the waste form performance criteria can be met within the confines of the expected variation in process equipment operating control. Guidance on laboratory testing and Process Control Programs (PCPs), as set forth in the TPP, would be followed. ${ }^{95}$ In addition to the waste form performance criteria required under the new NRC TPP, the following criteria would be met: (1) $0 \%$ free water must be obtained after 24 $h$ and beyond and (2) thermal cycling tests as described in the TPP must be successful. Additionally, a newly proposed mean unconfined compressive strength of 500 psi must be demonstrated after $28 \mathrm{~d}$ in the case of cement-based matrices.

The prevailing criterion would be the treatability standard established for F006 nonwaste waters by the LDR. The treated waste form would be subjected to a total-constituent analysis and the TCLP to ensure compliance with LDR treatability standards. In an effort to avoid perpetual mixed waste storage of the solidified waste, characterization data would be collected to support a delisting petition. Such a petition would be submitted to the EPA; however, whether such a petition to remove the waste stream from regulation as a hazardous waste would be approved is 
uncertain. If the delisting petition were approved, the product would be stored as low-level radioactive waste, and radioactive waste disposal options would be pursued.

Extensive bench-scale treatability tests would be required to support applicable waste solidification/stabilization procurement to demonstrate that the proposed process would provide a waste form that meets LDR treatability standards. Confirmatory tests would be performed by Energy Systems staff members, and the vendor would provide data necessary to evaluate proposals.

\subsubsection{Assessment of Process Technology Options}

The current method applies criteria for assessing the process technology options to each (see Sect. 3.4). The result of implementing the formalized selection process is a prioritized ranking of alternative process technology options, including a rating for (1) effectiveness, (2) implementability, and (3) cost. A quantitative evaluation of process technology options was completed by using a quantitative approach developed by O'Brien for the performance criteria. ${ }^{11}$ The following analysis is the first application of the approach to a mixed waste remediation project where actual data were incorporated. These criteria and the numerical values input to the equations are described in detail in Appendix D; the results are presented in Table 11. A summary of the logic influencing the score for the performance criteria is presented in the paragraphs that follow.

\section{Effectiveness}

\section{Volume Reduction}

Volume reduction is defined as the volume of effluent material that requires monitoring and storage, divided by the volume of the influent waste stream. Because the waste must be stored until a final disposal option is available, a measure of volume reduction for each alternative is an important consideration. The cost of each option also reflects the volume reduction achieved by each process option because new storage facilities must be constructed to store the waste.

\footnotetext{
"Definition and formulas for performance criteria have been modified by the author to more accurately reflect the performance criteria relevant to ORR mixed waste.
} 
Table 11. Performance measures by process technology option

\begin{tabular}{|c|c|c|c|}
\hline Performance criteria & Dewatering & Drying & $\begin{array}{l}\text { Solidification/ } \\
\text { stabilization }\end{array}$ \\
\hline \multicolumn{4}{|c|}{ Effectiveness } \\
\hline Volume reduction & 0.400 & 0.577 & -1.224 \\
\hline $\begin{array}{l}\text { Compliance with } \\
\text { ARARs }\end{array}$ & 0.470 & 0.370 & 1.000 \\
\hline Waste generation & 0.623 & 0.616 & 0.577 \\
\hline Throughput & 0.885 & 0.885 & 0.812 \\
\hline Effective benefit & 0.500 & 0.500 & 0.183 \\
\hline Risk to employees & 0.400 & 0.333 & 0.286 \\
\hline Environmental/health & 0.500 & 0.400 & 0.667 \\
\hline Total effectiveness & 0.540 & 0.526 & 0.329 \\
\hline \multicolumn{4}{|c|}{ Implementability } \\
\hline Permits & 0.500 & 0.333 & 0.500 \\
\hline Industrial availability & 0.929 & 0.875 & 0.889 \\
\hline Simplicity of design & 0.714 & 0.625 & 0.556 \\
\hline Robustness & 0.800 & 0.900 & 0.700 \\
\hline Implementation risk & 0.633 & 0.633 & 0.433 \\
\hline Technical risk & 0.607 & 0.531 & 0.431 \\
\hline Demonstrability & 0.786 & 0.688 & 0.667 \\
\hline Implementation time & 0.625 & 0.625 & 0.481 \\
\hline Future disposal & 0.941 & 1.000 & -1.224 \\
\hline Total implementability & 0.726 & 0.690 & 0.381 \\
\hline \multicolumn{4}{|c|}{ Cost-Effectiveness } \\
\hline Implementation & 0.735 & 0.758 & 0.692 \\
\hline Automation & 0.833 & 0.809 & 0.250 \\
\hline Training & 0.559 & 0.545 & 0.150 \\
\hline Total cost effectiveness & 0.709 & 0.704 & 0.364 \\
\hline \multicolumn{4}{|c|}{ Total } \\
\hline Average score & 0.658 & 0.640 & 0.358 \\
\hline
\end{tabular}


Solidification/stabilization generates the greatest volume of waste requiring storage because the volume is increased by a factor of 2.2. Dewatering achieves significant volume reduction. Drying achieves slightly greater reduction in the weight of waste being stored; however, the overall volume reduction is slightly offset because of the poor packing density of the dried waste.

\section{Compliance with ARARs}

This criterion is defined by the amount of ARAR-defined rate of emission or releases to the environment divided by the allowable emission rate. Compliance with ARARs is a requirement for each option; therefore, all of the options score $\leq 1$ for this performance criterion. The solidification/stabilization option has no appreciable gaseous emissions and consumes liquid; however, a small volume of process water may be discharged. Dewatering generates a liquid effluent that is discharged through an NPDES discharge point. Drying generates both liquid and a gaseous effluents.

\section{Waste Generation-Secondary Waste Streams}

The generation of secondary waste streams is consistent between all options because the number of pallets and drums to be disposed of is the same for each option. Secondary waste streams also include equipment that cannot be decontaminated. Drying generates slightly more secondary waste than dewatering because more unit operations are used and the process is more labor intensive. Solidification/stabilization is expected to generate more secondary waste than the other technology options: (1) in terms of personnel clothing because the process will take more time to complete and is more labor intensive and (2) in terms of equipment because equipment that will be difficult to decontaminate will be required.

\section{Throughput}

Throughput is measured as the time per unit of waste remediated. The throughputs for the drying and dewatering options are identical. The throughput of the solidification/stabilization option, however, is lower because the complexity of operation requires a longer schedule.

\section{Effective Benefit}

Effective benefit is defined as the time required to treat $50 \%$ of the waste. The effective benefits of the drying and dewatering options are identical because the schedules to complete the 
operations are the same. Solidification/stabilization scores lower because of the longer period of time required to "see beneficial results in the environment." ${ }^{10}$

\section{Risk to Employees}

The risk to employees is evaluated by comparing each individual option with the no-action alternative. Solidification/stabilization has the highest risk to employees because the operation is more labor-intensive. Drying also carries risk to employees because of the potential for workers to inhale respirable fines; however, the operation will not require as many labor hours as the solidification/stabilization option. Dewatering presents the lowest risk to employees since the process has a simple design; however, some exposure may be incurred by workers during removal of the filter cake from the filter press.

\section{Environmental/Public Health Risk}

Environmental/public health risk is evaluated as compared with the risk of the no-action alternative. The solidification/stabilization alternative has the lowest risk because the waste is permanently contained. The drying option has higher risk than the dewatering option because of the potential for airborne contamination; however, this is offset by the fact that the dewatering option may eventually result in the formation of free liquid in the storage container. The presence of free liquid in a storage configuration may present a slight risk when the design life of the containers is reached ( 30 years) if final treatment is not implemented in that time frame.

\section{Implementability}

\section{Permits}

Permits must be obtained for all treatment scenarios. The NPDES permit will be used for liquid effluent, and storage permits will be obtained. Air permits are not required for the dewatering option or the solidification/stabilization option. The drying process technology will require a permit; therefore, this option scores lower for the permit performance criterion.

\section{Industrial Availability}

All processes must be industrially available to meet system requirements; however, some system components may not have been fully demonstrated or may not be frequently implemented as a mobile process. For example, the solidification/stabilization process uses a uniquely designed 
trough configuration for receipt of the grouted waste. The curing time required for grout and space limitations dictates an innovative approach. Since this component of the solidification/stabilization system is not industrially available, the system as a whole is ranked lower. The drying system uses an industrially available dryer that is not commonly mobilized. In spite of the fact that industrial firms are willing to mobilize the system, the ranking for the drying process is lower than for dewatering. Filter presses are routinely mobilized throughout the industrial sector. Each of the process alternatives will use specially adapted techniques for removing sludge from drums.

\section{Simplicity of Design}

The number of unit operations that comprise a particular process technology option is used to quantify the simplicity of design (see Figs. 3, 5, and 6). The dewatering option has the least number of system components (i.e., 14) and, therefore, is ranked highest for simplicity of design. Drying has two additional system components-drying and off-gas treatment. Solidification/stabilization has the highest number of unit operations (i.e., 18).

\section{Robustness}

This performance criterion measures the ability of the system to accommodate unanticipated inputs without modification. Solidification/stabilization requires the most narrow "window of operation" for successful operation (e.g., anions and organic species can influence the grout set). The grout formulation must be modified if unanticipated species are encountered. Dewatering and drying process options are equally "forgiving" in terms of modification of the system to process a range of influent characteristics. This statement assumes that the off-gas system for the drying process has been designed to accommodate volatile species and species that may be entrained in the offgas (e.g., radionuclides).

\section{Implementation Risk}

Implementation risk is defined as the scheduled time from evaluation of the design to beginning of the operation. Drying and dewatering technology options have identical implementation risks, while solidification/stabilization requires 1.5 months longer to implement because the process would be more difficult to mobilize and preoperational testing would be more in-depth. This 
scenario assumes that no pilot-scale testing of the solidification/stabilization option is pursued, resulting in an increase in the technical risk.

\section{Technical Risk}

Technical risk is assessed by evaluating the ratio of unit operations that have been demonstrated under both actual and similar waste and site conditions to the total number of unit operations. None of the technical components of the processing options has been successfully demonstrated at the K-25 Site, although the storage of processed drums has been successfully demonstrated. Several of the unit operations have been demonstrated with similar waste and under similar site conditions. Since the solidification/stabilization process technology is more complex than the other options, this system carries the highest technical risk.

\section{Demonstrability}

The score for demonstrability is the fraction of process components that cannot be demonstrated prior to full-scale implementation. Bench-scale testing is necessary for all process options; however, the level of confidence in bench-scale demonstration of the solidification/stabilization option is lower. Most experts agree that successful implementation of a solidification process requires pilot-scale demonstration. Therefore, the drying and dewatering options are considered to have been demonstrated during bench-scale testing, while the solidification option is not fully demonstrated. None of the technologies will be able to demonstrate waste removal from used drums.

\section{Implementation Time}

"Implementation time includes the time it takes for special studies, design, construction, and any other technical steps that may be required for implementation. ${ }^{196}$ This performance criterion is measured as the critical path time from identification of the problem to completion of operations. The solidification/stabilization option schedule is 6 months longer than the drying and dewatering process technology options because of the difficulty of determining the grout formulation and establishing process operations (see Table 8). 


\section{Future Disposal}

"Conditions external to the site that affect the implementability of remedial technologies include the availability and acceptability of off-site disposal sites." ${ }^{197}$ The volume of waste that will be difficult to reprocess if disposal criteria are not met by the processed waste form is used as a quantitative measure of performance. Concern was explicitly expressed by regulators, "... if the stabilized sludges do not meet the disposal criteria at the time of final disposal, then additional treatment will need to be provided." 12 The entire volume of the primary effluent stream from the solidification/stabilization option is used to evaluate this criterion, while the drying and dewatering processes generate a waste form that can easily be reprocessed. Dewatering scores slightly lower than drying because the mass of additives required to achieve the performance standard (i.e., pass the LRT) is greater.

\section{Cost Effectiveness}

\section{Implementation-Treatment and Storage}

The cost per unit of waste remediated is a normalized value for the implementation cost. In this case, all treatment schemes remediate the same volume of influent material. Ideally, each scenario would be evaluated for the life cycle cost, including disposal. In the mixed waste arena, this ideal cannot be attained. Since future disposal criteria are not known, it cannot be assumed that the grouted product could be disposed of in the future; therefore, the "life" of the project ends at the storage phase.

\section{Complexity of Operations-Automation}

The number of labor hours per hour of operation is used to evaluate the degree to which the process is automated. The solidification/stabilization process is the most labor-intensive of the three process options evaluated.

\section{Complexity of Operations-Training}

Each of the process options requires significant training requirements because of the radioactive nature of the material. Special training is required for each of the core unit operations (i.e., grout mixing, curing, dryer operation, and filter press operation). Since the solidification/stabilization process contains two operations that require special training and/or experience, this process is more complex with regard to specialized training requirements. 


\subsection{REMEDIATION OF SITE}

The current methodology requires the analysis of alternatives to develop a remediation strategy. The methodology differs from others in a detailed evaluation of the implementation requirements. Definitive and specific requirements were established for each activity required to implement the project, including quality assurance and training. In this strategy, ${ }^{62}$ the primary near-term focus is to remove liquid from and improve containment of the most vulnerable waste forms (i.e., drummed raw sludge) and provide compliant storage for all of the waste material in the most costeffective and expeditious manner.

The Pond Waste Management Project was established to implement the remediation plan. The objective of implementing this plan is to provide full compliance with the RCRA requirements for management of the stored wastes. Toward that end, RCRA-permitted storage and treatment facilities must be developed and operated in accordance with those permits. The ultimate objective of the plan is final disposition of the waste.

Under this plan, a phased program is proposed to correct the current compliance deficiencies and provide remediation and compliant long-term storage of the waste. Steps in the plan include implementation of improved container storage; development, testing, and implementation of a dewatering process for the stored raw-waste; and long-term storage and/or disposal of the stabilized waste form. Each phase of the proposed plan is intended to improve the containment of the stored waste and result in a corresponding reduction in the potential ES\&H risk of the waste inventory. Finally, a treated waste form will be produced that can meet hazardous waste delisting criteria and/or RCRA's LDR treatment standards to allow ultimate disposal as a nonhazardous radioactive waste or as a stabilized mixed waste.

A six-phase program for correction of the current noncompliance issues is outlined as follows:

Phase 1 -Immediate Actions. Continue activities providing maintenance and surveillance of the stored waste and monitoring of the drum storage yard runoff.

Phase 2 - Characterization. Statistically sample and characterize drums containing raw and stabilized sludge from the ponds.

Phase 3 - Temporary Storage. Modify existing facilities and construct new RCRAcompliant temporary storage to allow contained space for all dewatered raw sludge, as well as space for the decanted, stabilized-drum inventory that can be inspected during the period (to be determined) prior to completing final waste treatment activities. 
Phase 4 - Stabilized Drums. Subcontract operations to decant, repair, or overpack deteriorated drums and transfer those stabilized drums to existing or new storage facilities.

Phase 5 - Raw Sludge Drums. Subcontract the dewatering of raw sludge, place the dewatered material in compatible bulk containers, and transfer the containers to new storage facilities.

Phase 6 - Final Treatment. At a time to be determined, prepare waste materials as required for long-term storage or disposal.

Final closure of the processing and storage facilities will be performed in compliance with RCRA requirements at the conclusion of these activities. ${ }^{62}$

\subsubsection{Storage Facilities}

New RCRA-compliant buildings will be constructed to store low-level and hazardous wastes. The number of buildings will correspond to the selected treatment option; as a minimum, four threebay storage buildings ( 240 by $200 \mathrm{ft}$ ) and one two-bay storage building will be constructed. These buildings will contain preengineered metal bays that are $80 \mathrm{ft}$ wide and $200 \mathrm{ft}$ long. Planned waste storage in these facilities is illustrated in Fig. 4. Storage facilities have a design life of 30 years.

\subsubsection{Drum Containment System}

Waste storage containers will be procured to provide either long- or short-term containment of mixed waste sludge during phases 4,5 , and 6 of the project. During phases 4 and 5 , the storage containers will serve as primary containment for the processed waste. During phase 6 , the containers can serve as forms for solidified waste or containers for treated waste. The design allows filled containers to be stacked in a three-high array under either indoor or outdoor storage conditions. The container, which is a 120 -gal polyethylene vessel, is designed to contain the processed sludge for 30 years.

Pallets will be procured to aid in the materials-handling aspects of transporting and storing the drums and containers. The pallet design is compatible with existing drums and new containers. Each pallet will support filled containers or drums stacked in a three-high array. When used during transport, each pallet will support containers or drums stacked individually. 


\subsubsection{Treatment of Mixed waste Sludge}

Approximately $2,600,000 \mathrm{gal}$ of mixed waste sludge will be processed to prepare the waste for future solidification by removing rubble and to reduce the volume of waste requiring storage. An assessment of process technology options was conducted earlier to evaluate process technology options, as discussed in Sect. 4.4. Mixed waste sludge will be either dewatered or dried and stored in corrosion-resistant containers until a final treatment option is implemented.

The services of an industrial firm will be procured to remediate untreated waste as specified by the system requirements. Waste remediation will be conducted in two phases: process qualification and waste treatment.

Phase 1 of the waste remediation procurement demonstrated that the proposed technology will provide a final product that meets functional and operating requirements as outlined in Sect. 4.4.5. Performance qualification testing was conducted during Phase 1 to ensure that the proposed process will treat the waste to the specified performance criteria, using the most economical process conditions. A statistically valid experimental design was used to identify optimum process parameters. All tests were conducted by selected industrial firms at their facilities and will be confirmed through independent tests as necessary.

In addition to standard procurement requirements, criteria were selected to qualify industrial firms for this task. Qualified firms would participate in Phase 1 at their expense and furnish all information so that the results of the tests can be independently verified. Vendors must provide documentation that demonstrates the capability to perform the required process qualification tests. Qualified vendors provided evidence they have the appropriate EPA and state licenses and/or permits to store and perform studies on the mixed waste at their facilities (i.e., a license to receive special nuclear materials and a 45-day notification letter to their respective states of the company's intent to conduct treatability studies). To supplement the information supplied, an evaluation team may be sent to the vendor's facility for further evaluation purposes.

Phase 2 of the waste remediation procurement consists of the mobilization (i.e., construction, erection, and installation) and operation of facilities that will process the mixed waste sludge in 
accordance with the qualified process and the specified performance criteria. Drums containing raw waste, as well as 16,000 gal of mixed waste sludge stored at the STF, will be retrieved from storage and processed. Technical requirements for $\mathrm{QA}$, system inspection and testing, documentation, and on-site work assurance requirements have been specified..$^{82}$

Phase 2 qualification criteria include a liability clause; each firm will warrant that the treated waste will meet performance criteria after treatment in accordance with the requirements of the EPA LRT (SW-846 Method 9096). Health, safety, and environmental (HS\&E) capabilities must be demonstrated, including training requirements as summarized in Table 12.

Potential subcontractors are required to submit results of bench-scale testing, a preliminary system design report, a project plan and schedule, a written QA program summary, a training plan and schedule, equipment cleaning and verification/decontamination plan, and a process test plan to the government contractor, Energy Systems, for evaluation. Based on an analysis of these documents, a subcontractor will be selected to provide project planning, personnel, and process equipment for treating the waste to the required performance criteria. Technical, QA, system inspection and testing, documentation, and on-site work requirements will be met, as outlined in the Technical Specifications for Sludge Dewatering. ${ }^{82}$

Energy Systems will prepare Systems Engineering documents to support the implementation of the selected process (i.e., waste treatment). The documents most relevant to the treatment of raw sludge process include Waste Treatment NEPA Document; Safety Assessment of Waste Treatment; Failure Modes and Effect Analysis of Waste Treatment, Reliability/Availability/Maintainability Analysis of Waste Treatment; and Waste Management Plan for Waste Treatment. DOE Order 4700.1 requires the completion of a Project Plan and a Project Management Plan that cover all aspects of the project (e.g., solidified waste handling).

During the treatment process, the insult to human health and the environment shall be minimized in accordance with the ALARA principle in all phases of processing. The treated waste will be stored in new facilities, as discussed above. Either a dewatering or a drying process will be selected for raw waste treatment. Flow sheets that define the basic steps in these raw waste processes are shown in Figs. 3 and 5. 
Table 12. Training requirements for subcontracted personnel

\begin{tabular}{|c|c|c|c|c|}
\hline Type of training & $\begin{array}{l}\text { Radiation } \\
\text { worker } \\
\text { (h) }\end{array}$ & $\begin{array}{l}\text { Supervisor } \\
\text { (h) }\end{array}$ & $\begin{array}{l}\text { Nonradiation } \\
\text { worker } \\
\text { (h) }\end{array}$ & Visitor \\
\hline General Employee Training & 6.5 & 6.5 & 6.5 & $a$ \\
\hline Radiation Worker Training & 8 & 8 & Not required & $a$ \\
\hline $\begin{array}{l}\text { Personnel Contamination Monitoring } \\
\text { Training }\end{array}$ & 2 & 2 & Not required & a \\
\hline $\begin{array}{l}\text { Health and Safety for Hazardous Waste } \\
\text { Sites (SARA/OSHA) }\end{array}$ & $b$ & $b$ & Not required & a \\
\hline Hazard Communication Training $c$ & $b$ & $b$ & Not required & $d$ \\
\hline Respirator $c$ & e & $b$ & Not required & $d$ \\
\hline Personnel Protection Equipment & 1 & 1 & Not required & $a$ \\
\hline Confined Space Entry & 2 & 2 & 2 & $d$ \\
\hline K-25 Contingency Plan Familiarization & 0.5 & 0.5 & 0.5 & $a$ \\
\hline $\begin{array}{l}\text { Donning and Doffing Anticontamination } \\
\text { Clothing }\end{array}$ & 2 & 2 & Not required & $a$ \\
\hline HP Technician Qualification Training & $40^{e}$ & $\begin{array}{l}\text { Not } \\
\text { required }\end{array}$ & Not required & \\
\hline Standard Practice Procedure Training & $12^{e}$ & & & \\
\hline $\begin{array}{l}\text { Hazardous and Mixed Waste Disposal } \\
\text { Training for Generators }\end{array}$ & $f$ & $\begin{array}{l}\text { Not } \\
\text { required }\end{array}$ & $f$ & \\
\hline $\begin{array}{l}\text { Hazardous Waste and Mixed Waste } \\
\text { Satellite and } 90-\mathrm{d} \text { Storage Areas Training } \\
\text { for Managers }\end{array}$ & $\begin{array}{l}\text { Not } \\
\text { required }\end{array}$ & $f$ & Not required & \\
\hline
\end{tabular}

"Visitors shall receive the indicated training or shall be escorted by personnel who have received the training. Visitors shall review a 14-min site-access video.

${ }^{b}$ Supervisors and workers shall receive $24 \mathrm{~h}$ of training. Supervisors and workers shall receive $8 \mathrm{~h}$ of refresher training annually.

This training may be included in the 24-h Health and Safety for Hazardous Waste Site (SARA/OSHA) training as long as all requirements for the type of training are met.

${ }^{a}$ Conditions that require this training will be evaluated on a case-by-case basis for visitors.

'Visitors and escorts shall meet all respirator requirements if they enter an area requiring respirators.

${ }^{{ }_{\text {Health }}}$ physics technicians only.

8Subcontractor-provided training shall be in accordance with a Energy Systems-approved lesson plan. 


\subsection{STORAGE OF WASTE}

After the mixed waste sludge has been remediated, the filled containers will be processed for storage. A computerized inventory management system is used to track the position of drums or containers within the process. The completed data base will be used to establish the inventory of stored waste. A complete sequence of drum and container moving operations and inventory management data necessary to process the mixed waste sludge is shown in Table 13. Each of the major activities is described in more detail below..$^{82,88}$

\subsubsection{Inspections}

Final inspections of both processed sludge and waste containers shall be performed, with evidence that each person who verifies conformance of work activities for purposes of acceptance is qualified to perform the assigned inspection task. In addition, inspection personnel shall not report directly to the immediate supervisors who are responsible for performing the work being inspected. Plans for inspection activities (1) shall be prepared by the subcontractor; (2) shall identify methods, characteristics, and acceptance criteria; and (3) shall provide for recording inspection results. The inspection records shall include the following, as a minimum: identity of item inspected, date of inspection, inspector, type of observation, results or acceptability, and (if applicable) reference to information on action taken in connection with nonconformances. In the event that inspections identify nonconformances, corrective actions shall be taken and the item shall be reinspected. Documentation by a responsible authority shall be obtained to verify that inspection requirements have been satisfied. Independent audits of inspections or independent inspections may be conducted prior to transferring the container(s) to storage.

The inspection of containers shall include, as a minimum:

1. Visual inspection for signs of leakage, surface contamination, damage, or structural failure prior to moving container. As specified in 29 CFR 1910.120(j)(iii), the inspection shall include examination of containers for integrity prior to moving. 
Table 13. Sequence of operations used in processing mixed waste sludge

\begin{tabular}{|c|c|c|}
\hline Major activities & $\begin{array}{c}\text { Data to inventory management } \\
\text { system }\end{array}$ & $\begin{array}{l}\text { Data from inventory } \\
\text { management system }\end{array}$ \\
\hline \multicolumn{3}{|c|}{ Storage Yards } \\
\hline Affix bar-code label & $\begin{array}{l}\text { Bar-code number; } \\
\text { date/time stamp }\end{array}$ & Location \\
\hline Enter drum serial number & Drum serial number & $\begin{array}{l}\text { Verify serial number from } \\
\text { historical data base }\end{array}$ \\
\hline Inspect drum for integrity & Inspection results & \\
\hline Hold drum for processing & $\begin{array}{l}\text { Bar-code number; } \\
\text { date/time stamp }\end{array}$ & Location \\
\hline $\begin{array}{l}\text { Upload data from bar-code reader } \\
\text { to computer }\end{array}$ & Captured data & \\
\hline $\begin{array}{l}\text { Move drum to processing area; } \\
\text { scan bar-code label }\end{array}$ & $\begin{array}{l}\text { Bar-code number; } \\
\text { date/time stamp }\end{array}$ & Location \\
\hline \multicolumn{3}{|c|}{ Processing/PackagingArea } \\
\hline $\begin{array}{l}\text { Scan bar-code label; } \\
\text { assign batch number }\end{array}$ & $\begin{array}{l}\text { Bar-code number; } \\
\text { batch number; } \\
\text { date/time stamp }\end{array}$ & \\
\hline Enter drum serial number & Drum serial number & $\begin{array}{l}\text { Drum serial number } \\
\text { validation }\end{array}$ \\
\hline \multicolumn{3}{|l|}{$\begin{array}{l}\text { Remove waste from drums included } \\
\text { in batch and process batch }\end{array}$} \\
\hline $\begin{array}{l}\text { Sample batch; } \\
\text { assign and enter sample number }\end{array}$ & $\begin{array}{l}\text { Sample/batch number; } \\
\text { date/time stamp }\end{array}$ & \\
\hline $\begin{array}{l}\text { Package processed sludge into } \\
\text { storage container; label container; } \\
\text { assign and enter batch and container } \\
\text { serial number }\end{array}$ & $\begin{array}{l}\text { Batch and container serial } \\
\text { number }\end{array}$ & Printed label \\
\hline Weigh container & $\begin{array}{l}\text { Bar-code number; } \\
\text { weight of container }\end{array}$ & \\
\hline $\begin{array}{l}\text { Inspect container; move container to } \\
\text { staging area }\end{array}$ & $\begin{array}{l}\text { Inspection results; } \\
\text { date/time stamp }\end{array}$ & Location \\
\hline \multicolumn{3}{|c|}{ Staging Area } \\
\hline $\begin{array}{l}\text { Container ready for storage; inspect } \\
\text { container; transfer container to } \\
\text { storage; } \\
\text { independent audit }\end{array}$ & $\begin{array}{l}\text { Inspection results; } \\
\text { date/time stamp; } \\
\text { results of audit }\end{array}$ & \\
\hline
\end{tabular}


2. Verification that each container includes the proper label and label information and that the labels are completed correctly and legibly.

3. Verification that containers are closed and sealed and that the integrity of the seal has been visually examined.

4. Verification that container weight and process control sample number have been identified.

5. Verification of radiological surveys of containers after transport to staging areas.

6. Verification that container integrity has not been compromised and that the container is suitable for transport, stacking, and storage.

7. Entry of appropriate inspection data into the computerized inventory management system.

\subsubsection{Container Cleaning and Management}

During treatment, care shall be taken to prevent contamination of the outside of the containers. Exterior surfaces shall be kept free of contamination to ensure that the container does not present a radiological or toxicological hazard to personnel or the environment. If the exterior surfaces become contaminated by spills or if known contact occurs with contaminated containers, equipment, or other contaminated sources, these surfaces shall be cleaned immediately in accordance with the requirements described below. Prior to transporting containers to the storage facility, additional cleaning shall be performed when needed to meet these requirements:

1. Each container shall be free of waste deposits or loose films of waste that could become airborne, be brushed off on contact, or present an environmental hazard through runoff if sprayed with water (by rain or the fire sprinkler system).

2. The surface radioactivity on the exterior of the container shall meet the criteria for decontamination and demobilization. 
3. Cleaning shall be done in a manner that will minimize the volume of secondary and tertiary waste produced, and the cleaning shall not harm the container or its markings and labels.

4. The cleanliness of the container shall be verified and documented by a radiological survey and visual inspection.

Varying structural conditions of the original drums may be encountered during the process. The process option shall include methods to transfer drums that

1. are in good condition,

2. show evidence of some corrosion, and

3. exhibit significant corrosion such that the structural integrity is violated.

Drums containing raw sludge are stacked two high, with four to a pallet. Either pallets already in use for storage of the waste or new pallets may serve as the means for transporting the raw sludge drums to treatment. In either case, the pallets should be in good, undamaged condition and capable of supporting the weight they will be expected to bear.

Each of the storage containers used to contain the processed sludge has a 120-gal capacity and is constructed of polyethylene. ${ }^{98}$ These containers require pallets for transportation.

After each container has been closed and secured, three types of labels should be affixed: hazardous material, radioactive material, and bar-code. The container should be inspected, and the appropriate data should be entered into the computerized inventory management system prior to transport. Labeling operations should be performed immediately after the processed waste has been packaged.

"Handling" refers to moving drums between storage areas, staging areas, and sludge processing areas. The following handling requirements shall be met:

1. Minimize the handling of drums. Do not handle drums at staging areas merely to change locations or to gain access for inspection. Restrict all handling to movements necessary to 
transport drums to the processing operation or to move drums to the staging area. Minimize the distance that drums are transported prior to removing and processing the sludge.

2. Place drum handling equipment and/or transport vehicles near loading points and/or staging areas to minimize the moving distance.

3. Drums may be moved as a single unit using a correctly outfitted Energy Systems staff-approved hand truck, forklift, or other handling device.

4. Drums may be grouped and moved on pallets. All drums grouped on a pallet must be the same size and must be balanced. When pallets are used, a visual inspection must be made to verify the structural integrity of the pallet prior to its use. Pallets constructed of inferior materials or those that have been subject to abuse or wear and contain cracked or broken boards or sharp abrasive surfaces shall not be used to transport or temporarily store hazardous waste drums. When a pallet is used, the drums should be strapped to it Strapping should consist of nylon-reinforced tape or the equivalent. Two wraps of strapping tape (one at the top and one at the bottom) should be applied when more than one unit is placed on a pallet. Additional strapping should be installed with sufficient overlap to prevent the strapping from being loosened by stress.

5. The staging areas for drums meet the requirements specified for these areas.

The following precautions shall be taken while loading a transport vehicle with drums with or without pallets:

1. Distribute drums or pallets on the vehicle evenly. Pack the drums or pallets as close together as possible to improve load stability.

2. Do not allow drums or pallets to hang over the edge of the vehicle.

3. Prior to moving the transport vehicle, secure the drums to the body of the vehicle by use of restraining straps. Strapping pallets to the vehicle is acceptable. Verify the integrity of 
the retaining straps prior to using them. Ensure that all straps are sufficiently tight to prevent drums from falling.

4. Before unloading operations begin and the retaining straps are loosened, verify that the load has not shifted in such a way as to cause drums to fall from the vehicle. Correct any shifting prior to unloading.

5. When the load is stable, check the integrity of the drum seal and examine the container for external damage.

6. Prior to transferring containers to the Energy Systems staff, verify that containers meet the radioactive contamination limits specified in Sect. 4.6 .4 for decontamination and decommissioning.

7. Do not leave transport trucks running while being loaded or unloaded.

"Staging" refers to the temporary storage of drums or containers while they are awaiting processing, transport, inspection, or other operations. Staging shall only occur for

1. drums at the storage yards that do not have sufficient structural integrity to be transported, 2. drums at the location(s) for processing operations waiting for sludge removal,

3. containers at the locations for processing operations, and

4. containers of processed sludge prior to transfer to the storage facility.

The storage yards shall have staging areas for inspection and other operations. The following requirements for staging shall be met, as a minimum:

1. Ensure that containers are stacked no more than two high and two wide and have row clearances of no less than $4 \mathrm{ft}$ and a row length no greater than $150 \mathrm{ft}$.

2. Designate staging areas, as necessary, to meet requirement (1) as listed above and (2) the requirements of entry restriction for processing areas. 
3. For drums of sludge that have not been treated, provide an adequate level of secondary containment in relation to the volume of the containers in case of a spill. Adequate shall mean $10 \%$ of the total volume of containers present or the volume of the largest container, whichever is largest, plus 6 in. of rain (if the containment area is capable of accumulating rainwater).

4. Inspect staging areas daily.

5. Inspect containers when containers are placed in or removed from a staging area.

6. Inspect the staging area for compliance with 40 CFR 264.174 until waste processing has been completed.

\subsubsection{Spill Containment and Cleanup}

Prompt cleanup of any hazardous or radioactive material that is spilled is required in order to mitigate the spread of waste contaminants. Following such an incident, the "spill area" shall be inspected to ensure that proper cleanup measures were taken. In cases that involve large quantities of materials and require organized efforts, both the spill area and the cleanup area shall be identified by the use of flagging or barricades. Most spills will be of such small quantities that special-area identification will not be necessary; however, precautions shall be taken to prevent the accidental spread of contaminants. Entry to the spill and cleanup area shall be restricted to only those persons directly involved in the associated activities.

Adsorbents such as rags, diapers, Zorbal, sweeping compounds, and other frequently used materials shall be made readily available at all times at handling, transport, and operations locations. Containment booms and sandbags shall also be available on-site for use if necessary. Cleaning compounds that will become hazardous waste materials shall not be used.

Both the appropriate cleaning materials and the necessary personnel and equipment must be readily available at all handling, transport, and process operations locations. In instances where the spilled material is collected in a containment device and can be retrieved in its pure form, the 
material should be carefully placed in its original storage container. Retrieval of the spilled material may be accomplished by using air-operated diaphragm pumps or any method not requiring the use of adsorbents (e.g., sweeping compound, absorbent diapers, rags). If the spilled material must be retrieved by using adsorbents, the retrieved material, along with its recovery agents, should be placed in storage containers meeting waste storage requirements. ${ }^{90}$ All collected materials should be properly identified and placed in storage containers. A "Hazardous Waste" label should be attached to the container to identify its contents. Appropriate waste disposal forms should be completed for each container, and storage should be in accordance with requirements. ${ }^{90}$ The cleanup of any nonradioactive spill or release is considered complete when the spill area meets the decommissioning and demobilization requirements.

All launderable personal protective equipment shall be decontaminated. When possible, equipment will be washed and rinsed to accommodate its reuse. Rinse waters should be stored and treated as secondary liquid waste. Any disposable equipment that cannot be cleaned according to the standards specified below for decontamination and demobilization shall be handled as secondary solid waste.

\subsubsection{Decontamination and Demobilization}

All facilities and equipment, with the exception of the computerized equipment related to the inventory management system, shall be decontaminated and removed from the site by the subcontractor. The subcontractor shall remove or decontaminate all waste residues, contaminated containment system components, and contaminated subsoils and structures. Facilities shall be cleaned and dismantled, and the resulting solid waste material shall be packaged for storage in accordance with requirements. ${ }^{90}$ Any liquid waste generated by decontamination activities may be disposed of at the CNF in accordance with waste acceptance criteria. ${ }^{89}$ All radioactive and hazardous wastes must be removed from equipment. Prior to release, all decontaminated equipment and facilities shall be swipe-sampled, the swipe shall be analyzed for hazardous constituents, and the results shall be reported to Energy Systems. The requested analyses shall be based on those hazardous constituents known to be present in the waste. Equipment shail be certified by the subcontractor's health and safety officer to be free of hazardous constituents prior to off-site release and shall be tagged with release tags. 
Radioactive surface contamination criteria for release are as follows:
Alpha activity (total)
$<300 \mathrm{dpm} / 100 \mathrm{~cm}^{2}$
Alpha activity (transferable)
$<20 \mathrm{dpm} / 100 \mathrm{~cm}^{2}$
Beta-gamma activity (total)
$<5000 \mathrm{dpm} / 100 \mathrm{~cm}^{2}$
Beta-gamma activity (transferable)
$<1000 \mathrm{dpm} / 100 \mathrm{~cm}^{2}$

In cases where surface contamination by both alpha- and beta-gamma-emitting nuclides exists, the established limits shall apply independently. ${ }^{99}$

As used in the above limits, disintegrations per minute (dpm) refer to the rate of emission by radioactive material as determined by correcting the counts per minute observed by an appropriate detector for background, efficiency, and geometric factors associated with the instrumentation.

Upon completion of the processing activity, the equipment will be surveyed and inspected before it is removed from the work area to establish a postprocessing radiation contamination profile. If the equipment contamination profile exceeds the DOE requirements, the subcontractor shall carry out the necessary radioactive decontamination on-site. Waste generated because of decontamination after operations will be accepted, as discussed earlier under secondary and tertiary waste disposal. Equipment shall be designed to facilitate decontamination. Individual components such as motors, pumps, and controls shall be decontaminated.

\subsection{SUMMARY OF APPLICATIONOF METHODOLOGY TO THE REMEDIATIONOF 32,000 DRUMS OF MIXED WASTE SLUDGE}

A generalized methodology for the remediation of a mixed waste site has been applied to the treatment of 32,000 drums of mixed waste sludge. Application of the methodology illustrates critical constraints affecting mixed waste management and identifies avenues for achieving project success. Definitive treatment standards for this mixed waste are lacking since disposal sites licensed to receive K-25 Site mixed waste are not available. Thus, the K-25 Site must store mixed waste for future disposal in facilities for which criteria have not been established. Despite the lack of disposal criteria, "actual or threatened releases of hazardous substances from these 
drums, as well as physical conditions at the site, if not addressed by implementing the response action . . . may present a current or potential threat to human health or the environment."12 In addition, regulators required remediation of specific noncompliance issues by February $1993 .^{62}$

Activities undertaken to remediate the 32,000 drums of mixed waste sludge are described in terms of a unique methodology that includes a straightforward hierarchial approach. The hierarchy consists of the following steps: (1) identify the problem; (2) characterize the problem; (3) establish system requirements; (4) select an alternative; (5) remediate the site; and (6) store the waste.

The key problem is identified as specific noncompliance issues regarding the storage of the mixed waste sludge. The problem is thoroughly characterized with regard to the history of the situation, the regulatory environment, and sample data. This background forms the basis for establishing system requirements. The key system requirement is to bring the drums into compliance with RCRA storage requirements.

Process technology options are evaluated first with regard to meeting system requirements and then with regard to CERCLA performance criteria. The following process technology options are investigated: (1) no action; (2) separation of hazardous and radioactive species; (3) dewatering; (4) drying; and (5) solidification/stabilization. The first two options were eliminated from detailed consideration because they did not meet the system requirements. The dewatering, drying, and solidification/stabilization options are described in detail and evaluated quantitatively. The evaluation clearly showed that, based on system constraints and project objectives, either dewatering or drying the mixed waste sludge was superior to the solidification/stabilization process option (see Table 11). The ultimate choice between the drying and the dewatering options will be made on the basis of the technical evaluation, conducted by the procurement team, of the relative merits of proposals submitted by potential subcontractors.

LDR requirements will not be met by dewatering or drying the waste (see Table 7); however, volume reduction, removal of debris, and placement of the waste in compatible containers will be achieved. Implementing the solidification alternative would have resulted in a waste form that would meet LDR requirements, but the volume would be significantly increased. Further, criteria 
for radioactive waste disposal have not been established because disposal sites are not currently available. The uncertainty associated with solidifying the waste to unknown standards contributed to the decision to dewater the raw waste rather than to solidify it. "DOE does not presently have access to a disposal site for this type of waste . . . Because the criteria for disposal of materials can change over time, DOE is reluctant to commit to a treatment process today that may not be acceptable when a disposal site finally becomes available." ${ }^{12}$

The method for implementing the selected process technology option, including subcontracting the remedial action to industry, is described in detail. Process-related technical specifications for the subcontract are also described. The schedule for the plan of action calls for completion of the improved storage phase in February 1993. Because a disposal site for treated waste is currently unavailable, the final treatment and disposition of the raw sludge will be postponed until a later date. The storage facilities and containers have a design life of 30 years. Through the mechanisms of the FFCA negotiations and/or actions determined under the RCRA RI/FS for the site, the deadline for waste treatment will be established in concert with the regulators. 


\section{EVALUATION AND CONCLUSIONS}

In response to the need for a comprehensive and consistent approach to the complex issue of mixed waste management (see Sect. 2), a generalized methodology for remediation of a mixed waste site was developed using requirements set forth in CERCLA and RCRA as a basis. Such a methodology is unique because mixed waste is governed by regulations for both hazardous and radioactive materials. These dual regulations provide driving forces for mixed waste remediation activities at all stages. Definitive treatment standards are lacking since disposal sites licensed to receive DOE mixed waste are limited. ${ }^{2,3}$ Thus, DOE sites must store mixed waste for future disposal in facilities for which criteria have not been established. Despite the lack of disposal criteria, numerous mixed waste sites may present a risk to the public, and regulations governing hazardous waste require remediation by specific deadlines. This regulatory quandary forms a challenging framework for mixed waste remediation activities.

This methodology includes a hierarchy of activities to be undertaken to remediate a mixed waste problem. The hierarchy consists of the following steps: (1) identify the problem; (2) assess the problem; (3) establish system requirements; (4) select an alternative; (5) remediate the site; and (6) store the waste or treat and dispose of the waste (see Fig. 1), ${ }^{7,8}$

\subsection{EVALUATION}

Texts $^{14-16}$ on process design have been used as a basis for comparing the remediation methodology under study. The application of standardized process design techniques to mixed waste remediation efforts differs primarily in emphasis; chemical process design focuses on profitability, while remediation process design focuses on compliance with environmental regulations.

Others have presented methodologies for waste remediation; ${ }^{17-30}$ however, the methodologies differ from the current method in scope, level of detail, or approach. In contrast to the present method, published methodologies do not provide guidance beyond the assessment stage of a project, do not include details regarding project implementation at a DOE site, do not cover issues specific to mixed waste, or do not explicitly outline the methodology used for solution of the problem under consideration. Waste minimization assessments ${ }^{31-35}$ have contributed to understanding issues 
regarding mixed waste generation as covered in the initial activities identified in the hierarchy under study (see Fig. 1) while performance assessments ${ }^{36-39}$ have clarified issues surrounding the final activities in the hierarchy (i.e., waste disposal). Remediation projects have been implemented with varying degrees of success without explicitly identifying the methodology employed. ${ }^{40-46}$ The current method draws upon the experience of others and presents a comprehensive approach to mixed waste site remediation.

\subsubsection{Process Design Methodologies}

A textbook definition of the procedure required to design a project includes: ${ }^{16}$ identification of the type of design; feasibility survey; process development; preliminary system design; design; and construction and operations (see Sect. 2.1). "Identification of the type of design" can be compared with the first step identified in the current methodology (i.e., identify problem). The concept is to determine the scope of work that is required to resolve the issue(s) at hand.

The textbook requirement to conduct a feasibility survey is similar to steps in the method under study: assess problem and establish system requirements. The textbook definition differs from the current method in that industrial process design and development are driven by profit motives, while remediation projects are driven by regulatory compliance motives. The present methodology requires consideration of feasibility survey factors, established by Peters and Timmerhaus, during "assessment of the problem" and "establishment of system requirements."16

The next step in the current method is to select the alternative. This can be compared with steps outlined by Peters and Timmerhaus: process development and preliminary system design. Identifying the need for additional research is considered part of process development by Peters and Timmerhaus, while the current method covers the need and scope of treatability studies under the activity "select alternative." Several process options are considered by the current method, and rough order-of-magnitude costs are established for each. The current method compares each option to a set of system requirements, which include costs, and eliminates alternatives that do not meet system requirements from further consideration. This procedure is comparable to that recommended by Peters and Timmerhaus. 
The current method expands upon the method recommended by Peters and Timmerhaus in that it employs a quantitative assessment of several variables that are relevant to the selection of a remediation alternative. Industrial process selection is based primarily on product marketability and return on investment.

The current method identifies "remediate site" as the implementation stage of the project (cf Peters and Timmerhaus on design, construction, and operations). Several principles of project implementation for industrial chemical processes and remediation projects are identical. The establishment of the basis for design, the preparation of a simplified flow diagram, the design of specific pieces of equipment, and the definition of utilities and labor are activities that must occur to implement both types of projects. For DOE remediation projects, however, a divergence occurs between the two project types in compliance with company policies vs compliance with DOE orders. Adherence to the policy of a company sponsoring chemical plant construction is beyond the scope of Peters and Timmerhaus, while the current method demonstrates the level of detail required to comply with DOE orders and successfully implement a project for DOE.

Construction scheduling and coordination and successful operations are of concern in implementing any project, regardless of the purpose of the project. Urgency to build and operate a chemical plant is driven by profit incentives, while urgency to build and operate a remediation project is driven by environmental compliance milestones.

Whether a remediation project is implemented through the use of a subcontractor (as described in the application of the current method) or through construction of a capital facility, the principles of sound project management apply. The current method demonstrates application of the recommendations of Peters and Timmerhaus by describing details of project implementation.

The similarity between industrial chemical plant and remediation project design and project implementation is apparent; the current method correlates with standard engineering practice. The final steps in the current method reflect the uncertainty in the regulatory requirements for mixed waste. These steps (i.e., store waste or treat and dispose of it) are not reflected in standard industrial design practice because such uncertainty would typically be eliminated prior to project implementation. 


\subsubsection{Remediation Methodologies}

A workshop on radioactive, hazardous, and/or mixed waste sludge management ${ }^{17}$ identified central issues that need resolution prior to treating off-specification products as (1) defining material to be treated, (2) determining the goal of treatment (i.e., shipment, storage, or disposal), and (3) assessing treatment alternatives. ${ }^{18}$ Activities identified as relevant to successful project completion during the workshop are comparable to the activities identified in the current method, including some of the evaluation criteria, although steps were not defined sequentially to develop a comprehensive methodology. Guidance provided by the workshop differs from the current method in that the CERCLA methodology for implementing activities was not addressed and a quantitative analysis of alternative process technology options was not developed or discussed.

The CERCLA methodology ${ }^{19}$ presents detailed actions for the initial stages of a remediation project: scoping of the remedial investigation/feasibility study, site characterization, treatability investigations, development and screening of alternatives, and detailed analysis of alternatives (cf Fig. 1, identify problem, assess problem, establish system requirements, and select alternative). Implementation of the remediation project (i.e., remediate site) is beyond the scope of the CERCLA methodology because the method must be generally applicable and cannot include sitespecific implementation requirements. The method under study expands upon the CERCLA methodology by applying quantitative measures to selection of a process alternative and by describing, in detail, the implementation requirements for DOE sites.

The activities described in the current method correlate with both the CERCLA process ${ }^{19}$ and the value engineering process ${ }^{20}$ (see Fig. 8). The current method is unique in the use of a quantitative assessment of performance factors (as qualitatively described by CERCLA evaluation criteria) and an in-depth assessment of factors affecting implementation. The author is aware that value engineering is applied to plant design and construction; however, the referenced report ${ }^{20}$ limits the comparison of remediation project assessment and value engineering to the evaluation stage of the project.

An overall process of site stabilization and closure has been presented by Trabalka, ${ }^{21}$ who outlines the following activities: determine exposure pathways of concern, establish performance 


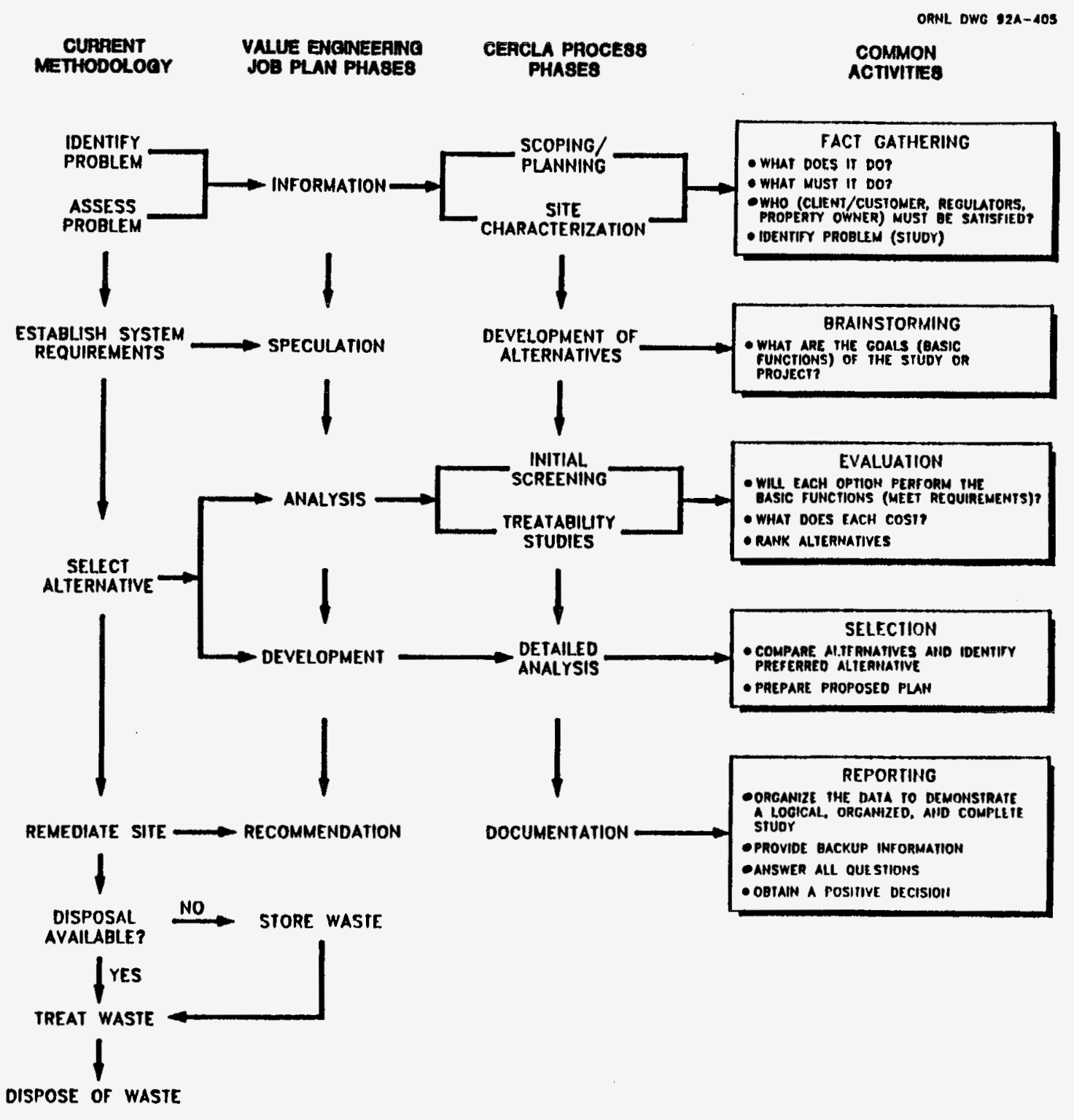

Fig. 8. Common activities in current, CERCLA, and value engineering methodologies. 
objectives, select and apply stabilization action, assess site performance, maintain stabilized site, and achieve site closure (cf Fig 1, assess problem, establish system requirements, select alternative, remediate site, treat waste, and dispose of waste). Since these activities are directed toward in situ remediation projects, the activities differ in approach from the methodology under study (e.g., assessment of site performance as compared with assessment of operational performance during waste treatment). Further, a quantitative approach to selection of the stabilization action is not employed.

Cleanup of the Hanford Site is being planned in a comprehensive manner with the expenditure of significant resources. ${ }^{22-28}$ The current methodology could easily be applied to the steps being implemented at the Hanford Site. Because the current method is applied to a remediation of a problem that is solvable by February 1993, aspects of implementation are considered in more detail than the Hanford documentation. The author was unable to locate documentation of the Hanford strategy in terms of a comprehensive methodology, although, by piecing aspects of the Hanford plan together, the elements of a comprehensive methodology appear to be employed. The current method explicitly follows the CERCLA methodology for evaluation of alternatives. No explicit reference to the use of CERCLA balancing criteria was noted in review of the Hanford literature, although the publication of a Record of Decision ${ }^{24}$ implies that a CERCLA process is being followed.

The use of the logic diagram technique ${ }^{29}$ developed by Smith appears to be quite powerful; however, specialized training is required to implement the approach. The requirements-tree technique addresses aspects of the current method except a quantitative assessment of alternative process options and a description of details regarding implementation of a project at a DOE site.

As described in Sect. 2.2, the approach to "comprehensive planning . . . before remediating a hazardous waste site ${ }^{130}$ is consistent with the current method; however, the focus is directed toward meeting information needs and development of data bases rather than project implementation. 


\subsubsection{Assessments}

In-depth assessments have been made of either the initial or the final activities identified in the hierarchy under study (see Fig. 1). The assessment and implementation of waste minimization programs may be discussed in terms of following the first five steps in the current hierarchy. Since the objective of a waste minimization program is to reduce volume, toxicity, and/or mass of waste as it is generated, issues such as availability of disposal sites and activities such as waste treatment and storage/disposal of waste do not apply. Examples of hierarchial approaches to waste minimization include systems developed at $\mathrm{ORNL}^{31-34}$ and Hanford. ${ }^{35}$

The performance assessment methodology recognizes the importance of establishing system parameters and uses a quantitative evaluation of disposal options. ${ }^{36-39}$ These methodologies address the final stage of the current method (i.e., dispose of waste). The approach to performance assessment is similar to the approach used in the current method for selection of a processing alternative, although probability distributions are not employed in the current method. The method under study evaluates engineering and design data to select a process alternative, while the performance assessment evaluates scientific data (e.g., radionuclide concentrations in the brines of a repository room) to estimate long-term radionuclide releases.

\subsubsection{Remediation Projects}

The review of remediation projects (see Sect. 2.4) illustrates the point that each step identified in the current methodology must be assessed to achieve project success.

The successful implementation of a waste remediation project at the Savannah River Site ${ }^{40}$ is clearly linked to the definition of system requirements and rigorous process control. The current method requires both of these features to achieve project success.

The methodology adopted by Rocky Flats ${ }^{41-42}$ reflects the steps in the current method; however, the point at which the process is subcontracted differs. The current method incorporates waste characterization into the assessment of the problem. These activities are completed by the organization with primary responsibility for project success (e.g., the primary government 
contractor). Delegation of the "assessment of the problem" to a subcontractor carries certain risks because the project scope and cost cannot be clearly defined until the extent of the problem is assessed.

The Portsmouth Gaseous Diffusion Plant ${ }^{43}$ remediation project illustrates the fact that a definition of regulatory requirements alone is not sufficient to establish system requirements. Engineering judgment and appropriate physical/chemical assessment of the problem must be integrated into the requirement to meet regulatory standards. The current method requires use of both regulatory and process engineering requirements to establish performance objectives.

The management of low-level mixed waste at the Hanford Site provides an example of establishing system requirements with staged compliance objectives ${ }^{44}$ that is similar to the application considered by the current method: compliance with interim storage objectives is preferred over the no-action alternative of leaving containers in noncompliant storage.

\subsubsection{Confirmation of Methodology}

This work has been applied to the national problem of DOE mixed waste treatment by the author. ${ }^{13}$ The methodology was applied in response to the need to conduct research and development and test equipment for treatment of mixed waste throughout the DOE complex. The status of each activity was described with regard to the general issue of the lack of capacity and capability to treat mixed waste. Review by a DOE-Headquarters staff member ${ }^{100}$ indicated that the structure of the methodology was comprehensive and allows for incorporation of newly defined problems or information. The validity of the structure was thus confirmed independently.

The development of a methodology to remediate a mixed waste site is consistent with chemical process plant design methods ${ }^{16}$ and with value engineering methods. ${ }^{20}$ The validity of the construction $^{57}$ of the method has been demonstrated by the incorporation of salient features of process design, DOE guidance, ${ }^{8}$ and CERCLA. ${ }^{10}$

The activities identified by the methodology as necessary to ensure project success are comparable to remediation methodologies developed by others. However, the current method differs from 
those developed by others in level of specificity required to establish system requirements, a quantitative approach to process alternative selection, a basis of regulatory guidance, and the level of detail required to comply with DOE orders and implement the selected course of action. The general applicability of the current method has been demonstrated by comparison with environmental assessments and remediation projects that did not explicitly identify the methodology by which the project was designed and implemented (see Sects. 2.3, 2.4, 5.1.3, and 5.1.4).

The usefulness of the construction of the model has been confirmed further by independent review by $\mathrm{K}-25$ staff members. ${ }^{59,60}$ It was stated that the document could be used as a training manual for engineers who are entering the field of remediation work at DOE sites.

\subsection{CONCLUSIONS}

The methodology is quite general and is useful as a guide to evaluating options and implementing mixed waste remediation projects at a DOE site. The evaluation of regulations is relevant for the current assessment; however, as new regulations are promulgated, the usefulness of the regulatory evaluation will diminish. The importance of evaluating current regulations is, nevertheless, emphasized by the present method. The significance of the use of sound process design engineering principles in the environmental arena is highlighted. Engineers, charged with the responsibility of successful project completion, must investigate regulatory, scientific, and engineering principles as applied to their work.

The reliability of the method was tested by parallel implementation of aspects of the model including planning and initial implementation stages of the remediation of 32,000 drums of mixed waste sludge. Process technology options were developed and evaluated first with regard to meeting system requirements and then with regard to CERCLA performance criteria. The following process technology options are investigated: (1) no action, (2) separation of hazardous and radioactive species, (3) dewatering, (4) drying, and (5) solidification/stabilization. The first two options were eliminated from detailed consideration because they did not meet the system requirements. A quantitative evaluation clearly showed that, based on system constraints and project objectives, either dewatering or drying the mixed waste sludge was superior to the 
solidification/stabilization process option (see Table 11). The ultimate choice between the drying and the dewatering options will be made on the basis of a technical evaluation of the relative merits of proposals submitted by potential subcontractors.

The application of the methodology for remediation of a mixed waste site is the first comprehensive case study, identified by the author, that is based on CERCLA evaluation criteria and uses a quantitative assessment of alternatives with data from rough order-of-magnitude material balance and cost estimates. Internal and external evaluations confirmed the suitability of the methodology with regard to construction and content. As of May 1992, the contract had not been awarded and the remediation activities have not begun. The method will not be validated in all aspects until the remediation project is successfully completed.

The "case-study" aspect of the current work serves as an illustration of the complexity of implementing mixed waste remediation projects. Because the application of the methodology was validated by a short-term project (implementation completed within 2 years), modification may be required to reflect requirements of longer-term remediation efforts. Other researchers may wish to develop comprehensive methodologies that take into consideration factors influencing long-term projects.

The uncertainty inherent with regard to the storage vs disposal options could be investigated by other researchers by applying techniques used to investigate market uncertainty. There is an analogy between industrial chemical process "profitability" and remediation project "regulatory compliance." Each provides the project driving force. Industrial chemical processes are scrutinized for profitability before implementation; some markets carry a high degree of risk or uncertainty. Techniques used to analyze this uncertainty could be applied to the regulatory uncertainty associated with mixed waste.

An institutional issue highlighted by this work is the lack of disposal facilities for DOE mixed waste and the lack of criteria governing the recycle and/or reuse of radioactive materials. Other researchers may wish to investigate methods for standardizing waste disposal criteria throughout the DOE complex to provide a consistent regulatory infrastructure. The development of a "treatability standard" or "best demonstrated available technology" structure for radioactive waste 
(similar to that developed by EPA for hazardous waste) could ensure that radioactive materials are disposed of safely. The current situation of "perpetual storage" of radioactive mixed waste could be transformed into the safe disposal of the waste if such criteria were established. 


\section{REFERENCES}

1. Leaf vs Hodel (Secretary of the Department of Energy), 586 Federal Supplement, 1163 (E.D. Tenn 1984).

2. Nevada Test Site Defense Waste Acceptance Criteria, Certification, and Transfer Requirements, prepared jointly by the U.S. Department of Energy, Nevada Operations Office and Reynolds Electrical and Engineering Co., Inc., NVO-325,UC-70B, October 2988.

3. L. P. Duffy, Director, Office of Environmental Restoration and Waste Management, Department of Energy, "Commercial Disposal of Department of Energy Radioactive (By-product and Low-Level) and Mixed Wastes," letter to W. A. Williams, EM-421, Environmental Restoration Division, Department of Energy, Sept. 13, 1991.

4. "Mixed-Waste Deal Frees Compliance Bill," Defense Cleanup, Vol. 2, No. 21, Pasha Publications, Inc., Oct. 25, 1991.

5. U.S. DOE, "Land Disposal Restriction Case-by-Case Extension Application for Radioactive Mixed Wastes," U.S. Department of Energy, Washington, D.C., 1991.

6. W. A. Ross and M. R. Elmore, "Locations, Volumes, and Characteristics of DOE's Mixed Low-Level Wastes," to be published in the Proceedings of Waste Management '92, Tucson, Ariz., February 1992.

7. D. R. Hopper, "Cleaning up Contaminated Waste Sites," Chem. Eng. 96(8), 94-110 (1989).

8. "U.S. Department of Energy Model Process Waste Assessment Plan," prepared by Hazardous Waste Remedial Actions Program, managed by Martin Marietta Energy Systems, Inc., and by the Pine Crest Corporation, PP91/14.CE, Jan. 15, 1991.

9. Guidance on Feasibility Studies Under CERCLA, EPA/540/G-85/003, U.S. Environmental Protection Agency, 1985.

10. Guidance on Conducting Remedial Investigations and Feasibility Studies Under CERCLA, EPA/540/G-89/004, U.S. Environmental Protection Agency, October 1988.

11. M. C. O'Brien, J. L. Morrison, M. J. Fudin, and J. G. Richardson, Performance-Based Technology Selection Filter, Preliminary Description Report, EG\&G-WTD-9899 Rev. 0, Idaho National Engineering Laboratory, November 1991.

12. Interim Action Record of Decision for the K-1417-A and K-1417-B Drum Storage Yards Oak Ridge K-25 Site, DOE-OR-991, prepared by the U.S. Department of Energy, Environmental Restoration Division, Oak Ridge, Tennessee, September 1991. 
13. J. B. Berry et al., Mixed Waste Technology Research, Development, Demonstration, Testing, and Evaluation (Draft), Mar. 25, 1992, unpublished.

14. H. A. Simon, The Sciences of the Artificial, MIT Press, Cambridge, Mass., 1969.

15. D. F. Rudd, G. J. Powers, and Jeffrey J. Siirola, Process Synthesis, Prentice-Hall, Inc., Englewood Cliffs, N.J., 1973, P. 15.

16. M. S. Peters and K. D. Timmerhaus, Plant Design and Economics for Chemical Engineers, Third Edition, McGraw-Hill Book Company, New York, 1980, pp. 12-17.

17. T. F. Lomenick, ed., Proceedings of the Workshop on Radioactive, Hazardous, or Mixed Waste Sludge Management, CONF-901264, Oak Ridge, Tenn., Dec. 4-6, 1990.

18. T. F. Lomenick, ed., J. B. Berry, C. H. Brown, and R. M. Cannon, "Treatment of OffSpec Product," pp. 289-92 in the Proceedings of the Workshop on Radioactive, Hazardous, or Mixed Waste Sludge Management, CONF-901264, Oak Ridge, Tenn., Dec. 4-6, 1990.

19. Guidance for Conducting Remedial Investigations and Feasibility Studies Under CERCLA, EPA-540-G-89 004, October 1988, pp. 1-7.

20. R. R. Land, "Establishment of Value Engineering in the Department of Energy's Formerly Utilized Remedial Action Program," pp. 433-40 in the Proceeding of Waste Management '90, Tucson, Ariz., Feb. 25-Mar. 1, 1990, Vol. 1.

21. J. R. Trabalka, Developing a Strategy and Closure Criteria for Radioactive and Mixed Waste Sites in the ORNL Remedial Action Program: Regulatory Interface, ORNL/TM10228, Oak Ridge National Laboratory, September 1987.

22. M. C. Brown and M. V. Berriochoa, Overview of the Hanford Clean-up Five-Year Plan, U.S. Department of Energy, Richland, Washington, September 1991.

23. Department of Energy, Final Environmental Impact Statement: Disposal of Hanford Defense High-Level, Transuranic, and Tank Wastes, Hanford Site, Richland, Washington, DOE/EIS-0113, U.S. Department of Energy-Headquarters, Richland, Washington, 1987.

24. Department of Energy, "Disposal of Hanford Defense High-Level, Transuranic, and Tank Wastes, Hanford Site, Richland, Washington; Record of Decision," Fed. Regist. 53(72), 12449-53 (1988).

25. Hanford Federal Facility Agreement and Consent Order, Vols. 1 and 2, Washington State Department of Ecology, U.S. Environmental Protection Agency, and U.S. Department of Energy, Olympia, Wash., 1990. 
26. R. J. Bliss, Hanford Site Tank Waste Disposal Strategy, Draft Revision 1, WHC-EP0511 , October, 1991.

27. K. D. Wiemers et al., Preliminary Assessment of Candidate Immobilization Technologies for Retrieved Single-Shell Tank Wastes, PNL-7918, January 1992.

28. P. J. Jacobsen and D. R. Duncan, Alternatives to Land Disposal of Solid Radioactive Mixed Waste on the Hanford Site: Progress Report, WHC-EP-0300, March 1990.

29. T. H. Smith, "Use of Requirements-Type Logic Trees to Guide Complex Environmental Remediation Activities," pp. 491-96 in the Proceedings of Waste Management '89, Tucson, Ariz., Feb. 26, 1989, EGG-M-88491, CONF-890207-18.

30. C. A. Geffen, B. A. Garrett, and M. B. Walter, "Information Management Systems for Integrating the Technical Data and Regulatory Requirements of Environmental Restoration Activities," pp. 447-52 in the Proceedings of Waste Management '90, Vol. 1, Tucson, Ariz., Feb. 25-Mar. 1, 1990.

31. R. M. Schultz, Waste Reduction Plan for the Oak Ridge National Laboratory, ORNL/TM-11283, Oak Ridge National Laboratory, April 1990.

32. C. M. Kendrick, Hazardous Waste Minimization Report for CY 1986, ORNL/TM-10516, Oak Ridge National Laboratory, December 1990.

33. M. D. Homan, C. M. Kendrick, and R. M. Schultz, Waste Reduction Program at Oak Ridge National Laboratory During CY 1990, ORNL/TM-11780, Oak Ridge National Laboratory, March 1991.

34. J. B. Berry and F. J. Homan, "Minimizing Waste by Charging the Generator," Hazardous and Industrial Solid Waste Minimization Practices, STP-1043, American Society for Testing and Materials, Baltimore, Md., August 1989.

35. D. H. Nichols, Hanford Site Annual Waste Reduction Report, 1990, DOE/RL-91-18, March 1991.

36. R. P. Rechard and M. S. Y. Chu, "Use of Risk to Resolve Conflicts in Assessing Hazards at Mixed-Waste Site," pp. 4.3.1-4.3.7 in the Proceedings of the First International Mixed Waste Symposium, Baltimore, Md., Aug. 26-29, 1991, SAND-910587C, CONF-910849-3.

37. M. S. Y. Chu et al., Risk Assessment and Ranking Methodologies of Hazardous Chemical Defense Waste: A State-of-the-Art Review and Evaluation. Task 1 Report, SAND-86-0530, June 1986.

38. C. M. King et al., "Performance Assessment Methods for Mixed Waste Sites at the Savannah River Plant," published in the Proceedings of the Annual Low-Level 
Radioactive Waste Management Program Conference, Denver, Colo., Aug. 25, 1987, DP-MS-87-80, CONF-870859-9.

39. E. J. Bonano and D. P. Gallegos, "Need to Use Probabilistic Risk Approach in Performance Assessment of Waste Disposal Facilities," published in the Proceedings of the Department of Energy Model Conference, Oak Ridge, Tenn., Oct. 14-17, 1991, SAND-91-0913C, CONF-9110168-2.

40. T. F. Lomenick, ed., and D. G. Thompson, "Processing Saltstone from Waste Streams at the Savannah River Plant," pp. 11-17, in the Proceedings of the Workshop on Radioactive, Hazardous, and/or Mixed Waste Sludge Management, Oak Ridge, Tenn., Dec. 4-6, 1990, CONF-901264.

41. T. F. Lomenick, ed., J. Wienand, C. Baldwin, and R. Tyler, "Treatment of Pond Sludge at the Rocky Flats Plant," pp. 35-40 in the Proceedings of the Workshop on Radioactive, Hazardous, and/or Mixed Waste Sludge Management, Oak Ridge, Tenn., Dec. 4-6, 1990, CONF-901264.

42. G. P. Motl and T. A. Bittner, "Stabilization of Rocky Flats Solar Pond Mixed Waste Sludge," published in the Proceedings of the 7th Annual DOE Model Conference, Oak Ridge, Tenn., Oct. 14-17, 1991, CONF-9110168.

43. T. F. Lomenick, ed., and R. Williams, "Diffusion Plant Sludge Storage Problems at the Portsmouth Gaseous Diffusion Plant," pp. 165-67 in the Proceedings of the Workshop on Radioactive, Hazardous, and/or Mixed Waste Sludge Management, Oak Ridge, Tenn., Dec. 4-6, 1990, CONF-901264.

44. T. F. Lomenick, ed., J. B. Berry, and L. A. Fort, "Treatment of Off-Spec Products," pp. 289-91 in the Proceedings of the Workshop on Radioactive, Hazardous, and/or Mixed Waste Sludge Management, Oak Ridge, Tenn., Dec. 4-6, 1990, CONF-901264.

45. J. S. Devgun and N. J. Beskid, "Waste Management and Environmental Compliance Aspects of a Major Remedial Action Program," pp. 639-44 in the Proceedings of Waste Management '91, Tucson, Ariz., Feb. 25-28, 1991, CONF-910270-13.

46. D. L. Eaton et al., "Issues in Radioactive Mixed Waste Compliance with RCRA: Some Examples from Ongoing Operations at the Idaho National Engineering Laboratory," pp. 343-48 in the Proceedings of Waste Management '90, Vol. 1, Tucson, Ariz., Feb. 25-Mar. 1, 1990.

47. The RCRA Land Disposal Restrictions: A Guide to Compliance, 1991 Edition, McCoy and Associates, Inc., ISBN: 0-930469-10-1, 1991.

48. J. Chowdhury, "The Battle over the Environment," Chem. Eng. 98(10), 30-451 (1991).

49. K. M. Kostelnik, Buried Waste Integrated Demonstration Plan, EGG-WTD-9870, December 1991. 
50. M. B. Sears et al., Sampling and Analysis of Radioactive Liquid Wastes and Sludges in the Melton Valley and Evaporator Facility Storage Tanks at ORNL, ORNL/TM-11652, Oak Ridge National Laboratory, September 1990.

51. R. N. Ceo, M. B. Sears, and J. T. Shor, Physical Characterization of Radioactive Sludges in Selected Melton Valley and Evaporator Facility Storage Tanks, ORNL/TM11653, Oak Ridge National Laboratory, October 1990.

52. J. J. Ferrada, Hazardous Chemical Waste Management, Garland Publishing, Inc., New York and London, 1990.

53. G. M. Holter to J. L. Scott, internal correspondence, Pacific Northwest Laboratories, Feb. 6, 1992.

54. Guidance on Conducting Remedial Investigations and Feasibility Studies Under CERCLA, EPA/540/G-89/004, U.S. Environmental Protection Agency, October 1988, pp. 1-9.

55. J. B. Berry to M. Larsen, internal correspondence, "Strategy and Program Plan for Mixed Waste Integrated Program, Office of Technology Development, Office of Environmental Restoration and Waste Management," SAIC, Idaho Falls, Idaho, February 1992.

56. R. L. Gillins to J. B. Berry, internal correspondence, "Draft Program Plan for the Mixed Waste Integrated Program," SAIC, Idaho Falls, Idaho, Mar. 31, 1992.

57. G. L. Wood and J. Harber, Nursing Research Methods, Critical Appraisal, and Utilization, C. V. Mosby Co., St. Louis, Mo., 1990.

58. J. H. Scarbrough, Chief, RCRA and Federal Facilities Branch, Waste Management Division, U.S. Environmental Protection Agency, Region IV, and T. Tiesler, Director, Division of Solid and Hazardous Waste, Tennessee Department of Environment and Conservation, "Response to Questions on Processing K-1417 Drums," letter to R. C. Sleeman, Environmental Restoration Division, Department of Energy, Oak Ridge, Tenn., July 31, 1991.

59. R. Eby, Director, K-25 Site Program Management Office, and M. B. Baer, Division Director, K-25 Pond Waste Management Project, personal communication, March 1992.

60. R. Eby, K-25 Site Program Manager, specialized training in Kepner-Tregoe alternatives assessment techniques, March 1992.

61. F. Mynatt et al., K-1047-B and $-C$ Ponds Drums and Bulk Storage, Volume 1. Corrective Actions Study, K-2066/V1, July 31, 1990.

62. M. B. Baer, J. B. Berry, T. J. McLaughlin, and C. M. Amonett, Plan for the Management of K-1047-B and -C Ponds Waste at the Oak Ridge K-25 Site, Pond Waste 
Management Project, K/PW-6, Martin Marietta Energy Systems, Inc., Oak Ridge Gaseous Diffusion Plant, Aug. 16, 1991.

63. J. L. Shoemaker and W. D. Bostick, Support for Characterization, Grout Formulations, and Stabilization of K-1407-B and -C Pond Sludge, K/QT-199, September 1988.

64. J. L. Shoemaker, K-25 Site, personal communication, July 1991.

65. T. M. Gilliam, ORNL, personal communication, September 1991.

66. Fed. Regist. 56(168), 42730-34 (1991).

67. J. B. Berry, E. S. Harrington, and A. J. Mattus, "Handling 78,000 Drums of MixedWaste Sludge," pp. 9.1.1-9.1.15 in the Proceedings of the First International Mixed Waste Symposium, Baltimore, Md., Aug. 26-29, 1991.

68. M. B. Baer et al., Action Plan for the Management of K-1407-B and $-C$ Ponds Waste at the Oak Ridge K-25 Site, Pond Waste Management Project, K/PW-3, Martin Marietta Energy Systems, Inc., Oak Ridge Gaseous Diffusion Plant, Jan. 31, 1991.

69. D. Hutchins, Martin Marietta Energy Systems, Inc., personal communication, June 1991.

70. Martin Marietta Energy Systems, Inc., "Disposal of Excess or Surplus Equipment or Material," Standard Practice Procedure No. 339.

71. Resource Conservation and Recovery Act Permit-by-Rule Application for the Oak Ridge K-25 Site, K/HS-376, EPA ID No. TN0-89-009-0004, October 1991.

72. Fed. Regist. 55(174), 37173-79 (1990).

73. D. W. Swindle, Director, Technical Integration, Environmental Restoration Division, Oak Ridge National Laboratory, "Request for Categorical Exclusion Determination-Proposed Use of Mobile Waste Treatment Services, Oak Ridge K-25 Site, Oak Ridge, Tennessee," letter to C. S. Gist, Branch Chief, Restoration Program Integration Branch, Environmental Restoration Division, U.S. Department of Energy, May 3, 1991.

74. C. E. Frye to J. R. Merriman and F. R. Mynatt, internal correspondence, "Readiness Review of the K-25 Site Request to Ship K-1407-B and -C Pond Sludge Samples OffSite for Treatability Studies to Be Performed by Licensed and Permitted Vendors," Dec. 13, 1991.

75. J. W. Zolyniak to C. M. Turner, internal correspondence, "Statistical Selection Plan for Building Raw Sludge Composites for Laboratory Scale Testing," July 18, 1991.

76. J. W. Zolyniak to C. M. Turner, internal correspondence, "Statistical Considerations for Differences in Sample Sizes for B and C Pond Sludge," Aug. 8, 1991. 
77. C. R. Kirkpatrick et al., Characterization of the K-1407 B and C Ponds Raw Sludges and Laboratory Cured Concrete Cubes, KTCD-1019, Martin Marietta Energy Systems, Inc., Oak Ridge K-25 Site, March 1992.

78. W. E. Bryan, Systems Requirements Document for the Pond Waste Management Project, K/D-5922, Rev. 1, Oct. 28, 1991.

79. J. B. Berry, ORNL, communication with vendors at Waste Management '91, Tucson, Ariz., February 1991.

80. J. B. Berry and E. S. Harrington, Pond Waste Management Project (PWMP) Technical Specification for Waste Remediation, JS-CM-714170-A002, May 10, 1991.

81. D. E. Brashears to T. J. McLaughlin, internal correspondence, "Rough Order of Magnitude PWMP Processing Options," July 25, 1991.

82. J. B. Berry and E. S. Harrington, Pond Waste Management Project (PWMP) Technical Specifications for Sludge Dewatering, JS-CM0714170-A002, October 1991.

83. T. M. Gilliam to J. B. Berry, ORNL, internal correspondence, "Bench Scale Treatability Studies," July 26, 1991.

84. R. H. Perry and C. H. Chilton, Chemical Engineers' Handbook, Sixth Edition, McGraw-Hill, New York, 1975.

85. Waste Water Treatment Plant Design, WPCF Manual of Practice No. 8, Water Pollution Control Federation, Washington, D.C., 1977.

86. E. S. Harrington, ORNL, personal communication, July 1991.

87. E. S. Harrington, T. M. Gilliam, C. M. Rudolph, ORNL, and J. W. Zolyniak, K-25 Site, personal communication, September 1991.

88. C. M. Amonett et al., Pond Waste Management Project (PWIP), Technical Specifications for Drum Processing Containing Stabilized Sludge, JS-KDE-714170A005, Sept. 25, 1991.

89. The Oak Ridge Gaseous Diffusion Plant K-1407-A Central Neutralization Facility Waste Acceptance Criteria, K/SS-538, February 1990.

90. Waste Acceptance Criteria for Storage, K/WD-2, July 25, 1991.

91. Readiness Review, CWMD-RR-2, "Review of Request from Y-12 for Resumption of Off-site Shipment of Low-level Waste for Volume Reduction by a Licensed Vendor," Aug. 30, 1991. 
92. Industrial Drying, A. Williams Gardner, Gulf Publishing Co., Houston, Tex., 1977, p. 256.

93. Water Environment and Technology, July 1991, pp. 28-32.

94. E. L. Youngblood, ORNL, personal communication, July 1991.

95. A. J. Mattus, ORNL, personal communication, May 1991.

96. Guidance on Feasibility Studies Under CERCLA, EPA 540/G-85/003, p. 3-5, Sect. 3.3.2.1, Par. 1.

97. Guidance on Feasibility Studies Under CERCLA, EPA 540/G-85/003, p. 3-4, Sect. 3.3.1.2, Par. 1.

98. J. L. Shoemaker et al., Pond Waste Management Project, Technical Specification for Waste Storage Containers, JS-KDE-714170-A002, Rev. 4, Aug. 20, 1991.

99. R. R. Redmond, K-25 Site, personal communication, February 1992.

100. K. Hain, DOE-Headquarters, Office of Technology Development, personal communication, April 1992. 
APPENDIX A

MANAGEMENT OF LOW-LEVEL WASTE ON THE OAK RIDGE RESERVATION 

Appendix A.

MANAGEMENT OF LOW-LEVEL WASTE ON THE

OAK RIDGE RESERVATION

\section{BACKGROUND}

Energy Systems administers a low-level waste (LLW) program that is designed to develop a comprehensive strategy for managing LLW on the ORR in the light of state and federal regulations and DOE orders. The strategy relies on the concept of waste segregation to provide needed control of the concentration and isotopic composition of LLW before final disposition. The approach to managing the segregated wastes depends on the level of contamination present. This approach is based on the performance assessment of the disposal site and the technology used for disposal of the waste. The LLW program has proposed five classes of LLW to be managed on the ORR. These are described below. The K-25 pond waste can only potentially qualify for Class I.

1. Below Regulatory Concern (BRC) Waste - LLW that is suitable for disposal in a sanitary/industrial landfill facility and will not expose any member of the public to an effective dose equivalent of more than 4 mrem/year at the time of disposal.

2. Class I Waste - LLW that is suitable for disposal using sanitary/industrial landfill technology and will not expose any member of the public to an effective dose equivalent of more than $10 \mathrm{mrem} /$ year at the time of disposal.

3. Class II Waste - LLW primarily containing fission product radionuclides with half-lives of 30 years or less that is suitable for disposal in engineered facilities designed to isolate the waste from the environment and public for a period sufficient to allow for the decay of radionuclides to such a level that any member of the public will not be exposed to an effective dose equivalent to more than $10 \mathrm{mrem} / \mathrm{year}$.

4. Class III Waste - LLW consisting of radionuclides that have long half-lives and will be disposed of in facilities having intruder protection. 
5. Class IV Waste - LLW that is not suitable for disposal on the ORR and would require either (a) treatment to reduce the level of contamination to a level consistent with any of the other four waste classifications or (b) shipment to an off-site LLW disposal facility.

\section{ALTERNATIVE METHODS FOR CALCULATING RADIONUCLIDE CONCENTRATIONS}

If more than one isotope is present in the waste package, the total activity concentration must follow the "sum-of-fractions" rule. That is, the sum of the ratios of each isotope's concentration in the waste package to that isotope's limiting concentration must be less than or equal to 1 , expressed mathematically as

$$
\sum_{i=1}^{n}\left(\frac{C}{C_{L}}\right)_{i} \leq 1.0
$$

where

$C=$ the measured or calculated concentration of a given radionuclide in the waste package plus the associated uncertainty,

$C_{L}=$ the concentration limit for that radionuclide shown in Table A.1, and

$n=$ the total number of principal radionuclides in the waste package.

For the purposes of waste acceptance, a radionuclide listed in Table A.1 may be considered to be absent if the following conditions apply:

1. The ratio of the concentration of the radionuclide in the waste to the concentration limit for that radionuclide does not exceed 0.1 and

$$
\frac{C}{C_{L}} \leq 0.1
$$


2. The sum of such ratios for all radionuclides considered not to be present does not exceed 0.25 ,

$$
\sum_{k=1}^{n}\left(\frac{C}{C_{L}}\right)_{k} \leq 0.25
$$

3. Radionuclides that are not specifically listed in Table A.1, including beta-gamma-emitting radionuclides with half-lives less than 5 years, may be considered not to be present if the activity of the particular radionuclide does not exceed $5 \%$ of the total activity of the waste package. 
Table A.1. Site-specific, dose-based concentration limits $\left(\mu \mathrm{Ci} / \mathrm{m}^{3}\right)$

\begin{tabular}{|c|c|c|}
\hline Nuclide & Class I & Class II \\
\hline $\mathrm{H}-3$ & $1.39 \mathrm{E}+10$ & $1.16 \mathrm{E}+12$ \\
\hline $\mathrm{Be}-10$ & $4.30 \mathrm{E}+04$ & $1.96 \mathrm{E}+06$ \\
\hline C-14 & $5.93 \mathrm{E}+05$ & $2.01 \mathrm{E}+02$ \\
\hline $\mathrm{Na}-22$ & $1.37 \mathrm{E}+05$ & $>1.00 \mathrm{E}+12$ \\
\hline $\mathrm{Co}-60$ & $1.14 \mathrm{E}+07$ & $>1.00 \mathrm{E}+12$ \\
\hline $\mathrm{Ni}-63$ & $8.82 E+04$ & $2.83 E+04$ \\
\hline Sr-90 & $1.40 \mathrm{E}+-3$ & $8.88 \mathrm{E}+05$ \\
\hline $\mathrm{Zr}-93$ & $2.55 \mathrm{E}+02$ & $2.55 \mathrm{E}+02$ \\
\hline Tc-99 & $1.07 \mathrm{E}+01$ & $5.53 \mathrm{E}+02$ \\
\hline $\mathrm{Cd}-113 \mathrm{~m}$ & $6.61 \mathrm{E}+04$ & $9.76 \mathrm{E}+09$ \\
\hline $\mathrm{Sn}-121 \mathrm{~m}$ & $1.35 \mathrm{E}+03$ & $5.74 \mathrm{E}+04$ \\
\hline Cs-137 & $6.98 \mathrm{E}+02$ & $2.53 \mathrm{E}+05$ \\
\hline$S m-151$ & $1.56 \mathrm{E}+06$ & $2.57 \mathrm{E}+07$ \\
\hline Eu-152 & $1.03 E+04$ & $1.35 \mathrm{E}+09$ \\
\hline Eu-154 & $1.81 \mathrm{E}+05$ & $5.13 E+12$ \\
\hline Eu-155 & $4.61 \mathrm{E}+07$ & $>1.00 \mathrm{E}+12$ \\
\hline Th-232 & $1.27 \mathrm{E}+00$ & 4.48E-01 \\
\hline U-233 & $1.22 \mathrm{E}+03$ & $2.36 \mathrm{E}+01$ \\
\hline $\mathrm{U}-235$ & $9.97 \mathrm{E}+00$ & $2.53 \mathrm{E}+01$ \\
\hline $\mathrm{U}-238$ & $2.09 \mathrm{E}+01$ & $2.75 \mathrm{E}+01$ \\
\hline Np-237 & $8.08 \mathrm{E}-03$ & $1.05 \mathrm{E}-02$ \\
\hline $\mathrm{Pu}-238$ & $5.46 \mathrm{E}+02$ & $1.49 \mathrm{E}+01$ \\
\hline Pu-239 & $2.17 \mathrm{E}-01$ & $2.95 \mathrm{E}-01$ \\
\hline $\mathrm{Pu}-241$ & $5.35 \mathrm{E}+02$ & $9.39 \mathrm{E}+03$ \\
\hline $\mathrm{Pu}-242$ & $9.19 \mathrm{E}-00$ & $4.99 \mathrm{E}+02$ \\
\hline Am-241 & $9.92 \mathrm{E}+00$ & $1.34 \mathrm{E}+02$ \\
\hline Am-243 & $4.61 \mathrm{E}-01$ & $1.81 \mathrm{E}+01$ \\
\hline $\mathrm{Cm}-243$ & $1.71 E+03$ & $1.03 E+06$ \\
\hline $\mathrm{Cm}-244$ & $1.42 \mathrm{E}+02$ & $2.14 \mathrm{E}+02$ \\
\hline Cf-252 & $2.56 \mathrm{E}+04$ & $>1.00 \mathrm{E}+12$ \\
\hline
\end{tabular}


APPENDIX B

PRELIMINARY SLUDGE CONSTITUENT ANALYSIS 

Samples: solidified cement cubes

Date completed: April 2, 1990

Number of samples: 18

Batches represented: $35-2641$ (C Pond only)

Draft waste classification limits ${ }^{a}(\mathrm{pCi} / \mathrm{g})$

\begin{tabular}{lcccc} 
Radionuclide & Range of results & Simple average & Limit A & Limit B \\
\cline { 3 - 5 } & $36-580 \mathrm{pCi} / \mathrm{g}$ & $160 \mathrm{pCi} / \mathrm{g}$ & 490 & 8 \\
${ }^{99} \mathrm{Tc}$ & $0.36-10 \mathrm{pCi} / \mathrm{g}$ & $2.7 \mathrm{pCi} / \mathrm{g}$ & 190 & 720 \\
${ }^{137} \mathrm{Cs}$ & $0.3-11 \mathrm{pCi} / \mathrm{g}$ & $2.3 \mathrm{pCi} / \mathrm{g}$ & 8.8 & 0.01 \\
${ }^{137} \mathrm{~Np}$ & $28.5-436 \mu \mathrm{g} / \mathrm{g}$ & $120 \mu \mathrm{g} / \mathrm{g}$ & 50 & 30 \\
${ }^{\text {Total U }}$ & $18.5-399 \mathrm{pCi} / \mathrm{g}$ & $(101 \mathrm{pCi} / \mathrm{g})$ & & \\
& & $1.0 \mathrm{wt} \%{ }^{235} \mathrm{U}$ & & 800 \\
${ }^{238} \mathrm{Pu}$ & $0.04-0.31 \mathrm{pCi} / \mathrm{g}$ & $0.13 \mathrm{pCi} / \mathrm{g}$ & 1160 & 800 \\
${ }^{239} \mathrm{Pu}$ & $0.25-13 \mathrm{pCi} / \mathrm{g}$ & $2.7 \mathrm{pCi} / \mathrm{g}$ & 690 & \\
\hline
\end{tabular}

"Waste classification:

Limit $A$ is based on exceeding the limits for any single radionuclide established by the LLW Disposal Development and Demonstration (LLWDDD) program.

Limit B is based on exceeding the limits for any single radionuclide established by the environmental impact statement for the site. 
Table B.2. Summary data for B Pond sampling (September 1988)

\begin{tabular}{|c|c|c|c|c|}
\hline Parameter & Mean & Maximum & Minimum & Unit \\
\hline Aluminum & 36,200 . & 49,000 . & 19,000 . & $\mu \mathrm{g} / \mathrm{g}$ \\
\hline Arsenic & 162. & 250. & 5.0 & $\mu \mathrm{g} / \mathrm{g}$ \\
\hline Barium & 221. & 290. & 120. & $\mu \mathrm{g} / \mathrm{g}$ \\
\hline Beryllium & 2.0 & 3.1 & 1.4 & $\mu \mathrm{g} / \mathrm{g}$ \\
\hline Boron & 110. & 190. & 77. & $\mu \mathrm{g} / \mathrm{g}$ \\
\hline Cadmium & 2.0 & 5.6 & 0.30 & $\mu \mathrm{g} / \mathrm{g}$ \\
\hline Calcium & 58,000 . & 200,000 . & 29,000 . & $\mu \mathrm{g} / \mathrm{g}$ \\
\hline Chromium & 815. & 2,400 & 290. & $\mu \mathrm{g} / \mathrm{g}$ \\
\hline Cobalt & 42. & 61. & 22. & $\mu \mathrm{g} / \mathrm{g}$ \\
\hline Copper & 1,030 & 1,600 & 420. & $\mu \mathrm{g} / \mathrm{g}$ \\
\hline Iron & 75,500 & 20,000 . & 35,000 . & $\mu \mathrm{g} / \mathrm{g}$ \\
\hline Lead & 121. & 180. & 66. & $\mu \mathrm{g} / \mathrm{g}$ \\
\hline Lithium & 23. & 37. & 16. & $\mu \mathrm{g} / \mathrm{g}$ \\
\hline Magnesium & 6,790 . & 16,000 . & 4,700 & $\mu \mathrm{g} / \mathrm{g}$ \\
\hline Manganese & 642. & 830. & 460. & $\mu \mathrm{g} / \mathrm{g}$ \\
\hline Molybdenum & 17. & 49. & 1.0 & $\mu \mathrm{g} / \mathrm{g}$ \\
\hline Nickel & 4,133 & 7,100 & 34. & $\mu \mathrm{g} / \mathrm{g}$ \\
\hline Niobium & $\leq 0.70$ & $\leq 0.70$ & $\leq 0.70$ & $\mu \mathrm{g} / \mathrm{g}$ \\
\hline Phosphorus & $\overline{12,790}$ & $\overline{2} 1,000$. & $\overline{6}, 200$ & $\mu \mathrm{g} / \mathrm{g}$ \\
\hline Potassium & 4,100 & 7,300 & 2,000 & $\mu \mathrm{g} / \mathrm{g}$ \\
\hline PCB & $\leq 0.0010$ & $\leq 0.0010$ & $\leq 0.0010$ & $\mu \mathrm{g} / \mathrm{g}$ \\
\hline Selenium & $\overline{88}$ & $\overline{140}$ & $\overline{5} .0$ & $\mu \mathrm{g} / \mathrm{g}$ \\
\hline Sodium & 1,151 & 3,100 . & 390. & $\mu \mathrm{g} / \mathrm{g}$ \\
\hline Strontium & 136. & 190. & 81. & $\mu \mathrm{g} / \mathrm{g}$ \\
\hline Thorium & 21. & 30. & 20. & $\mu \mathrm{g} / \mathrm{g}$ \\
\hline Titanium & 363. & 460. & 220. & $\mu \mathrm{g} / \mathrm{g}$ \\
\hline Vanadium & 44. & 61. & 17. & $\mu \mathrm{g} / \mathrm{g}$ \\
\hline Zinc & 607. & 810. & 480. & $\mu \mathrm{g} / \mathrm{g}$ \\
\hline Cesium & 15. & 16. & 15. & $\mathrm{dpm} / \mathrm{g}$ \\
\hline Neptunium & 7.2 & 17. & 1.3 & $\mathrm{dpm} / \mathrm{g}$ \\
\hline Plutonium & 7.1 & 19. & 1.9 & $\mathrm{dpm} / \mathrm{g}$ \\
\hline Technetium & 8,088 & 15,000 . & 2,500 . & $\mathrm{dpm} / \mathrm{g}$ \\
\hline Density & 1.1 & 1.2 & 1.1 & $\mathrm{~g} / \mathrm{mL}$ \\
\hline $\mathrm{pH} 7.0$ & 7.4 & 6.7 & & \\
\hline Uranium & 516. & 1,044 & 69. & $\mu \mathrm{g} / \mathrm{g}$ \\
\hline Uranium-235 & 1.2 & 1.3 & 1.1 & wt \% \\
\hline Acetone & $<0.0010$ & $\leq 0.0010$ & $\leq 0.0010$ & $\mu \mathrm{g} / \mathrm{g}$ \\
\hline Fluorocarbons & $\leq 0.0010$ & $\leq 0.0010$ & $\leq 0.0010$ & $\mu \mathrm{g} / \mathrm{g}$ \\
\hline Trans-1,2-dichloroethylene & $\leq 0.0030$ & $\leq 0.0030$ & $\leq 0.0030$ & $\mu \mathrm{g} / \mathrm{g}$ \\
\hline Phosphate (total) & $\overline{38,370}$ & 63,000 & $\overline{18,600}$ & $\mu \mathrm{g} / \mathrm{g}$ \\
\hline
\end{tabular}


Table B.3. Summary data for C Pond sampling (September 1988)

\begin{tabular}{|c|c|c|c|c|}
\hline Parameter & Mean & Maximum & Minimum & Units \\
\hline $\mathrm{pH}$ & 10. & 11. & 8.1 & $\mu \mathrm{g} / \mathrm{g}$ \\
\hline Aluminum & 25,392 & 42,000 & 8,500 . & $\mu \mathrm{g} / \mathrm{g}$ \\
\hline Arsenic & 20. & 97. & 5.0 & $\mu \mathrm{g} / \mathrm{g}$ \\
\hline Barium & 89. & 150. & 13. & $\mu \mathrm{g} / \mathrm{g}$ \\
\hline Beryliium & $\leq 0.030$ & $\leq 0.030$ & $\leq 0.030$ & $\mu \mathrm{g} / \mathrm{g}$ \\
\hline Boron & $\overline{4}, 252$ & 11,000 . & $\overline{85}$ & $\mu \mathrm{g} / \mathrm{g}$ \\
\hline Cadmium & 0.65 & 1.8 & 0.30 & $\mu \mathrm{g} / \mathrm{g}$ \\
\hline Calcium & 35,000 . & 90,000 . & 30,000 & $\mu \mathrm{g} / \mathrm{g}$ \\
\hline Chromium & 601. & 2,400 & 30. & $\mu \mathrm{g} / \mathrm{g}$ \\
\hline Cobalt & 51. & 210 & 2.0 & $\mu \mathrm{g} / \mathrm{g}$ \\
\hline Copper & 583. & 2,000 & 120. & $\mu \mathrm{g} / \mathrm{g}$ \\
\hline Iron & 25,185 . & 73,000 . & 2,500 & $\mu \mathrm{g} / \mathrm{g}$ \\
\hline Lead & 42. & 140. & 6.0 & $\mu \mathrm{g} / \mathrm{g}$ \\
\hline Lithium & 16. & 31. & 2.9 & $\mu \mathrm{g} / \mathrm{g}$ \\
\hline Magnesium & 7,885 . & 11,000 & $5,500$. & $\mu \mathrm{g} / \mathrm{g}$ \\
\hline Manganese & 383. & 1,000 & 73. & $\mu \mathrm{g} / \mathrm{g}$ \\
\hline Molybdenum & $\leq 1.0$ & $\leq 1.0$ & $\leq 1.0$ & $\mu \mathrm{g} / \mathrm{g}$ \\
\hline Nickel & $\overline{5}, 667$ & $\overline{2} 1,000$. & $\overline{2} 40$. & $\mu \mathrm{g} / \mathrm{g}$ \\
\hline Niobium & 2.7 & 5.3 & 0.70 & $\mu \mathrm{g} / \mathrm{g}$ \\
\hline Phosphorus & 5,016 & 1,8000 & 320. & $\mu \mathrm{g} / \mathrm{g}$ \\
\hline Potassium & 9,507 & 15,000 & 2,600 & $\mu \mathrm{g} / \mathrm{g}$ \\
\hline PCB & $\leq 0.0010$ & $\leq 0.0010$ & $\leq 0.0010$ & $\mu \mathrm{g} / \mathrm{g}$ \\
\hline Selenium & $\overline{6} .0$ & $\overline{13}$. & $\overline{5} .0$ & $\mu \mathrm{g} / \mathrm{g}$ \\
\hline Sodium & 7,388 & 15,000 & 740. & $\mu \mathrm{g} / \mathrm{g}$ \\
\hline Strontium & 111. & 150. & 95. & $\mu \mathrm{g} / \mathrm{g}$ \\
\hline Thorium & 37. & 52. & 20. & $\mu \mathrm{g} / \mathrm{g}$ \\
\hline Titanium & 361. & 770. & 110. & $\mu \mathrm{g} / \mathrm{g}$ \\
\hline Vanadium & 23. & 45. & 11. & $\mu \mathrm{g} / \mathrm{g}$ \\
\hline Zinc & 221. & 660. & 68. & $\mu \mathrm{g} / \mathrm{g}$ \\
\hline Cesium & 119. & 511. & 15. & $\mathrm{dpm} / \mathrm{g}$ \\
\hline Neptunium & 45. & 183. & 1.5 & $\mathrm{dpm} / \mathrm{g}$ \\
\hline Plutonium & 62. & 241. & 1.0 & $\mathrm{dpm} / \mathrm{g}$ \\
\hline Technetium & 3,476 & 13,600 & 293. & $\mathrm{dpm} / \mathrm{g}$ \\
\hline Density & 1.4 & 1.7 & 1.1 & $\mathrm{~g} / \mathrm{mL}$ \\
\hline Acetone & 0.32 & 1.0 & 0.10 & $\mu \mathrm{g} / \mathrm{g}$ \\
\hline Benzene & $\leq 0.040$ & $\leq 0.040$ & $\leq 0.040$ & $\mu g^{\prime}$ \\
\hline Bromodichloromethane & $\leq 0.020$ & $\leq 0.020$ & $\leq 0.020$ & $\mu g / g$ \\
\hline Bromoform & $\leq 0.050$ & $\leq 0.050$ & $\leq 0.050$ & $\mu \mathrm{g} / \mathrm{g}$ \\
\hline Carbon tetrachloride & $\leq 0.030$ & $\leq 0.030$ & $\leq 0.030$ & $\mu \mathrm{g} / \mathrm{g}$ \\
\hline Chlorobenzene & $\leq 0.060$ & $\leq 0.060$ & $\leq 0.060$ & $\mu \mathrm{g} / \mathrm{g}$ \\
\hline Chloroform & $\leq 0.020$ & $\leq 0.020$ & $\leq 0.020$ & $\mu \mathrm{g} / \mathrm{g}$ \\
\hline Cis-1,3-dichloropropene & $\leq 0.050$ & $\leq 0.050$ & $\leq 0.050$ & $\mu \mathrm{g} / \mathrm{g}$ \\
\hline Dibromochloromethane & $\leq 0.030$ & $\leq 0.030$ & $\leq 0.030$ & $\mu \mathrm{g} / \mathrm{g}$ \\
\hline Ethyl benzene & $\leq 0.070$ & $\leq 0.070$ & $\leq 0.070$ & $\mu \mathrm{g} / \mathrm{g}$ \\
\hline Freon-113 & $\overline{0} .11$ & $\overline{0.27}$ & $\overline{0} .10$ & $\mu \mathrm{g} / \mathrm{g}$ \\
\hline Freon-114 & $\leq 0.10$ & $\leq 0.10$ & $\leq 0.10$ & $\mu \mathrm{g} / \mathrm{g}$ \\
\hline Freon-123 & $\leq 0.10$ & $\leq 0.10$ & $\leq 0.10$ & $\mu \mathrm{g} / \mathrm{g}$ \\
\hline Methyl ethyl ketone & $\leq 0.10$ & $\leq 0.10$ & $\leq 0.10$ & $\mu \mathrm{g} / \mathrm{g}$ \\
\hline Methylene chloride & 0.030 & $\overline{0.040}$ & 0.030 & $\mu \mathrm{g} / \mathrm{g}$ \\
\hline Other balomethanes & $\leq 0.10$ & $\leq 0.10$ & $\leq 0.10$ & $\mu \mathrm{g} / \mathrm{g}$ \\
\hline Permethylated cyclosiloxane & $\leq .4$ & $\leqq 2.4$ & $\leq 2.4$ & $\mu \mathrm{g} / \mathrm{g}$ \\
\hline Tetrachloroethylene & $\leq 0.040$ & $\leq 0.040$ & $\leq 0.040$ & $\mu \mathrm{g} / \mathrm{g}$ \\
\hline Toluene & 0.062 & 0.090 & $\overline{0} .060$ & $\mu \mathrm{g} / \mathrm{g}$ \\
\hline Trans-1,2-dichloroethylene & $\leq 0.020$ & $\leq 0.020$ & $\leq 0.020$ & $\mu \mathrm{g} / \mathrm{g}$ \\
\hline Trans-1,3-dichloropropene & $\leq 0.050$ & $\leq 0.050$ & $\leq 0.050$ & $\mu \mathrm{g} / \mathrm{g}$ \\
\hline Trichloroethylene & $\leq 0.020$ & $\leq 0.020$ & $\leq 0.020$ & $\mu \mathrm{g} / \mathrm{g}$ \\
\hline Trichlorofluoromethane & $\leq 0.10$ & $\leq 0.10$ & $\leq 0.10$ & $\mu \mathrm{g} / \mathrm{g}$ \\
\hline Uranium & $\overline{5} 15$. & $\overline{1}, 841$. & 58. & $\mu \mathrm{g} / \mathrm{g}$ \\
\hline 1,1-dichloroethane & $\leq 0.050$ & $\leq 0.050$ & $\leq 0.050$ & $\mu \mathrm{g} / \mathrm{g}$ \\
\hline 1,1-dichloroethylene & $\leq 0.030$ & $\leq 0.030$ & $\leq 0.030$ & $\mu \mathrm{g} / \mathrm{g}$ \\
\hline $1,1,2$-trichloroethane & $\leq 0.050$ & $\leq 0.050$ & $\leq 0.050$ & $\mu \mathrm{g} / \mathrm{g}$ \\
\hline $1,1,2,2$,tetrachloroethane & $\leq 0.070$ & $\leq 0.070$ & $\leq 0.070$ & $\mu \mathrm{g} / \mathrm{g}$ \\
\hline 1,2-dichloroethane & $\leq 0.030$ & $\leq 0.030$ & $\leq 0.030$ & $\mu \mathrm{g} / \mathrm{g}$ \\
\hline 1,2-dichloropropane & $\leq 0.060$ & $\leq 0.060$ & $\leq 0.060$ & $\mu \mathrm{g} / \mathrm{g}$ \\
\hline Uranium-235 & 1.6 & $\overline{2} .6$ & $\overline{1} .3$ & wt $\%$ \\
\hline
\end{tabular}



APPENDIX C

SUMMARY OF DATA FOR SAMPLES OF SLUDGE CONTAINED IN DRUMS FROM PONDS B AND C 



\section{SUMMARY OF DATA FOR SAMPLES OF SLUDGE CONTAINED IN DRUMS FROM PONDS B AND C}

Data requirements were determined by analyzing the applicable regulations. Results of analyses required for the raw pond waste are summarized in Table C.1. Justification for each of the analyses follows. The TCLP analysis of the individual samples of sludge is necessary to classify the raw, untreated waste with respect to LDR requirements. Analysis for metals is necessary to determine whether the California list applies to the raw waste, which would result in the waste being banned from land disposal (effective July 8, 1987) and being subject to the storage prohibitions of 40 CFR Part 268.50. Radionuclide concentration data are necessary to determine whether the waste (1) would be potentially classified as Class I or Class III by Low-Level Waste Disposal Development and Demonstration (LLWDDD) and (2) would be suitable for disposal at a commercial mixed waste disposal facility. Anion data are necessary to establish the range of characteristics that a vendor may encounter during grouting operations so that, if necessary, the grout formulation can accommodate concentration variations. Total radioactivity screening is required prior to submitting the sample to the laboratory. Information on solids content is needed to establish the mass of solids being processed; this information is critical to sizing process equipment and establishing storage volume requirements. The $\mathrm{pH}$ of the waste must be checked to determine whether the level is greater than or equal to 12.5 (which would cause it to be characteristically hazardous).

Table C.2 is a listing of summary statistics for each analyses by type of sample. There were four different types of samples done: solid-solid phase, liquid-liquid phase, dry-dry sludge phase, and TCLP - wet sludge phase. In preparation for analysis, the samples were allowed to settle, and the liquid was decanted. This decanted liquid was analyzed as the liquid phase. The remaining sludge was divided into three subsamples. One of the subsamples, the dry sludge phase, was dried at $105^{\circ} \mathrm{C}$ for $24 \mathrm{~h}$. The solid phase was analyzed using the total analysis method, and the wet sludge phase was analyzed using the TCLP method. . . For each analysis and type of sample, the number of results, mean, median, minimum and maximum detected results, number of results below detection limits, minimum and maximum detection limit, number of drums, quantile for the $90 \%$ upper confidence bound, and units were recorded. The number of results for each analysis and type of sample includes analytical duplicates and field replicates; therefore, the number of results could be more than 22 and 16. Some samples did not allow all of the phases because they did not contain any liquid, were completely solid, etc. The means and medians were calculated with the detection limits set at their values, e.g., $<0.02=0.02$. The drum means were used to calculate the pond means and sample medians. The minimum and maximum of the detected results refer only to those 
results that were above detection limits. The number of detection limits refers to how many distinct detection limits there were. In most cases, there were zero, one or two detection limits. In four cases, there were ten or more distinct detection limits. These were antimony solid, pond C (16); silver - solid, pond C (14); molybdenum - solid, pond C (11); and antimony - solid, pond B (10). The quantile of the $90 \%$ upper confidence bound shows what quantile the maximum result bounds. The maximum result is listed under "Detected Results: Max." For example, we are approximately $90 \%$ confident that no more than $17 \%$ of alpha activity - solid results from pond B will be higher than $868 \mathrm{pCi} / \mathrm{g}$. Another way to say this is there is approximately $90 \%$ confidence that $83 \%$ of the alpha activity - solid results for pond $\mathrm{B}$ samples will be less than $868 \mathrm{pCi} / \mathrm{g}$. The reason this quantile changes is because the number of drums sampled is not the same for all the analyses. ${ }^{30}$

Table C.1. Analyses required for raw pond waste

\begin{tabular}{|c|c|c|c|}
\hline Analyte & $\begin{array}{l}\text { Individual } \\
\text { liquid }\end{array}$ & $\begin{array}{l}\text { Individual } \\
\text { sludge }\end{array}$ & $\frac{\text { Dried siudge }}{\text { Composite Individual }}$ \\
\hline TCLP $^{a}$ & & $\mathrm{X}$ & $\mathbf{X}$ \\
\hline Metals (28 elements) ${ }^{a}$ & $\mathbf{X}$ & $\mathrm{X}$ & $\mathrm{X}$ \\
\hline Total organic carbon & $\mathbf{X}$ & $\mathrm{X}$ & $\mathbf{X}$ \\
\hline $\begin{array}{l}\text { Anions }\left(\mathrm{Cl}, \mathrm{F}, \mathrm{SO}_{4}\right. \\
\left.\mathrm{PO}_{4}, \mathrm{NO}_{3}\right)\end{array}$ & $\mathbf{X}$ & $\mathbf{X}$ & $\mathbf{X}$ \\
\hline Uranium & & $\mathbf{X}$ & $\mathbf{X}$ \\
\hline U-235 & & & $\mathbf{X}$ \\
\hline AA metals (As, $\mathrm{Pb}, \mathrm{Se}, \mathrm{Tl}$ ) & $\mathbf{X}$ & $\mathrm{X}$ & $\mathbf{X}$ \\
\hline Mercury & & $\mathbf{X}$ & $\mathbf{X}$ \\
\hline Alpha, beta, gamma & $\mathbf{X}$ & $\mathbf{X}$ & $\mathbf{X}$ \\
\hline Total activity screen & $\mathbf{X}$ & $\mathbf{X}$ & $\mathbf{X}$ \\
\hline $\mathrm{pH}$ & & & $\mathbf{X}$ \\
\hline Density & $\mathbf{X}$ & $\mathbf{X}$ & $\mathbf{X}$ \\
\hline Total dissolved solids & $\mathbf{X}$ & $\mathbf{X}$ & $\mathbf{X}$ \\
\hline Total solids & $\mathbf{X}$ & $\mathbf{X}$ & \\
\hline Technetium-99 & $\mathbf{X}$ & $\mathrm{X}$ & \\
\hline $\begin{array}{l}\text { Thorium, plutonium, } \\
\text { neptunium }\end{array}$ & $\mathbf{X}$ & $\mathbf{X}$ & \\
\hline $\operatorname{VOA}^{b}$ & $\mathbf{X}$ & & \\
\hline PCB & $\mathbf{X}$ & & \\
\hline $\mathrm{BNA}^{c}$ & $\mathbf{X}$ & & \\
\hline Pesticides and herbicides & $\mathbf{X}$ & & \\
\hline Cyanides & $\mathbf{X}$ & & \\
\hline Oil and grease & $\mathbf{X}$ & & \\
\hline
\end{tabular}

aPriority samples.

${ }^{b} \mathrm{VOA}=$ volatile organic analysis .

BNA = base neutral acid (semivolatile). 
Table C.2. Summary of results from the K-1407-B holding pond and the K-1407-C retention basin

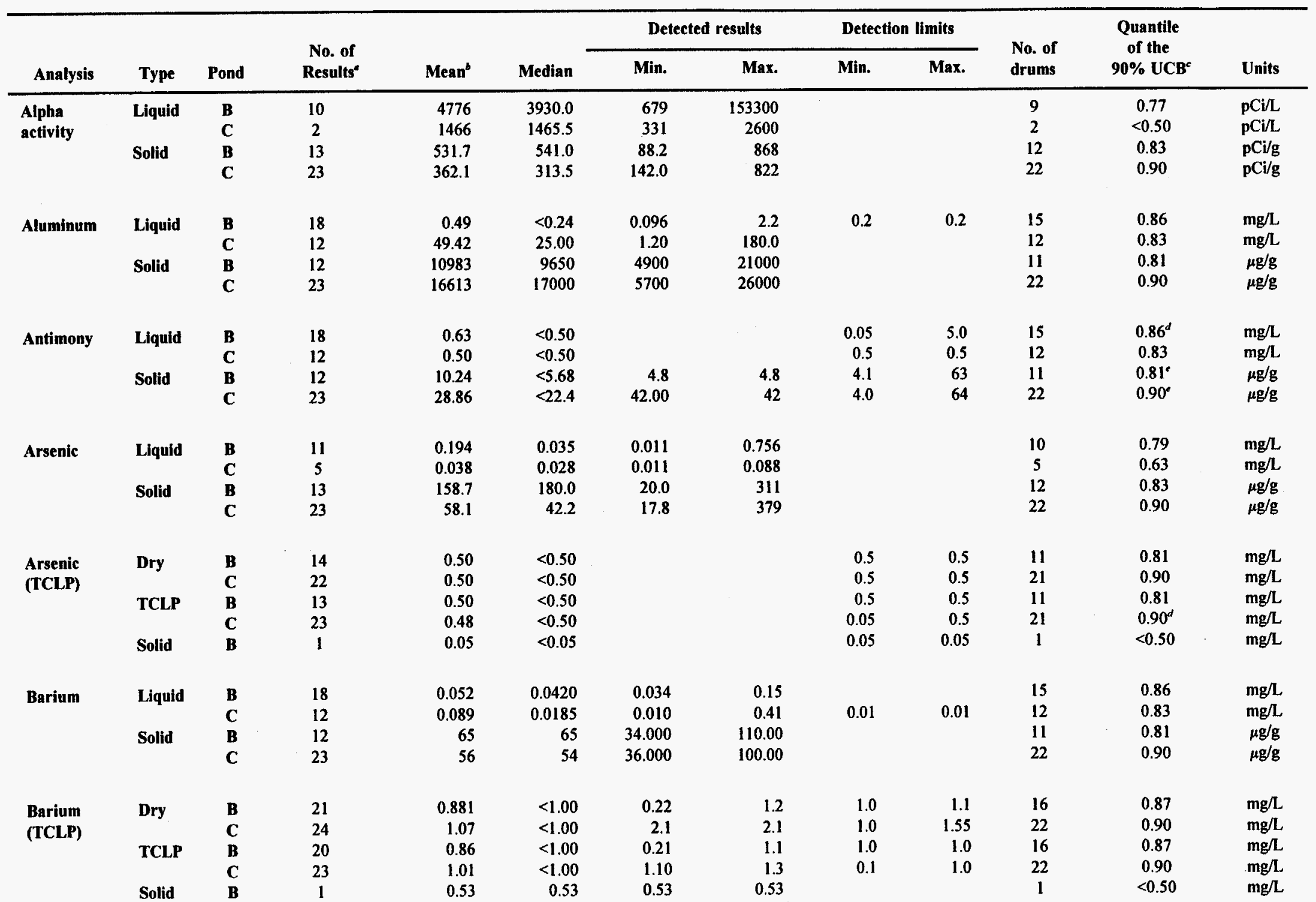


Table C.2 (continued)

\begin{tabular}{|c|c|c|c|c|c|c|c|c|c|c|c|c|}
\hline \multirow[b]{2}{*}{ Analysis } & \multirow[b]{2}{*}{ Type } & \multirow[b]{2}{*}{ Pond } & \multirow{2}{*}{$\begin{array}{l}\text { No. of } \\
\text { Results" }\end{array}$} & \multirow[b]{2}{*}{ Mean $^{6}$} & \multirow[b]{2}{*}{ Median } & \multicolumn{2}{|c|}{ Detected results } & \multicolumn{2}{|c|}{ Detection limits } & \multirow{2}{*}{$\begin{array}{l}\text { No. of } \\
\text { drums }\end{array}$} & \multirow{2}{*}{$\begin{array}{l}\text { Quantile } \\
\text { of the } \\
90 \% \mathrm{UCB}^{c}\end{array}$} & \multirow[b]{2}{*}{ Units } \\
\hline & & & & & & Min. & Max. & Min. & Max. & & & \\
\hline \multirow[t]{4}{*}{ Beryllium } & Liquid & $\mathbf{B}$ & 18 & 0.004 & $<0.003$ & 0.0003 & 0.0003 & 0.003 & 0.03 & 15 & $0.86^{e}$ & $\mathrm{mg} / \mathrm{L}$ \\
\hline & & C & 12 & 0.003 & $<0.003$ & 0.0031 & 0.0034 & 0.003 & 0.03 & 12 & $0.83^{e}$ & $\mathrm{mg} / \mathrm{L}$ \\
\hline & Solid & $\mathbf{B}$ & 12 & 0.66 & 0.615 & 0.36 & 0.96 & & & 11 & 0.81 & $\mu \mathrm{g} / \mathrm{g}$ \\
\hline & & C & 23 & 0.43 & 0.430 & 0.25 & 0.93 & 0.26 & 0.38 & 22 & 0.90 & $\mu \mathrm{g} / \mathrm{g}$ \\
\hline \multirow[t]{4}{*}{ Beta activity } & Liquid & B & 10 & 13268 & 7605 & 2320 & 62300 & & & 9 & 0.77 & $\mathrm{pCi} / \mathrm{L}$ \\
\hline & & C & 2 & 6995 & 6995 & 4630 & 9360 & & & 2 & $<0.50$ & $\mathrm{pCi} / \mathrm{L}$ \\
\hline & Solld & B & 13 & 1892 & 1350 & 328 & 4570 & & & 12 & 0.83 & $\mathrm{pCi} / \mathrm{g}$ \\
\hline & & $\mathbf{C}$ & 23 & 825 & 749 & 242 & 2450 & & & 22 & 0.90 & $\mathrm{pCi} / \mathrm{g}$ \\
\hline \multirow[t]{4}{*}{ Boron } & Liquid & $\mathbf{B}$ & 18 & 2.21 & 2.10 & 0.46 & 5.90 & & & 15 & 0.86 & $\mathrm{mg} / \mathrm{L}$ \\
\hline & & $\mathbf{C}$ & 12 & 0.50 & 0.47 & 0.20 & 0.86 & & & 12 & 0,83 & $\mathrm{mg} / \mathrm{L}$ \\
\hline & Solid & $\mathbf{B}$ & 4 & 11.5 & 10.50 & 9.0 & 16.0 & & & 4 & 0.56 & $\mu \mathrm{g} / \mathrm{g}$ \\
\hline & & C & 2 & 65.0 & 65.00 & 59.0 & 71.0 & & & 2 & $<0.50$ & $\mu \mathrm{g} / \mathrm{g}$ \\
\hline \multirow[t]{4}{*}{ Cadmium } & Liquid & B & 18 & 0.040 & $<0.03$ & & & 0.003 & 0.3 & 15 & $0.86^{d}$ & $\mathrm{mg} / \mathrm{L}$ \\
\hline & & C & 12 & 0.030 & $<0.03$ & & & 0.03 & 0.03 & 12 & 0.83 & $\mathrm{mg} / \mathrm{L}$ \\
\hline & Solid & B & 12 & 2.4 & 2.45 & 1.00 & 3.3 & 3.8 & 3.8 & 11 & $0.81^{\circ}$ & $\mu \mathrm{g} / \mathrm{g}$ \\
\hline & & $\mathrm{C}$ & 23 & 2.2 & 1.95 & 0.92 & 2.5 & 1.95 & 3.8 & 22 & $0.90^{\circ}$ & $\mu \mathrm{g} / \mathrm{g}$ \\
\hline \multirow{5}{*}{$\begin{array}{l}\text { Cadmium } \\
\text { (TCLP) }\end{array}$} & Dry & B & 21 & 0.0280 & $<0.030$ & 0.0036 & 0.051 & 0.003 & 0.03 & 16 & 0.87 & $\mathrm{mg} / \mathrm{L}$ \\
\hline & & $\mathbf{C}$ & 24 & 0.03 & $<0.030$ & & & 0.03 & 0.03 & 22 & 0.90 & $\mathrm{mg} / \mathrm{L}$ \\
\hline & TCLP & $\mathbf{B}$ & 20 & 0.0260 & $<0.030$ & 0.0039 & 0.040 & 0.003 & 0.03 & 16 & 0.87 & $\mathrm{mg} / \mathrm{L}$ \\
\hline & & C & 25 & 0.029 & $<0.030$ & & & 0.003 & 0.03 & 22 & $0.90^{d}$ & $\mathrm{mg} / \mathrm{L}$ \\
\hline & Solid & B & 1 & 0.003 & $<0.003$ & & & 0.003 & & 1 & $<0.50$ & $\mathrm{mg} / \mathrm{L}$ \\
\hline \multirow[t]{4}{*}{ Calcium } & Liquid & B & 18 & 587 & 660 & 230 & 770 & & & 15 & 0.86 & $\mathrm{mg} / \mathrm{L}$ \\
\hline & & C & 12 & 78.5 & 23.5 & 9.9 & 320 & & & 12 & 0.83 & $\mathrm{mg} / \mathrm{L}$ \\
\hline & Solid & $\mathbf{B}$ & 12 & 32808 & 19000 & 6700 & 96000 & & & 11 & 0.81 & $\mu \mathrm{g} / \mathrm{g}$ \\
\hline & & C & 23 & 76265 & 81000 & 3500 & 180000 & & & 22 & 0.90 & $\mu \mathrm{g} / \mathrm{g}$ \\
\hline \multirow[t]{4}{*}{ Cesium-137 } & Dry & B & 10 & 35.22 & 23.60 & -3.07 & 109.0 & & & 9 & 0.77 & $\mathrm{pCi} / \mathrm{L}$ \\
\hline & & C & 2 & 81.25 & 81.25 & 58.50 & 104.0 & & & 2 & $<0.50$ & $\mathrm{pCi} / \mathrm{L}$ \\
\hline & TCLP & $\mathbf{B}$ & 13 & 6.17 & 4.43 & 0.622 & 21.8 & & & 12 & 0.83 & $\mathrm{pCi} / \mathrm{g}$ \\
\hline & & C & 23 & 21.01 & 16.00 & 4.64 & 50.0 & & & 22 & 0.90 & $\mathrm{pCi} / \mathrm{g}$ \\
\hline
\end{tabular}


Table C.2 (continued)

\begin{tabular}{|c|c|c|c|c|c|c|c|c|c|c|c|c|}
\hline \multirow[b]{2}{*}{ Analysis } & \multirow[b]{2}{*}{ Type } & \multirow[b]{2}{*}{ Pond } & \multirow{2}{*}{$\begin{array}{l}\text { No. of } \\
\text { Results" }\end{array}$} & \multirow[b]{2}{*}{ Mean $^{6}$} & \multirow[b]{2}{*}{ Median } & \multicolumn{2}{|c|}{ Detected results } & \multicolumn{2}{|c|}{ Detection limits } & \multirow{2}{*}{$\begin{array}{l}\text { No. of } \\
\text { drums }\end{array}$} & \multirow{2}{*}{$\begin{array}{c}\text { Quantile } \\
\text { of the } \\
90 \% \mathrm{UCB}^{\mathrm{c}}\end{array}$} & \multirow[b]{2}{*}{ Units } \\
\hline & & & & & & Min. & Max. & Min. & Max. & & & \\
\hline \multirow[t]{4}{*}{ Chloride IC } & Liquid & $\mathbf{B}$ & 12 & 298.5 & 307 & 90 & 432 & & & 11 & 0.81 & $\mathrm{mg} / \mathrm{L}$ \\
\hline & & $\mathbf{C}$ & 8 & 169.6 & 162 & 113 & 270.0 & & & 8 & 0.75 & $\mathrm{mg} / \mathrm{L}$ \\
\hline & Solid & $\mathbf{B}$ & 14 & 179.8 & 183 & 28 & 305 & 100 & 100 & 13 & 0.84 & $\mu \mathrm{g} / \mathrm{g}$ \\
\hline & & $\mathbf{C}$ & 23 & 106.6 & $<100$ & 75 & 245.0 & 50 & 100 & 22 & 0.90 & $\mu \mathrm{g} / \mathrm{g}$ \\
\hline \multirow[t]{4}{*}{ Chromium } & Liquid & $\mathbf{B}$ & 18 & 0.126 & $<0.1$ & 0.021 & 0.021 & 0.01 & 1 & 15 & $0.86^{\circ}$ & $\mathrm{mg} / \mathrm{L}$ \\
\hline & & C & 12 & 0.224 & $<0.1$ & 0.110 & 0.97 & 0.1 & 0.1 & 12 & 0.83 & $\mathrm{mg} / \mathrm{L}$ \\
\hline & Solid & $\mathbf{B}$ & 12 & 190 & 207.5 & 86 & 330 & & & 11 & 0.81 & $\mu \mathrm{g} / \mathrm{g}$ \\
\hline & & C & 23 & 156 & 125.0 & 48 & 510 & & & 22 & 0.90 & $\mu \mathrm{g} / \mathrm{g}$ \\
\hline \multirow{5}{*}{$\begin{array}{l}\text { Chromium } \\
\text { (TCLP) }\end{array}$} & Dry & $\mathbf{B}$ & 21 & 0.08 & $<0.10$ & & & 0.01 & 0.1 & 16 & $0.87^{d}$ & $\mathrm{mg} / \mathrm{L}$ \\
\hline & & C & 24 & 0.12 & $<0.10$ & 0.13 & 0.35 & 0.1 & 0.1 & 22 & 0.90 & $\mathrm{mg} / \mathrm{L}$ \\
\hline & TCLP & $\mathbf{B}$ & 20 & 0.08 & $<0.10$ & & & 0.01 & 0.1 & 16 & $0.87^{d}$ & $\mathrm{mg} / \mathrm{L}$ \\
\hline & & C & 25 & 0.10 & $<0.10$ & 0.24 & 0.24 & 0.01 & 0.1 & 22 & 0.90 & $\mathrm{mg} / \mathrm{L}$ \\
\hline & Solid & B & 1 & 0.01 & $<0.01$ & & & 0.01 & 0.01 & 1 & $<0.50$ & $\mathrm{mg} / \mathrm{L}$ \\
\hline \multirow[t]{4}{*}{ Cobalt } & Liquid & $\mathbf{B}$ & 18 & 0.063 & $<0.05$ & & & 0.005 & 0.5 & 15 & $0.86^{d}$ & $\mathrm{mg} / \mathrm{L}$ \\
\hline & & C & 12 & 0.054 & $<0.05$ & 0.076 & 0.077 & 0.05 & 0.05 & 12 & 0.83 & $\mathrm{mg} / \mathrm{L}$ \\
\hline & Solid & B & 12 & 15.4 & 14.50 & 11.0 & 25.0 & & & 11 & 0.81 & $\mu \mathrm{g} / \mathrm{g}$ \\
\hline & & C & 23 & 14.7 & 13.00 & 6.8 & 26.0 & & & 22 & 0.90 & $\mu \mathrm{g} / \mathrm{g}$ \\
\hline \multirow[t]{4}{*}{ Copper } & Liquid & B & 18 & 0.0543 & $<0.040$ & 0.0051 & 0.45 & 0.004 & 0.04 & 15 & 0.86 & $\mathrm{mg} / \mathrm{L}$ \\
\hline & & C & 12 & 0.291 & 0.104 & 0.069 & 1.20 & 0.04 & 0.04 & 12 & 0.83 & $\mathrm{mg} / \mathrm{L}$ \\
\hline & Solid & $\mathbf{B}$ & 12 & 195 & 220.0 & 100 & 290 & & & 11 & 0.81 & $\mu \mathrm{g} / \mathrm{g}$ \\
\hline & & $\mathbf{C}$ & 23 & 143 & 140.0 & 71 & 270 & & & 22 & 0.90 & $\mu \mathrm{g} / \mathrm{g}$ \\
\hline \multirow[t]{4}{*}{ Density } & Liquid & B & 12 & 0.9859 & 0.9857 & 0.9806 & 0.996 & & & 11 & 0.81 & $\mathrm{~g} / \mathrm{mL}$ \\
\hline & & C & 8 & 0.9950 & 0.9894 & 0.9838 & 1.023 & & & 8 & 0.75 & $\mathrm{~g} / \mathrm{mL}$ \\
\hline & Solid & $\mathbf{B}$ & 14 & 1.35 & 1.31 & 1.11 & 1.74 & & & 13 & 0.84 & $\mathrm{~g} / \mathrm{mL}$ \\
\hline & & C & 23 & 1.46 & 1.46 & 0.92 & 1.84 & & & 22 & 0.90 & $\mathrm{~g} / \mathrm{mL}$ \\
\hline \multirow{2}{*}{$\begin{array}{l}\text { Dissolved } \\
\text { solids }\end{array}$} & Liquid & B & 12 & 3459 & 3394 & 2804 & 4426 & & & 11 & 0.81 & $\mathrm{mg} / \mathrm{L}$ \\
\hline & & C & 7 & 2526 & 2545 & 2058 & 2811 & & & 7 & 0.72 & $\mathrm{mg} / \mathrm{L}$ \\
\hline
\end{tabular}


Table C.2 (continued)

\begin{tabular}{|c|c|c|c|c|c|c|c|c|c|c|c|c|}
\hline \multirow[b]{2}{*}{ Analysis } & \multirow[b]{2}{*}{ Type } & \multirow[b]{2}{*}{ Pond } & \multirow{2}{*}{$\begin{array}{l}\text { No. of } \\
\text { Results }\end{array}$} & \multirow[b]{2}{*}{ Mean' } & \multirow[b]{2}{*}{ Median } & \multicolumn{2}{|c|}{ Detected results } & \multicolumn{2}{|c|}{ Detection limits } & \multirow{2}{*}{$\begin{array}{l}\text { No. of } \\
\text { drums }\end{array}$} & \multirow{2}{*}{$\begin{array}{l}\text { Quantile } \\
\text { of the } \\
90 \% \mathrm{UCB}\end{array}$} & \multirow[b]{2}{*}{ Units } \\
\hline & & & & & & Min. & Max. & Min. & Max. & & & \\
\hline \multirow[t]{4}{*}{ Fluoride SIE } & Liquid & B & 12 & 3.1 & 2.9 & 2.3 & 5 & & & 11 & .81 & $\mathrm{mg} / \mathrm{L}$ \\
\hline & & C & 8 & 13.1 & 11.5 & 4.8 & 28 & & & 8 & 0.75 & $\mathrm{mg} / \mathrm{L}$ \\
\hline & Solid & $\mathbf{B}$ & 14 & 49 & 29 & 19 & 300 & & & 13 & 0.84 & $\mu \mathrm{g} / \mathrm{g}$ \\
\hline & & C & 23 & 121 & 140 & 15 & 320 & & & 22 & 0.90 & $\mu \mathrm{g} / \mathrm{g}$ \\
\hline \multirow[t]{3}{*}{ Gamma Activity } & Liquid & $\mathbf{B}$ & & & & & & & & & & $\mathrm{pCi} / \mathrm{L}$ \\
\hline & & C & & & & & & & & & & $\mathrm{pCi} / \mathrm{L}$ \\
\hline & Solid & $\mathbf{B}$ & & & & & & & & & & $\mathrm{pCi} / \mathrm{g}$ \\
\hline \multirow[t]{6}{*}{ Lead } & Liquid & B & 11 & 0.0818 & 0.0134 & 0.001 & 0.2940 & & & 10 & 0.79 & $\mathrm{mg} / \mathrm{L}$ \\
\hline & & $\mathbf{C}$ & 5 & 0.0167 & 0.0038 & 4 & 0.0543 & & & 5 & 0.63 & $\mathrm{mg} / \mathrm{L}$ \\
\hline & Solid & $\mathbf{B}$ & 13 & 104.1 & 124 & 0.002 & 139 & & & 12 & 0.83 & $\mu \mathrm{g} / \mathrm{g}$ \\
\hline & & $\mathbf{C}$ & 23 & 50.8 & 45 & 2 & 187 & & & 22 & 0.90 & $\mu \mathrm{g} / \mathrm{g}$ \\
\hline & & & & & & 49.0 & & & & & & \\
\hline & & & & & & 32.8 & & & & & & \\
\hline \multirow[t]{5}{*}{ Lead (TCLP) } & Dry & B & 21 & 0.41 & $<0.5$ & & & 0.05 & 0.5 & 16 & $0.87^{d}$ & $\mathrm{mg} / \mathrm{L}$ \\
\hline & & C & 24 & 0.50 & $<0.5$ & & & 0.5 & 0.5 & 22 & 0.90 & $\mathrm{mg} / \mathrm{L}$ \\
\hline & TCLP & B & 20 & 0.41 & $<0.5$ & & & 0.05 & 0.5 & 16 & $0.87^{d}$ & $\mathrm{mg} / \mathrm{L}$ \\
\hline & & C & 25 & 0.48 & $<0.5$ & & & 0.05 & 0.5 & 22 & $0.90^{d}$ & $\mathrm{mg} / \mathrm{L}$ \\
\hline & Solid & B & 1 & 0.05 & $<0.05$ & & & 0.05 & 0.05 & 1 & & $\mathrm{mg} / \mathrm{L}$ \\
\hline \multirow[t]{4}{*}{ Magnesium } & Liquid & B & 18 & 106.8 & 110.0 & 51 & 160 & & & 15 & 0.86 & $\mathrm{mg} / \mathrm{L}$ \\
\hline & & C & 12 & 3.447 & 0.675 & 0.078 & 16 & 0.03 & 0.03 & 12 & 0.83 & $\mathrm{mg} / \mathrm{L}$ \\
\hline & Solid & B & 12 & 2042 & 1750 & 1100 & 3000 & & & 11 & 0.81 & $\mu \mathrm{g} / \mathrm{g}$ \\
\hline & & C & 23 & 2522 & 2700 & 1000 & 4100 & & & 22 & 0.90 & $\mu \mathrm{g} / \mathrm{g}$ \\
\hline \multirow[t]{4}{*}{ Manganese } & Liquid & B & 18 & 3.31 & 2.20 & 0.9 & 9.4 & & & 15 & 0.86 & $\mathrm{mg} / \mathrm{L}$ \\
\hline & & C & 12 & 0.36 & 0.068 & 0.027 & 1.8 & 0.01 & 0.01 & 12 & 0.83 & $\mathrm{mg} / \mathrm{L}$ \\
\hline & Solid & B & 12 & 488 & 260 & 150 & 2100 & & & 11 & 0.81 & $\mu \mathrm{g} / \mathrm{g}$ \\
\hline & & C & 23 & 498 & 460 & 120 & 1100 & & & 22 & 0.90 & $\mu \mathrm{g} / \mathrm{g}$ \\
\hline \multirow[t]{4}{*}{ Mercury } & Liquid & B & 19 & 0.0761 & 0.0440 & 0.002 & 0.72 & 0.02 & 0.056 & 16 & 0.87 & $\mathrm{mg} / \mathrm{L}$ \\
\hline & & $\mathbf{C}$ & 12 & 0.2309 & 0.1010 & 0.025 & 0.95 & 0.02 & 0.02 & 12 & 0.83 & $\mathrm{mg} / \mathrm{L}$ \\
\hline & Solid & B & 12 & 19.7 & 14.425 & 2.7 & 49.0 & & & 11 & 0.81 & $\mu \mathrm{g} / \mathrm{g}$ \\
\hline & & $\mathrm{C}$ & 23 & 25.4 & 15.0 & 4.7 & 81.0 & & & 22 & 0.90 & $\mu \mathrm{g} / \mathrm{g}$ \\
\hline
\end{tabular}


Table C.2 (continued)

\begin{tabular}{|c|c|c|c|c|c|c|c|c|c|c|c|c|}
\hline \multirow[b]{2}{*}{ Analysis } & \multirow[b]{2}{*}{ Type } & \multirow[b]{2}{*}{ Pond } & \multirow{2}{*}{$\begin{array}{l}\text { No. of } \\
\text { Results" }\end{array}$} & \multirow[b]{2}{*}{ Mean ${ }^{b}$} & \multirow[b]{2}{*}{ Median } & \multicolumn{2}{|c|}{ Detected results } & \multicolumn{2}{|c|}{ Detection limits } & \multirow{2}{*}{$\begin{array}{l}\text { No. of } \\
\text { drums }\end{array}$} & \multirow{2}{*}{$\begin{array}{l}\text { Quantile } \\
\text { of the } \\
90 \% \mathrm{UCB}^{\mathrm{c}}\end{array}$} & \multirow[b]{2}{*}{ Units } \\
\hline & & & & & & Min. & Max. & Min. & Max. & & & \\
\hline \multirow[t]{5}{*}{ Mercury (TCLP) } & Dry & B & 21 & 0.0332 & 0.0200 & 0.0100 & 0.400 & 0.002 & 0.02 & 16 & 0.87 & $\mathrm{mg} / \mathrm{L}$ \\
\hline & & $\mathbf{C}$ & 24 & 0.0760 & 0.0375 & 0.0046 & 0.280 & 0.02 & 0.02 & 22 & 0.90 & $\mathrm{mg} / \mathrm{L}$ \\
\hline & TCLP & B & 20 & 0.0135 & $<0.0200$ & 0.0055 & 0.020 & 0.0002 & 0.02 & 16 & 0.87 & $\mathrm{mgl}$ \\
\hline & & C & 25 & 0.0240 & 0.0200 & 0.0047 & 0.067 & 0.02 & 0.02 & 22 & 0.90 & $\mathrm{mg} / \mathrm{L}$ \\
\hline & Solid & B & & & & & & & & & & $\mathrm{mg} / \mathrm{L}$ \\
\hline \multirow{2}{*}{ Molybdenum } & Solid & B & 12 & 3.88 & 3.35 & 1.70 & 5.5 & 0.86 & 13 & 11 & $0.81^{e}$ & $\mu \mathrm{g} / \mathrm{g}$ \\
\hline & & C & 23 & 5.99 & 3.40 & 0.96 & 8.4 & 0.81 & 13 & 22 & $0.90^{\circ}$ & $\mu \mathrm{g} / \mathrm{g}$ \\
\hline \multirow[t]{2}{*}{ Neptunium-237 } & Solid & B & 13 & 13.59 & 9.7 & 1.42 & 46.2 & & & 12 & 0.83 & pCi/g \\
\hline & & C & 23 & 22.17 & 16.2 & 6.60 & 62.7 & & & 22 & 0.90 & $\mathrm{pCi} / \mathrm{g}$ \\
\hline \multirow[t]{4}{*}{ Nickel } & Liquid & B & 18 & 0.62 & 0.600 & 0.07 & 1.2 & & & 15 & 0.86 & $\mathrm{mg} / \mathrm{L}$ \\
\hline & & C & 12 & 1.347 & 0.495 & 0.130 & 4.5 & & & 12 & 0.83 & $\mathrm{mg} / \mathrm{L}$ \\
\hline & Solld & B & 12 & 1014 & 1050 & 590 & 1400 & & & 11 & 0.81 & $\mu \mathrm{g} / \mathrm{g}$ \\
\hline & & C & 23 & 1042 & 830 & 270 & 2200 & & & 22 & 0.90 & $\mu \mathrm{g} / \mathrm{g}$ \\
\hline \multirow{5}{*}{ Nickel (TCLP) } & Dry & B & 21 & 8.85 & 8.10 & 1.80 & 15.0 & & & 16 & 0.87 & $\mathrm{mg} / \mathrm{L}$ \\
\hline & & C & 24 & 5.05 & 3.55 & 0.59 & 16.0 & & & 22 & 0.90 & $\mathrm{mg} / \mathrm{L}$ \\
\hline & TCLP & B & 20 & 4.31 & 3.25 & 2.10 & 12.0 & & & 16 & 0.87 & $\mathrm{mg} / \mathrm{L}$ \\
\hline & & C & 25 & 3.61 & 3.10 & 0.27 & 9.5 & & & 22 & 0.90 & $\mathrm{mg} / \mathrm{L}$ \\
\hline & Solid & B & 1 & 0.05 & $<0.05$ & & & 0.05 & 0.05 & 1 & $<0.50$ & $\mathrm{mg} / \mathrm{L}$ \\
\hline \multirow[t]{4}{*}{ Nitrate } & Liquid & B & 12 & 40 & $<50$ & & & 5 & 50 & 11 & $0.81^{d}$ & $\mathrm{mg} / \mathrm{L}$ \\
\hline & & C & 8 & 40 & $<50$ & & & 5 & 50 & 8 & $0.75^{d}$ & $\mathrm{mg} / \mathrm{L}$ \\
\hline & Solid & B & 14 & 33 & $<23$ & & & 2 & 100 & 13 & $0.84^{d}$ & $\mu \mathrm{g} / \mathrm{g}$ \\
\hline & & C & 23 & 52 & $<50$ & & & 10 & 100 & 22 & $0.90^{d}$ & $\mu \mathrm{g} / \mathrm{g}$ \\
\hline \multirow[t]{2}{*}{ Plutonium-238 } & Solid & B & 13 & 0.2096 & 0.20 & 0.0000 & 0.510 & & & 12 & 0.83 & $\mathrm{pCi} / \mathrm{g}$ \\
\hline & & C & 23 & 0.3358 & 0.31 & 0.0863 & 0.885 & & & 22 & 0.90 & pCi $/ g$ \\
\hline \multirow[t]{2}{*}{ Plutonium-239 } & Solid & B & 13 & 10.384 & 11.9 & 0.551 & 21.9 & & & 12 & 0.83 & pCi/g \\
\hline & & C & 23 & 23.663 & 17.6 & 0.181 & 62.2 & & & 22 & 0.90 & $\mathrm{pCi} / \mathrm{g}$ \\
\hline \multirow[t]{2}{*}{ Potassium } & Solid & B & 12 & 1595 & 1350 & 370 & 3700 & & & 11 & 0.81 & $\mu \mathrm{g} / \mathrm{g}$ \\
\hline & & C & 23 & 3182 & 3300 & 490 & 5200 & & & 22 & 0.90 & $\mu \mathrm{g} / \mathrm{g}$ \\
\hline
\end{tabular}


Table C.2 (continued)

\begin{tabular}{|c|c|c|c|c|c|c|c|c|c|c|c|c|}
\hline \multirow[b]{2}{*}{ Analysis } & \multirow[b]{2}{*}{ Type } & \multirow[b]{2}{*}{ Pond } & \multirow{2}{*}{$\begin{array}{l}\text { No. of } \\
\text { Results" }\end{array}$} & \multirow[b]{2}{*}{ Mean' } & \multirow[b]{2}{*}{ Median } & \multicolumn{2}{|c|}{ Detected results } & \multicolumn{2}{|c|}{ Detection limits } & \multirow{2}{*}{$\begin{array}{l}\text { No. of } \\
\text { drums }\end{array}$} & \multirow{2}{*}{$\begin{array}{l}\text { Quantile } \\
\text { of the } \\
90 \% \mathrm{UCB}^{c}\end{array}$} & \multirow[b]{2}{*}{ Units } \\
\hline & & & & & & Min. & Max. & Min. & Max. & & & \\
\hline \multirow{4}{*}{$\begin{array}{l}\text { Protactinium- } \\
234 \mathrm{~m}\end{array}$} & Liquid & $\mathbf{B}$ & 10 & 7153.5 & 51115 & -825 & 21800 & & & 9 & 0.77 & $\mathrm{pCi} / \mathrm{L}$ \\
\hline & & $\mathrm{C}$ & 2 & 12180.0 & 12180 & 8260 & 16100 & & & 2 & $<0.50$ & $\mathrm{pCi} / \mathrm{L}$ \\
\hline & Solid & $\mathbf{B}$ & 13 & 359.1 & 422 & 34 & 720 & & & 12 & 0.83 & $\mathrm{pCi} / \mathrm{g}$ \\
\hline & & C & 23 & 438.8 & 413 & 116 & 865 & & & 22 & 0.90 & $\mathrm{pCi} / \mathrm{g}$ \\
\hline \multirow[t]{4}{*}{ Selenium } & Liquid & $\mathbf{B}$ & 11 & 0.0071 & 0.007 & 0.0020 & 0.0168 & & & 10 & 0.79 & $\mathrm{mg} / \mathrm{L}$ \\
\hline & & $\bar{C}$ & 5 & 0.0097 & 0.01 & 0.0086 & 0.0100 & & & 5 & 0.63 & $\mathrm{mg} / \mathrm{L}$ \\
\hline & Solid & B & 13 & 4.64 & 5.42 & 0.79 & 9.54 & & & 12 & 0.83 & $\mu \mathrm{g} / \mathrm{g}$ \\
\hline & & $\mathrm{C}$ & 23 & 1.95 & 1.38 & 0.74 & 13.6 & & & 22 & 0.90 & $\mu \mathrm{g} / \mathrm{g}$ \\
\hline \multirow{5}{*}{$\begin{array}{l}\text { Selenium } \\
\text { (TCLP) }\end{array}$} & Dry & $\mathbf{B}$ & 21 & 0.41 & $<0.50$ & & & 0.05 & 0.5 & 16 & $0.87^{d}$ & $\mathrm{mg} / \mathrm{L}$ \\
\hline & & $\mathbf{C}$ & 24 & 0.50 & $<0.50$ & & & 0.5 & 0.5 & 22 & 0.90 & $\mathrm{mg} / \mathrm{L}$ \\
\hline & TCLP & $\mathbf{B}$ & 20 & 0.41 & $<0.50$ & & & 0.05 & 0.5 & 16 & $0.87^{d}$ & $\mathrm{mg} / \mathrm{L}$ \\
\hline & & $\mathbf{C}$ & 25 & 0.48 & $<0.50$ & & & 0.05 & 0.5 & 22 & $0.90^{d}$ & $\mathrm{mg} / \mathrm{L}$ \\
\hline & Solld & B & 1 & 0.05 & $<0.05$ & & & 0.05 & 0.05 & 1 & $<0.50$ & $\mathrm{mg} / \mathrm{L}$ \\
\hline \multirow[t]{2}{*}{ Silicon } & Solid & B & 4 & 423 & 415 & 230 & 630 & & & 4 & 0.56 & $\mu \mathrm{g} / \mathrm{g}$ \\
\hline & & C & 2 & 360 & 360 & 350 & 370 & & & 2 & $<0.50$ & $\begin{array}{l}\mu \mathrm{g} / \mathrm{g} \\
\mu \mathrm{g}\end{array}$ \\
\hline \multirow[t]{4}{*}{ Silver } & Liquid & $\mathbf{B}$ & 18 & 0.075 & $<0.06$ & & & 0.006 & 0.6 & 15 & $0.86^{d}$ & $\mathrm{mg} / \mathrm{L}$ \\
\hline & & C & 12 & 0.060 & $<0.06$ & 0.063 & 0.063 & 0.06 & 0.06 & 12 & 0.83 & $\mathrm{mg} / \mathrm{L}$ \\
\hline & Solid & B & 12 & 1.65 & 1.20 & 0.73 & 1.5 & 0.57 & 7.5 & 11 & $0.81^{\circ}$ & $\mu \mathrm{g} / \mathrm{g}$ \\
\hline & & C & 23 & 3.51 & $<2.685$ & 0.55 & 6.0 & 0.48 & 7.6 & 22 & $0.90^{\circ}$ & $\mu \mathrm{g} / \mathrm{g}$ \\
\hline \multirow{5}{*}{$\begin{array}{l}\text { Silver } \\
\text { (TCLP) }\end{array}$} & Dry & $\mathbf{B}$ & 21 & 0.08 & $<0.10$ & & & 0.01 & 0.1 & 16 & $0.87^{d}$ & $\mathrm{mg} / \mathrm{L}$ \\
\hline & & C & 24 & 0.10 & $<0.10$ & & & 0.1 & 0.1 & 22 & 0.90 & $\mathrm{mg} / \mathrm{L}$ \\
\hline & TCLP & B & 20 & 0.082 & $<0.10$ & 0.014 & 0.014 & 0.01 & 0.1 & 16 & $0.87^{\circ}$ & $\mathrm{mg} / \mathrm{L}$ \\
\hline & & C & 25 & 0.120 & $<0.10$ & 0.18 & 0.56 & 0.01 & 0.1 & 22 & 0.90 & $\mathrm{mg} / \mathrm{L}$ \\
\hline & Solid & $\mathbf{B}$ & 1 & 0.010 & $<0.01$ & & & 0.01 & 0.01 & 1 & $<0.50$ & $\mathrm{mg} / \mathrm{L}$ \\
\hline \multirow[t]{4}{*}{ Sodium } & Liquid & $\mathbf{B}$ & 18 & 216 & 230 & 140 & 300 & & & 15 & 0.86 & $\mathrm{mg} / \mathrm{L}$ \\
\hline & & C & 12 & 472 & 455 & 340 & 650 & & & 12 & 0.83 & $\mathrm{mg} / \mathrm{L}$ \\
\hline & Solid & B & 12 & 469 & 380 & 250 & 950 & & & 11 & 0.81 & $\mu \mathrm{g} / \mathrm{g}$ \\
\hline & & C & 23 & 926 & 940 & 230 & 2000 & & & 22 & 0.90 & $\mu \mathrm{g} / \mathrm{g}$ \\
\hline
\end{tabular}


Table C.2 (continued)

\begin{tabular}{|c|c|c|c|c|c|c|c|c|c|c|c|c|}
\hline \multirow[b]{2}{*}{ Analysis } & \multirow[b]{2}{*}{ Type } & \multirow[b]{2}{*}{ Pond } & \multirow{2}{*}{$\begin{array}{l}\text { No. of } \\
\text { Results" }\end{array}$} & \multirow[b]{2}{*}{ Mean' } & \multirow[b]{2}{*}{ Median } & \multicolumn{2}{|c|}{ Detected results } & \multicolumn{2}{|c|}{ Detection limits } & \multirow{2}{*}{$\begin{array}{l}\text { No. of } \\
\text { drums }\end{array}$} & \multirow{2}{*}{$\begin{array}{l}\text { Quantile } \\
\text { of the } \\
90 \% \mathrm{UCB}^{\mathrm{c}}\end{array}$} & \multirow[b]{2}{*}{ Units } \\
\hline & & & & & & Min. & Max. & Min. & Max. & & & \\
\hline \multirow[t]{4}{*}{ Sulfate } & Liquid & $\mathbf{B}$ & 12 & 1790 & 1890.0 & 1304 & 2040 & & & 11 & 0.81 & $\mathrm{mg} / \mathrm{L}$ \\
\hline & & C & 8 & 1078 & 1185.0 & 355 & 1450 & & & 8 & 0.75 & $\mathrm{mg} / \mathrm{L}$ \\
\hline & Solid & $\mathbf{B}$ & 14 & 3421 & 3722.5 & 612 & 6649 & & & 13 & 0.84 & $\mu \mathrm{g} / \mathrm{g}$ \\
\hline & & C & 23 & 1427 & 1298.0 & 477 & 4003 & & & 22 & 0.90 & $\mu \mathrm{g} / \mathrm{g}$ \\
\hline \multirow[t]{4}{*}{ Technetium-99 } & Liquid & $\mathbf{B}$ & & & & & & & & & & \\
\hline & & C & & & & & & & & & & \\
\hline & Solid & B & 13 & 2397 & 2925 & 14 & 5310 & & & 12 & 0.83 & $\mathrm{pCi} / \mathrm{g}$ \\
\hline & & C & 23 & 1110 & 797 & 332 & 3230 & & & 22 & 0.90 & $\mathrm{pCi} / \mathrm{g}$ \\
\hline \multirow[t]{4}{*}{ Thallium } & Liquid & $\mathbf{B}$ & 11 & 0.0023 & 0.0011 & 0.001 & 0.0065 & & & 10 & 0.79 & $\mathrm{mg} / \mathrm{L}$ \\
\hline & & C & 5 & 0.0013 & 0.0014 & 0.001 & 0.0014 & & & 5 & 0.63 & $\mathrm{mg} / \mathrm{L}$ \\
\hline & Solid & $\mathbf{B}$ & 13 & 2.23 & 2.24 & 0.30 & 4.52 & & & 12 & 0.83 & $\mu \mathrm{g} / \mathrm{g}$ \\
\hline & & C & 23 & 0.78 & 0.62 & 0.48 & 3.73 & & & 22 & 0.90 & $\mu \mathrm{g} / \mathrm{g}$ \\
\hline \multirow[t]{3}{*}{ Thorium-228 } & Liquid & $\mathbf{B}$ & 1 & 2690 & 2690 & 2690 & 2690 & & & 1 & $<0.50$ & $\mathrm{pCi} / \mathrm{L}$ \\
\hline & Solid & $\mathbf{B}$ & 13 & 1.367 & 1.11 & 0.413 & 4.81 & & . & 12 & 0.83 & $\mathrm{pCi} / \mathrm{g}$ \\
\hline & & $\mathbf{C}$ & 23 & 1.215 & 1.01 & 0.430 & 2.28 & & & 22 & 0.90 & $\mathrm{pCi} / \mathrm{g}$ \\
\hline \multirow[t]{2}{*}{ Thorium-230 } & Solid & B & 13 & 84.2 & 74.7 & 14.0 & 294.0 & & & 12 & 0.83 & $\mathrm{pCi} / \mathrm{g}$ \\
\hline & & $\mathbf{C}$ & 23 & 78.8 & 70.3 & 31.5 & 157.0 & & & 22 & 0.90 & $\mathrm{pCi} / \mathrm{g}$ \\
\hline \multirow[t]{2}{*}{ Thorium-232 } & Solid & B & 13 & 3.34 & 1.51 & 0.23 & 11.5 & & & 12 & 0.83 & pCi/g \\
\hline & & C & 23 & 4.12 & 1.52 & 0.44 & 20.2 & & & 22 & 0.90 & $\mathrm{pCi} / \mathrm{g}$ \\
\hline \multirow[t]{4}{*}{ Thorium-234 } & Liquid & $\mathbf{B}$ & 10 & 2159.5 & 1575.0 & -184.0 & 9520 & & & 9 & 0.77 & $\mathrm{pCi} / \mathrm{L}$ \\
\hline & & $\mathbf{C}$ & 2 & 103.5 & 103.5 & -518.0 & 725.0 & & & 2 & $<0.50$ & $\mathrm{pCi} / \mathrm{L}$ \\
\hline & Solid & $\mathbf{B}$ & 13 & 206.1 & 256.5 & 32.4 & 360.0 & & & 12 & 0.83 & $\mathrm{pCi} / \mathrm{g}$ \\
\hline & & C & 23 & 137.3 & 93.5 & 54.0 & 300.5 & & & 22 & 0.90 & $\mathrm{pCi} / \mathrm{g}$ \\
\hline \multirow{4}{*}{$\begin{array}{l}\text { Total organic } \\
\text { carbon (TOC) }\end{array}$} & Liquid & $\mathbf{B}$ & 11 & 26 & 29 & 11 & 44 & & & 10 & 0.79 & $\mathrm{mg} / \mathrm{L}$ \\
\hline & & C & 7 & 47 & 36 & 15 & 84 & & & 7 & 0.72 & $\mathrm{mg} / \mathrm{L}$ \\
\hline & Solid & $\mathbf{B}$ & 13 & 3.41 & 3.40 & 0.32 & 7.0 & & & 12 & 0.83 & $\%$ \\
\hline & & C & 23 & 1.00 & 0.75 & 0.27 & 4.5 & & & 22 & 0.90 & $\%$ \\
\hline
\end{tabular}


Table C.2 (continued)

\begin{tabular}{|c|c|c|c|c|c|c|c|c|c|c|c|c|}
\hline \multirow[b]{2}{*}{ Analysis } & \multirow[b]{2}{*}{ Type } & \multirow[b]{2}{*}{ Pond } & \multirow{2}{*}{$\begin{array}{l}\text { No. of } \\
\text { Results" }\end{array}$} & \multirow[b]{2}{*}{ Mean' } & \multirow[b]{2}{*}{ Median } & \multicolumn{2}{|c|}{ Detected results } & \multicolumn{2}{|c|}{ Detection limits } & \multirow{2}{*}{$\begin{array}{l}\text { No. of } \\
\text { drums }\end{array}$} & \multirow{2}{*}{$\begin{array}{l}\text { Quantile } \\
\text { of the } \\
90 \% \text { UCB }\end{array}$} & \multirow[b]{2}{*}{ Units } \\
\hline & & & & & & Min. & Max. & Min. & Max. & & & \\
\hline Total & Liquid & $\mathbf{B}$ & 12 & 0.5 & 0.5 & 0.3 & 0.7 & & & 11 & 0.81 & $\mathrm{mg} / \mathrm{L}$ \\
\hline \multirow[t]{3}{*}{ Phosphate } & & $\mathbf{C}$ & 8 & 0.8 & 0.7 & 0.3 & 2.0 & & & 8 & 0.75 & $\mathrm{mg} / \mathrm{L}$ \\
\hline & Solid & $\mathbf{B}$ & 14 & 7.8 & 8.5 & 1.5 & 12.0 & & & 13 & 0.84 & $\mu \mathrm{g} / \mathrm{g}$ \\
\hline & & C & 23 & 30.7 & 18.0 & 1.5 & 130.0 & & & 22 & 0.90 & $\mu \mathrm{g} / \mathrm{g}$ \\
\hline \multirow[t]{2}{*}{ Total solids } & Solid & B & 14 & 35.65 & 34.645 & 14.42 & 64.68 & & & 13 & 0.84 & $\%$ \\
\hline & & $\mathbf{C}$ & 22 & 56.29 & 57.74 & 26.30 & 83.77 & & & 21 & 0.90 & $\%$ \\
\hline \multirow[t]{4}{*}{ Uranium } & Liquid & $\mathbf{B}$ & 17 & 3.46 & 4.30 & 0.10 & 8.29 & & & 15 & 0.86 & $\mathrm{mg} / \mathrm{L}$ \\
\hline & & $\mathbf{C}$ & 5 & 0.683 & 0.131 & 0.018 & 1.93 & & & 5 & 0.63 & $\mathrm{mg} / \mathrm{L}$ \\
\hline & Solid & $\vec{B}$ & 14 & 706 & 821.5 & 134 & 1040 & & & 13 & 0.84 & $\mu \mathrm{g} / \mathrm{g}$ \\
\hline & & C & 23 & 445 & 387 & 157 & 1050 & & & 22 & 0.90 & $\mu \mathrm{g} / \mathrm{g}$ \\
\hline Uranium & Liquid & B & 12 & 5.3 & 5.25 & 2.0 & 8.7 & & & 11 & 0.81 & $\mathrm{mg} / \mathrm{L}$ \\
\hline \multirow[t]{3}{*}{ fuorometric } & & $\mathbf{C}$ & 8 & 0.3 & 0.19 & 0.16 & 1.1 & 0.1 & 0.1 & 8 & 0.75 & $\mathrm{mg} / \mathrm{L}$ \\
\hline & Solid & $\mathbf{B}$ & 14 & 1629 & 2000 & 200 & 2700 & & & 13 & 0.84 & $\mu \mathrm{g} / \mathrm{g}$ \\
\hline & & C & 23 & 910 & 790 & 290 & 2800 & & & 22 & 0.90 & $\mu \mathrm{g} / \mathrm{g}$ \\
\hline \multirow[t]{7}{*}{ Uranium-235 } & Liquid & B & 17 & 1.3 & 1.3 & 1.1 & 1.6 & & & 15 & 0.86 & wt \% \\
\hline & & $\mathbf{B}$ & 7 & 258 & 158 & 135 & 734 & & & 6 & 0.68 & $\mathrm{pCi} / \mathrm{L}$ \\
\hline & & C & 5 & 1.4 & 1.3 & 1.2 & 1.9 & & & 5 & 0.63 & wt \% \\
\hline & Solid & $\mathbf{B}$ & 14 & 1.3 & 1.3 & 1.2 & 1.5 & & & 13 & 0.84 & wt \% \\
\hline & & $\mathbf{B}$ & 13 & 21.57 & 25.60 & 3.77 & 34.55 & & & 12 & 0.83 & $\mathrm{pCi} / \mathrm{g}$ \\
\hline & & $\mathbf{C}$ & 23 & 1.39 & 1.30 & 1.20 & 2.70 & & & 22 & 0.90 & wt \% \\
\hline & & $\mathbf{C}$ & 21 & 14.86 & 11.95 & 5.00 & 31.35 & & & 20 & 0.89 & $\mathrm{pCi} / \mathrm{g}$ \\
\hline \multirow[t]{4}{*}{ Vanadium } & Liquid & B & 18 & 0.063 & $<0.05$ & & & 0.005 & 0.5 & 15 & $0.86^{d}$ & $\mathrm{mg} / \mathrm{L}$ \\
\hline & & C & 12 & 0.083 & $<0.05$ & 0.052 & 0.27 & 0.05 & 0.05 & 12 & 0.83 & $\mathrm{mg} / \mathrm{L}$ \\
\hline & Solid & B & 12 & 17.88 & 16.50 & 9.6 & 34.00 & & & 11 & 0.81 & $\mu \mathrm{g} / \mathrm{g}$ \\
\hline & & C & 23 & 22.20 & 22.00 & 9.50 & 34.00 & & & 22 & 0.90 & $\mu \mathrm{g} / \mathrm{g}$ \\
\hline
\end{tabular}


Table C.2 (continued)

\begin{tabular}{|c|c|c|c|c|c|c|c|c|c|c|c|c|}
\hline \multirow[b]{2}{*}{ Analysis } & \multirow[b]{2}{*}{ Type } & \multirow[b]{2}{*}{ Pond } & \multirow{2}{*}{$\begin{array}{l}\text { No. of } \\
\text { Results" }\end{array}$} & \multirow[b]{2}{*}{ Mean } & \multirow[b]{2}{*}{ Median } & \multicolumn{2}{|c|}{ Detected results } & \multicolumn{2}{|c|}{ Detection limits } & \multirow{2}{*}{$\begin{array}{l}\text { No. of } \\
\text { drums }\end{array}$} & \multirow{2}{*}{$\begin{array}{c}\text { Quantile } \\
\text { of the } \\
90 \% \mathrm{UCB}^{c}\end{array}$} & \multirow[b]{2}{*}{ Units } \\
\hline & & & & & & Min. & Max. & Min. & Max. & & & \\
\hline \multirow{4}{*}{$\begin{array}{l}\text { Water } \\
\text { weight loss }\end{array}$} & Dry & $\mathbf{B}$ & 18 & 46.97 & 55.175 & 1.46 & 75.87 & & & 14 & 0.85 & $\%$ \\
\hline & & $\mathbf{C}$ & 18 & 39.40 & 38.920 & 1.24 & 61.01 & & & 17 & 0.87 & $\%$ \\
\hline & Solid & B & 7 & 62.95 & 65.230 & 35.32 & 85.58 & & & 6 & 0.68 & $\%$ \\
\hline & & $\mathbf{C}$ & 18 & 41.71 & 40.375 & 16.23 & 73.70 & & & 18 & 0.88 & $\%$ \\
\hline \multirow[t]{4}{*}{ Zinc } & Liquid & $\mathbf{B}$ & 16 & 0.212 & 0.031 & 0.0095 & 1.70 & 0.02 & 0.02 & 15 & 0.86 & $\mathrm{mg} / \mathrm{L}$ \\
\hline & & $\mathrm{C}$ & 11 & 0.118 & 0.045 & 0.0260 & 0.49 & & & 11 & 0.81 & $\mathrm{mg} / \mathrm{L}$ \\
\hline & Solid & B & 12 & 126.0 & 150.0 & 50 & 180 & & & 11 & 0.81 & $\mu \mathrm{g} / \mathrm{g}$ \\
\hline & & C & 23 & 77.0 & 68.5 & 44 & 130 & & & 22 & 0.90 & $\mu \mathrm{g} / \mathrm{g}$ \\
\hline \multirow[t]{4}{*}{ pH } & Liquid & $\mathbf{B}$ & 12 & 7.5 & 7.4 & 7.2 & 7.7 & & & 11 & 0.81 & \\
\hline & & $\mathbf{C}$ & 8 & 10.6 & 10.7 & 8.4 & 12.1 & & & 8 & 0.75 & \\
\hline & Solid & $\mathbf{B}$ & 11 & 7.8 & 7.15 & 7.0 & 11.6 & & & 10 & 0.79 & \\
\hline & & $\mathbf{C}$ & 19 & 10.6 & 10.9 & 7.2 & 11.6 & & & 18 & 0.88 & \\
\hline
\end{tabular}

${ }^{8}$ The number of results includes analytical duplicates and field replicates.

${ }^{\mathrm{b}}$ The mean and median were calculated with the detection limits set at their value (e.g., $<0.02=0.02$ ) and by using the drum means.

'A number in this column is the quantile bounded by the maximum value, with approximately $90 \%$ confidence. For example, there is approximately $90 \%$ confidence that $83 \%$ of the alpha activity results on solid phase for pond B samples will be less than $868 \mathrm{pCi} / \mathrm{L}$.

${ }^{d}$ There is more than one detection limit; therefore, the maximum value that bounds the quantile could be anywhere from zero to the maximum detection limit.

'The maximum detection limit was higher than the maximum detected result; there the quantile may be bounded by a number higher than the maximum detected result. 

APPENDIX D

QUANTITATIVE ASSESSMENT OF ALTERNATIVES 

Balancing Criteria Values

Dewater Raw Waste

\begin{tabular}{||l|c||}
\hline Effectiveness Rating: & 0.540 \\
\hline Implementability Rating: & 0.726 \\
Cost-Effectiveness Rating: & 0.709 \\
\hline \hline Overall Rating: & 0.658 \\
\hline
\end{tabular}




\section{A. EFFECTIVENESS}

Volume Reduction:

0.400

Compliance to ARARs:

0.470

Waste Generation:

0.623

Throughput:

0.885

Effective Benefit:

0.500

Risk to Employees:

0.400

Environmental/Health:

0.500

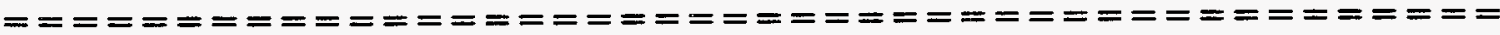
$=\mathrm{x}=\mathrm{x}=\mathrm{x}=\mathrm{=}=\mathrm{=}=\mathrm{=}=\mathrm{=}=\mathrm{=}=\mathrm{=}=$

\section{Overall Effectiveness: $\quad 0.540$}

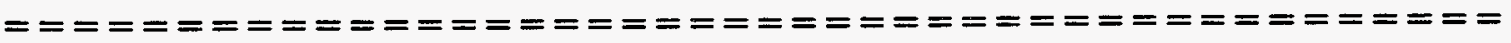

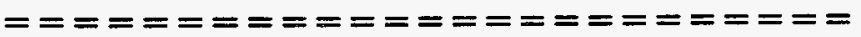

\section{Volume Reduction}

The driver is the volumetric fraction of total output over input.

Driver: $V_{0}$

$$
\nabla_{\mathbf{i}}
$$

Score $=0.400\left(=1-V_{0} / V_{i}\right)$

$\mathrm{V}_{\mathrm{o}}=$ volume of output material from the process that requires monitoring and storage (gal)

$V_{\mathrm{a}}=1,559,094$

$\mathrm{V}_{\mathrm{i}}=$ volume of waste stream as defined in the input requirements (gal)

$V_{i}=2,600,000$ 


\section{Compliance with ARARs}

This is measured as the degree to which the mean fractions of ARAR - defined emissions or releases to the environment are lower than the maximum allowable levels.

$$
\begin{aligned}
& \text { Driver: - } \\
& \mathrm{A}_{\text {allow }} \\
& \text { Score }=0.470 \\
& \mathrm{~A}_{\text {act }}=\text { actual concentration of pollutant of concern } \\
& \mathrm{A}_{\text {actl }}=13 \\
& \mathrm{~A}_{\text {act2 }}=19.0 \\
& \mathrm{~A}_{\text {act3 }}=1.9 \\
& \mathrm{~A}_{\text {act4 }}=62 \\
& \left.\sum_{i=1}^{k} V_{w_{i}} V_{w_{i}} \sum_{j=1}^{l}\left(A_{\text {act }} / A_{\text {allow }}\right)\right] \\
& \mathrm{A}_{\text {allow2,4 }}=270 \\
& \mathrm{~A}_{\text {allow }}=\text { allowable concentration of pollutant of concern } \\
& =26
\end{aligned}
$$

$\mathrm{Vw}=$ mass of waste stream

$\mathrm{V}_{\mathrm{w} 1,2}=813,424$

$V_{w 3,4}=141,951$ 


\section{Secondary Waste Generation}

This score is based on the amount of contaminated process material generated during remediation.

Driver: $V_{i}$

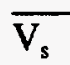

Score $=0.623\left(=\mathrm{V}_{\mathrm{i}} / \mathrm{V}_{\mathrm{s}}\right)$

$\mathrm{V}_{\mathrm{s}}=$ volume of contaminated process material produced by the system (gal).

$\mathrm{V}_{\mathrm{s}}=417,205$

$V_{i}=$ volume of waste stream as defined in the input requirements (gal $\times 10$ ).

$V_{i}=260,000$

\section{Throughput}

This is a measure of the time required per unit of waste remediated.

Driver: $\mathbf{T}_{\mathrm{r}}$

$$
\overline{V_{i}}
$$

Score $=0.885\left(=1-\mathrm{T}_{\mathrm{r}} / \mathrm{V}_{\mathrm{i}}\right)$

$\mathrm{T}_{\mathrm{r}}=$ time to remediate (weeks)

$\mathrm{T}_{\mathrm{r}}=30$

$\mathrm{Vi}=$ volume of waste stream as defined in the input requirements $\left(\mathrm{gal} \times 10^{4}\right)$

$V_{i}=260$ 
Effective Benefit

This is a measure of the time needed to remediate $50 \%$ of the waste.

Driver: $T_{h}$

Score $=0.500\left(=1-\mathrm{T}_{\mathrm{h}} / 30\right)$

$T_{h}=$ time to treat $50 \%$ of waste (weeks).

$T_{h}=15.0$

Risk to Employees

Rate as proportional risk to employees with/without process.

Driver: $\mathbf{R}_{\mathbf{m p}}$

$\overline{\mathbf{R}_{\mathbf{p}}}$

Score $=0.400\left(=0.2 \times R_{m p} / R_{p}\right)$

$R_{p}=$ quantized risk with process

$R_{p}=5$

$\mathbf{R}_{\mathrm{mp}}=$ quantized risk without process

$R_{n p}=10$ 


\section{Environmental/Public Health}

Score as fraction of potential toxic loss to environment

Driver: $\mathbf{M}_{\mathbf{c p}}$

$\overline{\mathbf{M}_{\mathrm{c}}}$

Score $=0.500\left(=0.2 \times M_{c p} / M_{c}\right)$

$\mathrm{Mc}=$ potential toxic loss to environment

$M_{c}=4$

Mcp = toxic content of processed waste input

$\mathbf{M}_{\mathrm{cp}}=10$ 


\title{
B. IMPLEMENTABILITY
}

Permits:

Industrial Availability:

Simplicity of Design:

0.714

Robustness:

0.800

Implementation Risk:

0.633

Technical Risk:

Demonstrability:

0.786

Implementation Time:

0.625

Future Disposal:

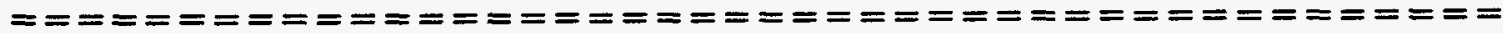

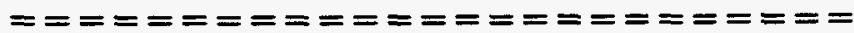

Overall Useful Life Factor: 0.726

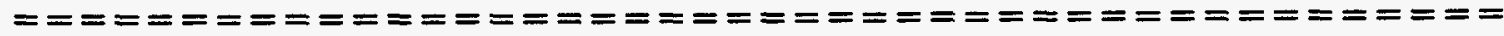

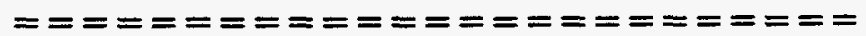

\section{Permits}

(conditions external to the site)

Measure based on number of permits required.

Driver: $\mathbf{N}_{\mathbf{p}}$

Score $=0.500\left(=1 / \mathrm{N}_{\mathrm{p}}\right)$

$\mathrm{Np}=$ estimated gross number of permits required

$\mathbf{N}_{p}=2$ 


\section{Industrial Availability}

This item assesses the ability of a subcontractor to supply the required equipment.

Driver: $F_{s}$

$$
\overline{F_{t}}
$$

Score $=0.929\left(=F_{s} / F_{v}\right)$

$F_{s}=$ commercially off-the-shelf functional subelements

$F_{s}=13$

$F_{t}=$ total functional subelements

$F_{t}=14$

\section{Simplicity of Design}

Rate simplicity of design by identifying number of functional units.

Driver: $F_{t}$

Score $=0.714\left(=10 \times 1 / F_{V}\right)$

$F_{t}=$ total functional subelements

$F_{1}=14$ 


\section{Robustness}

This item measures the ability of a system to process a range of inputs without affecting system operation or product quality.

Driver: $\mathbf{N}_{\text {ok }}$

$$
\overline{\mathrm{N}_{0}}
$$

Score $=0.800\left(=N_{\text {ok }} / N_{o}\right)$

$\mathrm{N}_{\mathrm{ok}}=$ number of predefined influent characteristics that do not have significant potential to affect system performance

$\mathrm{N}_{\mathrm{ok}}=8$

$N_{0}=$ number of predefined influent characteristics the system will be required to process

$N_{0}=10$

\section{Implementation Risk}

This score is based on the scheduled time from approval of contract to beginning of operation.

Driver: $T_{c}$

Score $=0.633\left(=1-T_{c} / 30\right)$

$T_{c}=$ time to begin remediation (weeks).

$\mathrm{T}_{\mathrm{c}}=11.0$ 


\section{Technical Risk}

This score is the ratio of the number of subelements demonstrated in both actual and similar environments to the total number of subelements.

Driver: $C_{d}+C_{s}$

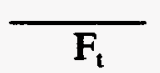

Score $=0.607\left(=\left(C_{d}+0.75 \times C_{s}\right) / F_{t}\right]$

$C_{d}=$ number of demonstrated subelements

$C_{d}=1$

$C_{s}=$ number of similar demonstrated sets

$C_{s}=10$

$F_{t}=$ total functional subelements

$F_{t}=14$

\section{Demonstrability}

Score is based on function of subelements not demonstrable before full-scale implementation.

Driver: $\mathbf{C}_{\mathbf{n}}$

$$
\overline{F_{t}}
$$

Score $=0.786\left(=1-C_{n} / F_{v}\right)$

$C_{n}=$ number of subelements that cannot be demonstrated

$C_{n}=3$

$F_{t}=$ total functional subelements

$F_{t}=14$ 


\section{Implementation Time}

Temporal risk is measured as the critical path time from identification of the problem to completion of operations.

Driver: $\mathbf{T}_{\mathbf{i}}$

Score $=0.625\left(=50 \times 1 / \mathrm{T}_{\mathrm{i}}\right)$

$\mathrm{T}_{\mathrm{i}}=$ critical path time to complete operations (weeks).

$\mathrm{T}_{\mathrm{i}}=80$

\section{Future Disposal}

Measure as fraction of waste that will be difficult to reprocess.

Driver: $V_{n o}$

$$
\overline{V_{i}}
$$

Score $=0.941\left(=1-\mathrm{V}_{\mathrm{no}} / \mathrm{V}_{\mathrm{i}}\right)$

$V_{n o}=$ volume of waste that will be difficult to reprocess (gal).

$\mathrm{V}_{\mathrm{no}}=154,350$

$\mathrm{Vi}=$ total volume of waste $(\mathrm{gal} \times 10)$ stream as defined in input requirements $V_{i}=2,600,000$ 


\section{COST-EFFECTIVENESS}

Implementation:

0.735

Ops Complexity - Automation:

0.833

Ops Complexity - Training:

0.559

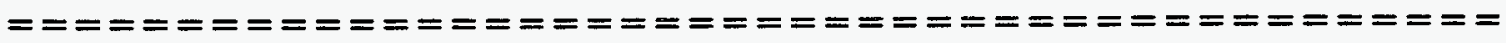
$=\mathrm{x}=\mathrm{=}=\mathrm{=}=\mathrm{=}=\mathrm{=}=\mathrm{=}=\mathrm{=}=\mathrm{=}=\mathrm{=}=$

Overall Operating Maintenance Factor: 0.709

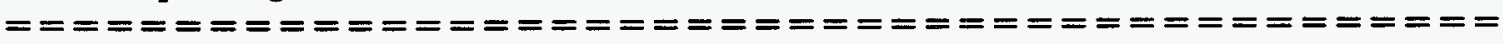

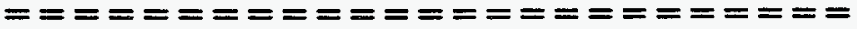

\section{Implementation Cost}

Score based on cost per unit volume of waste treated.

Driver: $\quad C_{m}$<smiles></smiles>

Score $=0.735\left(=1-C_{m} / V_{i}\right)$

$\mathrm{C}_{\mathrm{m}}=$ implementation cost $(\$ \mathrm{~K})$

$C_{m}=69,000$

$V_{i}=$ volume $(\mathrm{gal} \times 10)$ of waste stream as defined in the input requirements

$V_{i}=260,000$ 


\section{Complexity of Operations-Automation}

This score is a function of operational labor hours per hour of operation.

Driver: $\mathrm{O}$

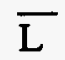

Score $=0.833(=10 \times \mathrm{O} / \mathrm{L})$

$\mathbf{L}=$ operation labor hours

$\mathrm{L}=40,320$

$\mathrm{O}=$ operation hours

$\mathrm{O}=3,360$

\section{Complexity of Operations-Training}

This is a measure of the fraction of staff that require specialized training or experience to operate the system.

Driver: SE

$$
\overline{\mathbf{S}}
$$

Score $=0.559(=1-\mathrm{SE} / \mathrm{S})$

SE $=$ staff requiring specialized training or experience

$\mathrm{SE}=128$

$S=$ total operational staff

$S=290$ 


\section{Balancing Criteria Values}

Dry Raw Waste

\begin{tabular}{|lc|}
\hline & 0.526 \\
\hline Effectiveness Rating: & 0.690 \\
\hline Implementability Rating: & 0.704 \\
\hline Cost-Effectiveness Rating: & 0.640 \\
\hline \hline Overall Rating: & \\
\hline
\end{tabular}




\section{A. EFFECTIVENESS}

Volume Reduction:

0.577

Compliance to ARARs:

0.370

Waste Generation:

0.616

Throughput:

0.885

Effective Benefit:

0.500

Risk to Employees:

0.333

Environmental/Health:

0.400

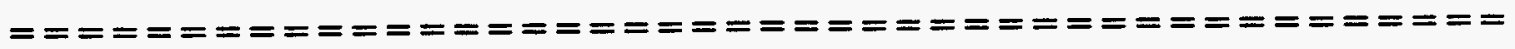

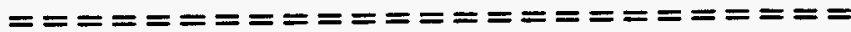

Overall Effectiveness:

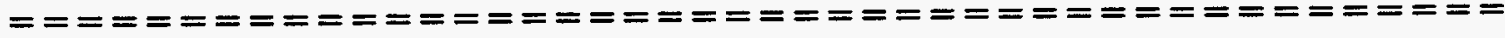

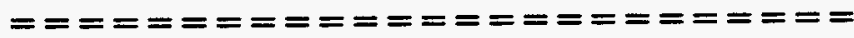

\section{Volume Reduction}

The driver is the volumetric fraction of total output over input.

Driver: $\quad V_{0}$

$$
\overline{V_{i}}
$$

Score $=0.577\left(=1-V_{o} / V_{i}\right)$

$\mathrm{V}_{\mathrm{o}}=$ volume of output material from the process that requires monitoring and storage (gal)

$V_{0}=1,098,824$

$V_{i}=$ volume of waste stream as defined in the input requirements (gal)

$V_{i}=2,600,000$ 


\section{Compliance with ARARs}

This is measured as the degree to which the mean fractions of ARAR-defined emissions or releases to the environment are lower than the maximum allowable levels.

Driver: $A_{\text {act }}$

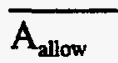

Score $=0.370$

$$
\left.=1-\frac{\left[\sum_{i=1}^{k} V_{w_{i}} \sum_{j=1}^{l}\left(A_{\text {act }} / A_{\text {allow }}\right)\right]}{\sum_{i=1}^{k} V_{w_{i}}}\right]
$$

$A_{\text {act }}=$ actual concentration of pollutant of concern

$A_{\text {actl }}=13$

$\mathrm{A}_{\mathrm{ac} 2}=19.0$

$A_{\text {act } 3}=1.9$

$A_{\text {act4 }}=62$

$\mathrm{A}_{\mathrm{act} 4}=1$

$A_{\text {allow }}=$ allowable concentration of pollutant of concern

$A_{\text {allow } 1,3}=26$

$\mathrm{A}_{\text {allow } 2,4}=\mathbf{2 7 0}$

$A_{\text {allows }}=10$

$\mathrm{Vw}=$ mass of waste stream

$V_{\mathrm{w1,2}}=813,424$

$V_{\mathrm{w} 3,4}=141,951$

$\mathrm{V}_{\mathrm{w} 5}=1$ 


\section{Secondary Waste Generation}

This score is based on the amount of contaminated process material generated during remediation.

Driver: $\mathrm{V}_{\mathrm{i}}$<smiles>[Y]=[V]</smiles>

Score $=0.616\left(=\mathrm{V}_{\mathrm{i}} / \mathrm{V}_{\mathrm{s}}\right)$

$\mathrm{V}_{\mathrm{s}}=$ volume of contaminated process material produced by the system (gal)

$V_{s}=422,231$

$V_{i}=$ volume of waste stream as defined in the input requirements (gal $\times 10$ )

$V_{i}=260,000$

\section{Throughput}

This is a measure of the time required per unit of waste remediated.

Driver: $T_{r}$

$$
\overline{V_{i}}
$$

Score $=0.885\left(=1-\mathrm{T}_{\mathrm{r}} / \mathrm{V}_{\mathrm{i}}\right)$

$T_{r}=$ time to remediate (weeks)

$T_{r}=30$

$V_{i}=$ volume of waste stream as defined in the input requirements $\left(\mathrm{gal} \times 10^{4}\right)$

$V_{i}=260$ 


\section{Effective Benefit}

This is a measure of the time needed to remediate $50 \%$ of the waste.

Driver: $T_{h}$

Score $=0.500\left(=1-\mathrm{T}_{\mathrm{h}} / 30\right)$

$\mathrm{T}_{\mathrm{h}}=$ time to treat $50 \%$ of waste (weeks)

$T_{\mathrm{h}}=15.0$

Risk to Employees

Rate as proportional risk to employees with/without process.

Driver: $R_{\mathrm{mp}}$

$$
\overline{\mathrm{R}_{\mathrm{p}}}
$$

Score $=0.333\left(=0.2 \times R_{\text {mp }} / R_{p}\right)$

$R_{p}=$ quantized risk with process

$R_{\mathrm{p}}=6$

$R_{\mathrm{mp}}=$ quantized risk without process

$R_{\mathrm{nq}}=10$ 
Environmental/Public Health

Score as fraction of potential toxic loss to environment

Driver: $\mathbf{M}_{\mathrm{cp}}$

$\overline{\mathbf{M}_{c}}$

Score $=0.400\left(=0.2 \times \mathrm{M}_{\mathrm{cp}} / \mathrm{M}_{\mathrm{c}}\right)$

$M_{c}=$ potential toxic loss to environment

$\mathrm{M}_{\mathrm{c}}=5$

$\mathbf{M}_{\mathrm{cp}}=$ toxic content of processed waste input

$\mathbf{M}_{\mathrm{cp}}=10$ 


\section{B. IMPLEMENTABILITY}

Permits:

Industrial Availability:

Simplicity of Design:

Robustness:

Implementation Risk:

Technical Risk:

Demonstrability:

Implementation Time:

Future Disposal:
0.333

0.875

0.625

0.900

0.633

0.531

0.688

0.625

1.000

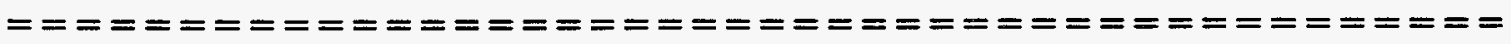

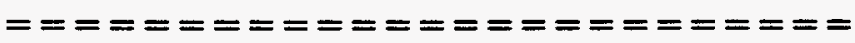

\section{Overall Useful Life Factor: \\ 0.690}

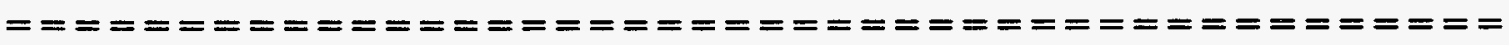
$=\mathrm{x}=\mathrm{=}=\mathrm{=}=\mathrm{=}=\mathrm{=}=\mathrm{=}=\mathrm{=}=\mathrm{=}=\mathrm{=}=\mathrm{=}=$

\section{Permits}

(conditions external to the site)

Measure based on number of permits required.

Driver: $\mathbf{N}_{\mathbf{p}}$

Score $=0.333\left(=1 / \mathrm{N}_{\mathrm{p}}\right)$

$\mathbf{N}_{p}=$ estimated gross number of permits required

$\mathbf{N}_{\mathrm{p}}=3$ 
Industrial Availability

This item assesses the ability of a subcontractor to supply the required equipment.

Driver: $\mathrm{F}_{\mathrm{s}}$<smiles>[PH3-]</smiles>

Score $=0.875\left(=F_{s} / F_{t}\right)$

$F_{s}=$ commercially off-the-shelf functional subelements

$F_{s}=14$

$F_{t}=$ total functional subelements

$F_{t}=16$

\section{Simplicity of Design}

Rate simplicity of design by identifying number of functional units.

Driver: $F_{t}$

Score $=0.625\left(=10 \times 1 / F_{v}\right)$

$F_{t}=$ total functional subelements

$F_{t}=16$ 


\section{Robustness}

This item measures the ability of a system to process a range of inputs without affecting system operation or product quality.

Driver: $\mathbf{N}_{\mathrm{ok}}$

$\overline{N_{0}}$

Score $=0.900$ $\left(=\mathbf{N}_{\mathrm{ok}} / \mathbf{N}_{\mathrm{o}}\right)$

$\mathbf{N}_{\mathrm{ok}}=$ number of predefined influent characteristics that do not have significant potential to affect system performance

$\mathbf{N}_{\mathrm{ok}}=9$

$\mathbf{N}_{\mathrm{o}}=$ number of predefined influent characteristics the system will be required to process

$\mathrm{N}_{\mathrm{o}}=10$

\section{Implementation Risk}

This score is based on the scheduled time from approval of contract to beginning of operation.

Driver: $\mathbf{T}_{c}$

Score $=0.633\left(=1-T_{c} / 30\right)$

$T_{c}=$ time to begin remediation (weeks).

$T_{c}=11.0$ 
Technical Risk

This score is the ratio of the number of subelements demonstrated in both actual and similar environments to the total number of subelements.

Driver: $C_{d}+C_{s}$

$$
\overline{F_{t}}
$$

Score $=0.607\left(=\left(C_{d}+0.75 \times C_{s}\right) / F_{t}\right]$

$C_{d}=$ number of demonstrated subelements

$C_{d}=1$

$C_{s}=$ number of similar demonstrated sets

$C_{s}=10$

$F_{\mathrm{t}}=$ total functional subelements

$F_{t}=16$

\section{Demonstrability}

Score is based on function of subelements not demonstrable before full-scale implementation.

Driver: $C_{n}$<smiles>[Te]</smiles>

Score $=0.688$

$$
\left(=1-C_{n} / F_{t}\right)
$$

$C_{n}=$ number of subelements that cannot be demonstrated

$C_{n}=5$

$F_{t}=$ total functional subelements

$F_{t}=16$ 


\section{Implementation Time}

Temporal risk is measured as the critical path time from identification of the problem to completion of operations.

Driver: $T_{i}$

Score $=0.625\left(=50 \times 1 / \mathrm{T}_{i}\right)$

$T_{i}=$ critical path time to complete operations (weeks)

$\mathrm{T}_{\mathrm{i}}=80$

\section{Future Disposal}

Measure as fraction of waste that will be difficult to reprocess.

Driver: $\mathrm{V}_{\mathrm{no}}$

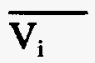

Score $=1.000$

$$
\left(=1-V_{n o} / V_{j}\right)
$$

$V_{n o}=$ volume of waste that will be difficult to reprocess (gal).

$\mathrm{V}_{\mathrm{no}}=0$

$V_{i}=$ total volume of waste $(\mathrm{gal} \times 10)$ stream as defined in input requirements

$V_{i}=2,600,000$ 


\section{COST-EFFECTIVENESS}

Implementation:

0.758

Ops Complexity - Automation: $\quad 0.809$

Ops Complexity - Training: $\quad 0.545$

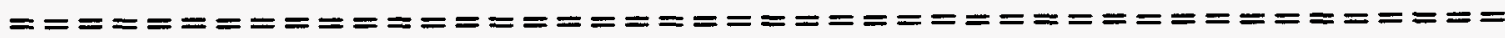

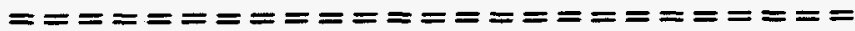

Overall Operating Maintenance Factor: 0.704

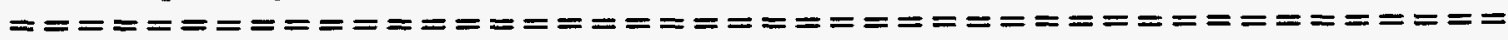

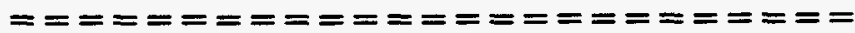

\section{Implementation Cost}

Score based on cost per unit volume of waste treated.

Driver: $\mathbf{C}_{m}$

$$
\overline{V_{i}}
$$

Score $=0.758\left(=1-C_{m} / V_{i}\right)$

$\mathrm{C}_{\mathrm{m}}=$ implementation cost $(\$ \mathrm{~K})$

$C_{m}=63,000$

$\mathrm{V}_{\mathrm{i}}=$ volume $(\mathrm{gal} \times 10)$ of waste stream as defined in the input requirements

$V_{i}=260,000$ 


\section{Complexity of Operations-Automation}

This score is a function of operational labor hours per hour of operation.

Driver: $\quad 0$

$\overline{\mathbf{L}}$

Score $=0.809(=10 \times \mathrm{O} / \mathrm{L})$

$\mathrm{L}=$ operation labor hours

$\mathrm{L}=41,526$

$\mathrm{O}=$ operation hours

$\mathrm{O}=3,360$

\section{Complexity of Operations-Training}

This is a measure of the fraction of staff that require specialized training or experience to operate the system.

Driver: SE

\section{$\overline{\mathbf{S}}$}

Score $=0.545(=1-\mathrm{SE} / \mathrm{S})$

$\mathrm{SE}=$ staff requiring specialized training or experience

$\mathrm{SE}=140$

$S=$ total operational staff

$S=308$ 
Balancing Criteria Values

Dry Raw Waste

\begin{tabular}{|lc||}
\hline Effectiveness Rating: & 0.329 \\
\hline Implementability Rating: & 0.381 \\
\hline Cost-Effectiveness Rating: & 0.364 \\
\hline \hline & 0.358 \\
\hline
\end{tabular}




\section{A. EFFECTIVENESS}

Volume Reduction:

$-1.224$

Compliance to ARARs:

1.000

Waste Generation:

0.577

Throughput:

0.812

Effective Benefit:

0.183

Risk to Employees:

0.286

Environmental/Health:

0.667

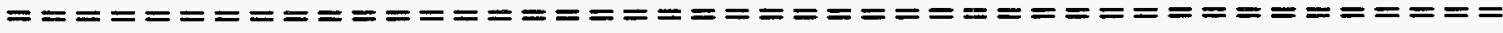

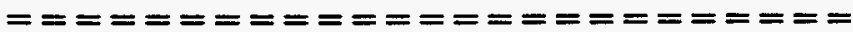

Overall Effectiveness:

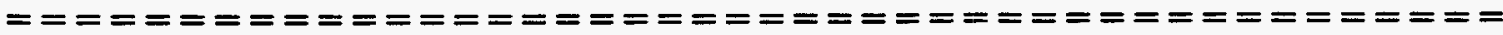

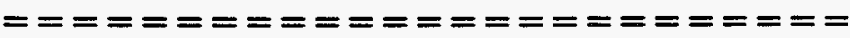

\section{Volume Reduction}

The driver is the volumetric fraction of total output over input.

Driver: $\quad V_{0}$

$$
\overline{\mathrm{V}_{\mathbf{i}}}
$$

Score $=-1.224\left(=1-V_{0} / V_{i}\right)$

$\mathrm{V}_{\mathrm{o}}=$ volume of output material from the process that requires monitoring and storage (gal)

$V_{0}=5,783,000$

$V_{i}=$ volume of waste stream as defined in the input requirements (gal)

$V_{i}=2,600,000$ 


\section{Compliance with ARARs}

This is measured as the degree to which the mean fractions of ARAR - defined emissions or releases to the environment are lower than the maximum allowable levels.

Driver: $A_{\text {act }}$

A allow

Score $=1.000$

$$
\left[-\frac{\left[\sum_{i=1}^{k} V_{w_{i}} \sum_{j=1}^{l}\left(A_{\text {act }} / A_{\text {allow }}\right)\right]}{\sum_{i=1}^{k} V_{w_{i}}}\right]
$$

$A_{\text {act }}=$ actual concentration of pollutant of concern

$A_{\text {actl }}=0$

$\mathrm{A}_{\text {allow }}=$ allowable concentration of pollutant of concern

$\mathrm{A}_{\text {allow1 }}=1$

$\mathrm{V}_{\mathrm{w}}=$ mass of waste stream

$\mathrm{V}_{\mathrm{wl}}=1$

\section{Secondary Waste Generation}

This score is based on the amount of contaminated process material generated during remediation.

Driver: $V_{i}$

$$
\overline{\mathrm{V}_{s}}
$$

Score $=0.577\left(=\mathrm{V}_{\mathrm{i}} / \mathrm{V}_{\mathrm{s}}\right)$

$\mathrm{V}_{\mathrm{s}}=$ volume of contaminated process material produced by the system (gal)

$V_{s}=450,236$

$V_{i}=$ volume of waste stream as defined in the input requirements (gal $\times 10$ )

$V_{i}=260,000$ 


\section{Throughput}

This is a measure of the time required per unit of waste remediated.

Driver: $T_{r}$ $\overline{V_{i}}$

Score $=0.812\left(=1-\mathrm{T}_{\mathrm{r}} / \mathrm{V}_{\mathrm{i}}\right)$

$T_{r}=$ time to remediate (weeks)

$\mathrm{T}_{\mathrm{r}}=49$

$\mathrm{V}_{\mathrm{i}}=$ volume of waste stream as defined in the input requirements $\left(\mathrm{gal} \times 10^{4}\right.$ )

$V_{i}=260$

\section{Effective Benefit}

This is a measure of the time needed to remediate $50 \%$ of the waste.

Driver: $T_{h}$

Score $=0.183\left(=1-\mathrm{T}_{\mathrm{h}} / 30\right)$

$T_{h}=$ time to treat $50 \%$ of waste (weeks)

$T_{h}=24.5$ 


\section{Risk to Employees}

Rate as proportional risk to employees with/without process.

Driver: $R_{n p}$<smiles>[R]</smiles>

Score $=0.286\left(=0.2 \times \mathbf{R}_{\mathrm{mp}} / \mathbf{R}_{\mathrm{p}}\right)$

$R_{\mathrm{p}}=$ quantized risk with process

$\mathbf{R}_{\mathrm{p}}=7$

$R_{\mathrm{np}}=$ quantized risk without process

$R_{\mathrm{np}}=10$

\section{Environmental/Public Health}

Score as fraction of potential toxic loss to environment

Driver: $\mathbf{M}_{\mathbf{c p}}$

$$
\overline{\mathbf{M}_{\mathrm{c}}}
$$

Score $=0.667\left(=0.2 \times \mathrm{M}_{\mathrm{cp}} / \mathrm{M}_{\mathrm{c}}\right)$

$\mathbf{M}_{\mathrm{c}}=$ potential toxic loss to environment

$\mathbf{M}_{\mathrm{c}}=\mathbf{3}$

$\mathbf{M}_{\mathrm{cp}}=$ toxic content of processed waste input

$M_{c p}=10$ 


\section{B. IMPLEMENTABILITY}

Permits:

Industrial Availability:

Simplicity of Design:

Robustness:

Implementation Risk:

Technical Risk:

Demonstrability:

Implementation Time:

Future Disposal:
0.500

0.889

0.556

0.700

0.433

0.431

0.667

0.481

$-1.224$

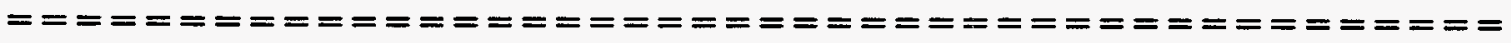
$=\mathrm{z}=\mathrm{z}=\mathrm{=}=\mathrm{=}=\mathrm{=}=\mathrm{=}=\mathrm{=}=\mathrm{=}=\mathrm{=}=\mathrm{=}$

\section{Overall Useful Life Factor:

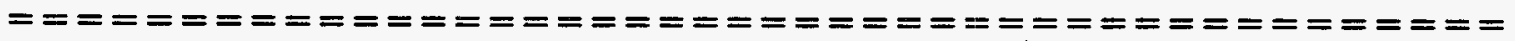
$=\mathrm{x}=\mathrm{=}=\mathrm{=}=\mathrm{=}=\mathrm{=}=\mathrm{=}=\mathrm{=}=\mathrm{=}=\mathrm{=}=\mathrm{=}=$

\section{Permits}

(conditions external to the site)

Measure based on number of permits required.

Driver: $\mathbf{N}_{\mathbf{p}}$

Score $=0.500\left(=1 / \mathrm{N}_{\mathrm{p}}\right)$

$\mathbf{N}_{\mathrm{p}}=$ estimated gross number of permits required

$N_{p}=2$ 


\section{Industrial Availability}

This item assesses the ability of a subcontractor to supply the required equipment.

Driver: $F_{s}$<smiles>I</smiles>

Score $=0.889\left(=F_{s} / F_{f}\right)$

$F_{s}=$ commercially off-the-shelf functional subelements

$F_{s}=16$

$F_{\mathrm{t}}=$ total functional subelements

$F_{t}=18$

\section{Simplicity of Design}

Rate simplicity of design by identifying number of functional units.

Driver: $F_{\mathbf{t}}$

$$
\text { Score }=0.556\left(=10 \times 1 / F_{v}\right)
$$

$F_{t}=$ total functional subelements

$F_{t}=18$ 


\section{Robustness}

This item measures the ability of a system to process a range of inputs without affecting system operation or product quality.

Driver: $\mathbf{N}_{\text {ok }}$<smiles>C1CN1</smiles>

Score $=0.700\left(=\mathrm{N}_{\mathrm{ok}} / \mathrm{N}_{\mathrm{o}}\right)$

$\mathrm{N}_{\mathrm{ok}}=$ number of predefined influent characteristics that do not have significant potential to affect system performance

$\mathrm{N}_{\mathrm{ok}}=7$

$\mathrm{N}_{\mathrm{o}}=$ number of predefined influent characteristics the system will be required to process

$\mathrm{N}_{\mathrm{o}}=10$

\section{Implementation Risk}

This score is based on the scheduled time from approval of contract to beginning of operation.

Driver: $T_{c}$

Score $=0.433\left(=1-T_{c} / 30\right)$

$T_{c}=$ time to begin remediation (weeks).

$T_{c}=17.0$ 
Technical Risk

This score is the ratio of the number of subelements demonstrated in both actual and similar environments to the total number of subelements.

Driver: $C_{d}+C_{s}$

$$
F_{t}
$$

Score $=0.431\left(=\left(C_{d}+0.75 \times C_{s}\right) / F_{t}\right]$

$C_{d}=$ number of demonstrated subelements

$C_{d}=1$

$C_{s}=$ number of similar demonstrated sets

$C_{s}=9$

$F_{t}=$ total functional subelements

$F_{t}=18$

\section{Demonstrability}

Score is based on function of subelements not demonstrable before full-scale implementation.

Driver: $C_{n}$<smiles>[Te]</smiles>

Score $=0.667\left(=1-C_{n} / F\right)$

$C_{n}=$ number of subelements that cannot be demonstrated

$C_{n}=6$

$F_{t}=$ total functional subelements

$F_{t}=18$ 


\section{Implementation Time}

Temporal risk is measured as the critical path time from identification of the problem to completion of operations.

Driver: $T_{i}$

Score $=0.481\left(=50 \times 1 / \mathrm{T}_{\mathfrak{i}}\right)$

$\mathrm{T}_{\mathrm{i}}=$ critical path time to complete operations (weeks)

$T_{i}=104$

\section{Future Disposal}

Measure as fraction of waste that will be difficult to reprocess.

Driver: $\quad V_{n o}$<smiles>[Y]=[V]</smiles>

Score $=-1.224\left(=1-\mathrm{V}_{\mathrm{no}} / \mathrm{V}_{\mathrm{i}}\right)$

$V_{\mathrm{no}}=$ volume of waste that will be difficult to reprocess (gal).

$V_{n o}=5,783,000$

$V_{i}=$ total volume of waste $(\mathrm{gal} \times 10)$ stream as defined in input requirements $\mathrm{V}_{\mathrm{i}}=2,600,000$ 


\section{COST-EFFECTIVENESS}

Implementation:

0.692

Ops Complexity - Automation:

0.250

Ops Complexity - Training:

0.150

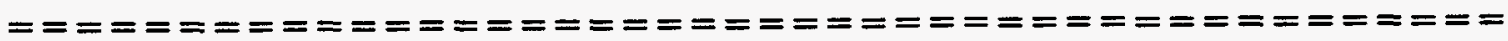
$==\mathrm{E}=\mathrm{=}=\mathrm{=}=\mathrm{=}=\mathrm{=}=\mathrm{=}=\mathrm{=}=\mathrm{=}=\mathrm{=}$

Overall Operating Maintenance Factor: 0.364

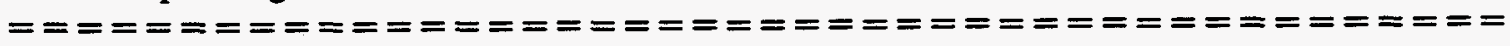
$\mathrm{N}=\mathrm{=}=\mathrm{=}=\mathrm{=}=\mathrm{=}=\mathrm{=}=\mathrm{=}=\mathrm{=}=\mathrm{=}=\mathrm{=}$

\section{Implementation Cost}

Score based on cost per unit volume of waste treated.

Driver: $C_{m}$

$$
\overline{V_{i}}
$$

Score $=0.692\left(=1-C_{m} / V_{i}\right)$

$\mathrm{C}_{\mathrm{m}}=$ implementation cost (\$K)

$C_{m}=80,000$

$\mathrm{V}_{\mathrm{i}}=$ volume $(\mathrm{gal} \times 10)$ of waste stream as defined in the input requirements

$V_{i}=260,000$ 


\section{Complexity of Operations-Automation}

This score is a function of operational labor hours per hour of operation.

Driver: $\mathrm{O}$

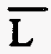

Score $=0.250(=10 \times \mathrm{O} / \mathrm{L})$

$\mathbf{L}=$ operation labor hours

$L=172,480$

$\mathbf{O}=$ operation hours

$\mathrm{O}=4,312$

\section{Complexity of Operations-Training}

This is a measure of the fraction of staff that require specialized training or experience to operate the system.

Driver: SE

$$
\overline{\mathbf{S}}
$$

Score $=0.150(=1-\mathrm{SE} / \mathrm{S})$

$\mathrm{SE}=$ staff requiring specialized training or experience

$\mathrm{SE}=34$

$S=$ total operational staff

$S=40$ 
ORNL/TM-12250

\section{INTERNAL DISTRIBUTION}

1. J. B. Berry

2. A. G. Croff

3. L. E. McNeese

4. S. M. Robinson

5. Central Research Library

6. Document Reference Center

7. ORNL Patent Section

8. ORNL Laboratory Records

9. ORNL Laboratory Records, RC

\section{EXTERNAL DISTRIBUTION}

10. Office of Assistant Manager, Energy Research and Development, DOE-OR, P.O. Box 2001, Oak Ridge, Tennessee 37831

11-12. Office of Scientific and Technical Information, P.O. Box 62, Oak Ridge, Tennessee 37831 